Ed. 44 Vol. 9 N. ${ }^{\circ} 4$ Noviembre 2020_Febrero 2021

Publicación trimestral

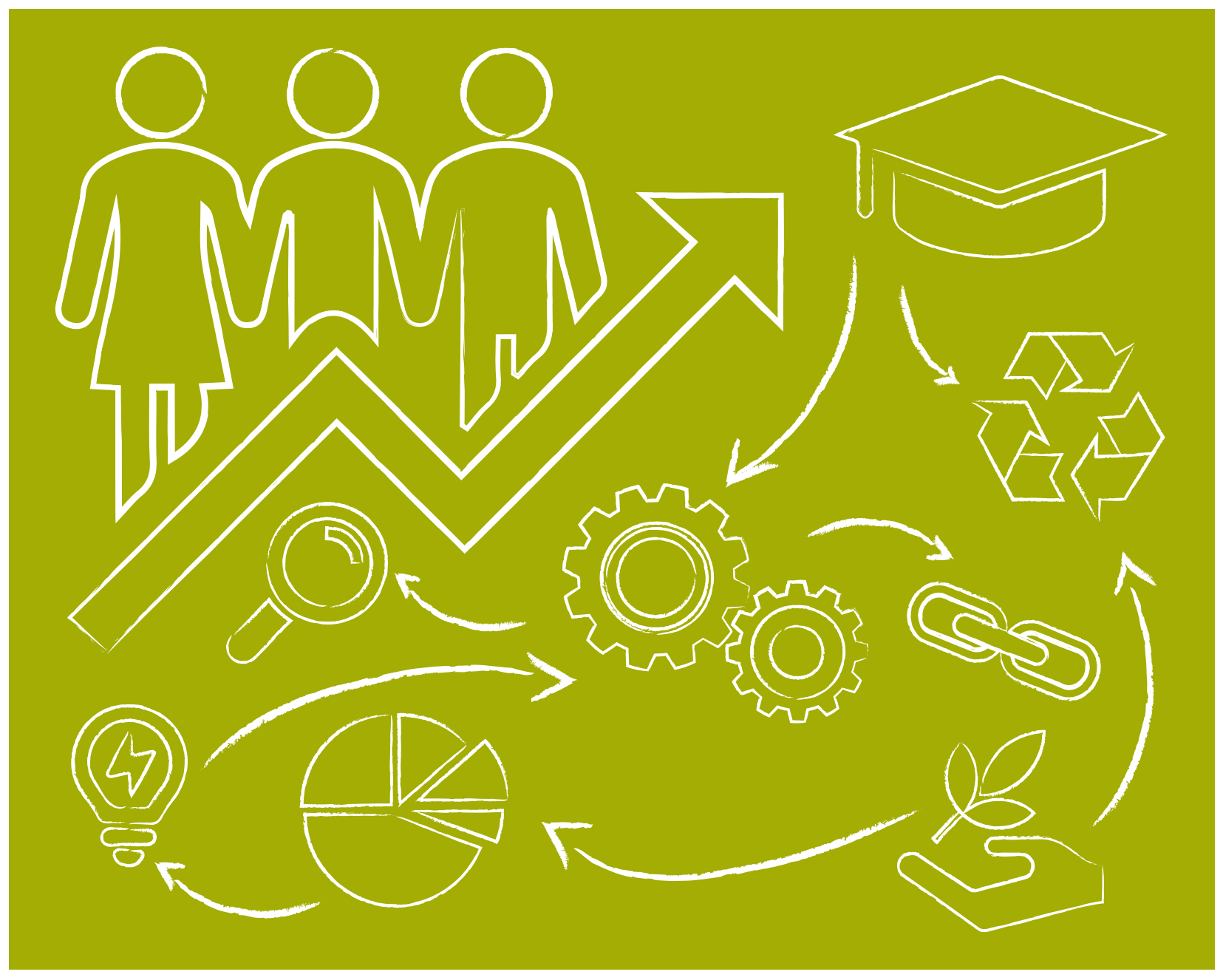




\section{G Empresa. Investigación y pensamiento crítico.}

Periodicidad trimestral. Quarterly periodicity.

Edición 44, Volumen 9, Número 4 (Noviembre 2020 - Febrero 2021).

Edition 44, Volume 9, Issue 4 (November - February).

Tirada nacional e internacional. National and internacional circulation.

Artículos revisados por el método de evaluación de pares de doble ciego.

Articles reviewed by the double blind peer evaluation method.

ISSN: $2254-3376$

No de Depósito Legal: A 268 - 2012

DOI: https://doi.org/10.17993/3cemp.2020.090444

Edita:

Área de Innovación y Desarrollo, S.L.

C/ Alzamora 17, Alcoy, Alicante (España)

Tel: 965030572

info@3ciencias.com_www.3ciencias.com

\section{(a) $(1) \Theta$}

Todos los derechos reservados. Se autoriza la reproducción total o parcial de los artículos citando la fuente y el autor.

This publication may be reproduced by mentioning the source and the authors.

Copyright (C) Área de Innovación y Desarrollo, S.L. 


\section{CONSEJO EDITORIAL EDITORIAL BOARD}

Director

Editores adjuntos

Editores asociados
Víctor Gisbert Soler

María J. Vilaplana Aparicio

Maria Vela Garcia

David Juárez Varón

F. Javier Cárcel Carrasco

\section{CONSEJO DE REDACCIÓN DRAFTING BOARD}

Dr. David Juárez Varón. Universidad Politécnica de Valencia (España)

Dr. Martín León Santiesteban. Universidad Autónoma de Occidente (México)

Dr. F. Javier Cárcel Carrasco. Universidad Politécnica de Valencia (España)

Dr. Alberto Rodríguez Rodríguez. Universidad Estatal del Sur de Manabi (Ecuador)

\section{CONSEJO ASESOR ADVISORY BOARD}

Dra. Ana Isabel Pérez Molina. Universidad Politécnica de Valencia (España)

Dr. Julio C. Pino Tarragó. Universidad Estatal del Sur de Manabi (Ecuador)

Dr. Jorge Francisco Bernal Peralta. Universidad de Tarapacá (Chile)

Dr. Roberth O. Zambrano Santos. Instituto Tecnológico Superior de Portoviejo (Ecuador)

Dr. Sebastián Sánchez Castillo. Universidad de Valencia (España)

Dra. Sonia P. Ubillús Saltos. Instituto Tecnológico Superior de Portoviejo (Ecuador)

Dr. Jorge Alejandro Silva Rodríguez de San Miguel. Instituto Politécnico Nacional (México) 


\section{CONSEJO EDITORIAL EDITORIAL BOARD}

Área téxtil

Área financiera

Organización de empresas y RRHH

Estadística; Investigación operativa

Economía y empresariales

Sociología y Ciencias Políticas

Derecho

Ingeniería y Tecnología

Tecnologías de la Información y la Comunicación

Ciencias de la salud
Dr. Josep Valldeperas Morell

Universidad Politécnica de Cataluña (España)

Dr. Juan Ángel Lafuente Luengo

Universidad Faime I (España)

Dr. Francisco Llopis Vañó

Universidad de Alicante (España)

Dra. Elena Pérez Bernabeu

Universidad Politécnica de Valencia (España)

Dr. José Joaquín García Gómez

Universidad de Almería (España)

Dr. Rodrigo Martínez Béjar

Universidad de Murcia (España)

Dra. María del Carmen Pastor Sempere

Universidad de Alicante (España)

Dr. David Juárez Varón

Universidad Politécnica de Valencia (España)

Dr. Manuel Llorca Alcón

Universidad Politécnica de Valencia (España)

Dra. Mar Arlandis Domingo

Hospital San Fuan de Alicante (España) 


\section{POLÍTICA EDITORIAL}

\section{OBJETIVO EDITORIAL}

La Editorial científica 3Ciencias pretende transmitir a la sociedad ideas y proyectos innovadores, plasmados, o bien en artículos originales sometidos a revisión por expertos, o bien en los libros publicados con la más alta calidad científica y técnica.

\section{COBERTURA TEMÁTICA}

3C Empresa es una revista de carácter científico - social, donde se difunden trabajos originales, escritos en español o inglés, para su divulgación con análisis empíricos y teóricos sobre los mercados financieros, liderazgo, recursos humanos, microestructura de mercado, contabilidad pública y gestión empresarial.

\section{NUESTRO PÚBLICO}

- Personal investigador.

- Doctorandos.

- Profesores de universidad.

- Oficinas de transferencia de resultados de investigación (OTRI).

- Empresas que desarrollan labor investigadora y quieran publicar alguno de sus estudios. 


\section{AIMS AND SCOPE}

\section{PUBLISHING GOAL}

3Ciencias wants to transmit to society innovative projects and ideas. This goal is reached thought the publication of original articles which are subdue to peer review or thorough the publication of scientific books.

\section{TEMATIC COVERAGE}

3C Empresa is a scientific - social journal, where original works are spread, written in Spanish and English, for dissemination with empirical and theoretical analyzes on financial markets, leadership, human resources, market microestructure, public accounting and bussines management.

\section{OUR TARGET}

- $\quad$ Research staff.

- $\quad$ PhD students.

- Professors.

- Research Results Transfer Office.

- Companies that develop research and want to publish some of their works. 


\section{NORMAS DE PUBLICACIÓN}

3C Empresa es una revista arbitrada que utiliza el sistema de revisión por pares de doble ciego (doubleblind peer review), donde expertos externos en la materia sobre la que trata un trabajo lo evalúan, siempre manteniendo el anonimato, tanto de los autores como de los revisores. La revista sigue las normas de publicación de la APA (American Psychological Association) para su indización en las principales bases de datos internacionales.

Cada número de la revista se edita en versión electrónica (e-ISSN: 2254 - 3376), identificándose cada trabajo con su respectivo código DOI (Digital Object Identifier System).

\section{PRESENTACIÓN TRABAJOS}

Los artículos se presentarán en tipo de letra Baskerville, cuerpo 11, justificados y sin tabuladores. Han de tener formato Word. La extensión será de no más de 6.000 palabras de texto, incluidas referencias. Los trabajos deben ser enviados exclusivamente por plataforma de gestión de manuscritos OJS:

https://ojs.3ciencias.com/

Toda la información, así como las plantillas a las que deben ceñirse los trabajos se encuentran en:

https://www.3ciencias.com/revista/informacion-para-autores/

https://www.3ciencias.com/normas-de-publicacion/plantillas/ 


\section{SUBMISSION GUIDELINES}

3C Empresa is an arbitrated journal that uses the double-blind peer review system, where external experts in the field on which a paper deals evaluate it, always maintaining the anonymity of both the authors and of the reviewers. The journal follows the standards of publication of the APA (American Psychological Association) for indexing in the main international databases.

Each issue of the journal is published in electronic version (e-ISSN: 2254-3376), each work being identified with its respective DOI (Digital Object Identifier System) code.

\section{PRESENTATION WORK}

The papers will be presented in Baskerville typeface, body 11, justified and without tabs. They must have Word format. The extension will be no more than 6.000 words of text, including references. Papers must be submitted exclusively by OJS manuscript management platform:

https://ojs.3ciencias.com/

All the information, as well as the templates to which the works must adhere, can be found at: https://www.3ciencias.com/en/journals/infromation-for-authors/ https://www.3ciencias.com/en/regulations/templates/ 


\section{ESTRUCTURA}

Los trabajos originales tenderán a respetar la siguiente estructura: introducción, métodos, resultados, discusión/conclusiones, notas, agradecimientos y referencias bibliográficas.

Es obligatoria la inclusión de referencias, mientras que notas y agradecimientos son opcionales. Se valorará la correcta citación conforme a la $7 .^{\text {a }}$ edición de las normas APA.

\section{RESPONSABILIDADES ÉTICAS}

No se acepta material previamente publicado (deben ser trabajos inéditos). En la lista de autores firmantes deben figurar única y exclusivamente aquellas personas que hayan contribuido intelectualmente (autoría), con un máximo de 4 autores por trabajo. No se aceptan artículos que no cumplan estrictamente las normas.

\section{INFORMACIÓN ESTADÍSTICA SOBRE TASAS DE ACEPTACIÓN E INTERNACIONALIZACIÓN}

- $\quad$ Número de trabajos aceptados publicados: 5.

- Nivel de aceptación de manuscritos en este número: 78,56\%

- $\quad$ Nivel de rechazo de manuscritos: 21,44\%.

- Internacionalización de autores: 2 países (México y Pakistán)

Normas de publicación: https://www.3ciencias.com/normas-de-publicacion/instrucciones/ 


\section{STRUCTURE}

The original works will tend to respect the following structure: introduction, methods, results, discussion/ conclusions, notes, acknowledgments and bibliographical references.

The inclusion of references is mandatory, while notes and acknowledgments are optional. The correct citation will be assessed according to the 7th edition of the APA standards.

\section{ETHICAL RESPONSIBILITIES}

Previously published material is not accepted (they must be unpublished works). The list of signatory authors should include only and exclusively those who have contributed intellectually (authorship), with a maximum of 4 authors per work. Articles that do not strictly comply with the standards are not accepted.

\section{STATISTICAL INFORMATION ON ACCEPTANCE AND INTERNATIONALIZATION FEES}

- $\quad$ Number of accepted papers published: 5 .

- Level of acceptance of manuscripts in this number: 78,56\%.

- Level of rejection of manuscripts: $21,44 \%$.

- Internationalization of authors: 2 countries (Mexico and Pakistan).

Guidelines for authors: https://www.3ciencias.com/en/regulations/instructions/ 


\section{INDEXACIONES INDEXATIONS}

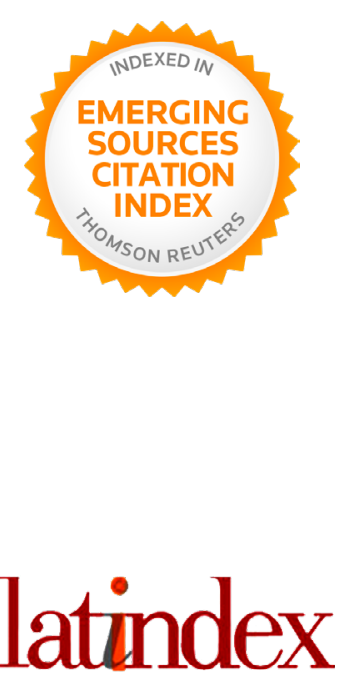

C|| | clasificación integrada $\stackrel{\square}{\mathbb{2}} \mid \mathbf{C}$ de revistas científicas_

OAJ $\begin{gathered}\text { Open Academic } \\ \text { Journals Index }\end{gathered}$
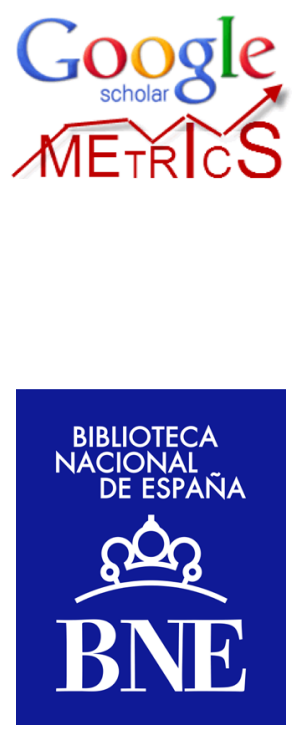

\section{CARHUS PIUS}

REVISTES CIENTIELOUES DE CIINCIFS SOCIALS S HUMANITATS
REDIB

Red Iberoamericana
de Innovación y Conocimiento Cientifico

\section{Matriu d'Informació} per a l'Avaluació de Revistes

\author{
JOURNAL SCHOLAR \\ METRICS
} ARTS, HUMANITIES, AND SOCIAL SCIENCES

\section{EBSCOhost}

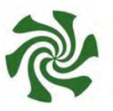

DULCINEA 


\section{INDEXACIONES INDEXATIONS}

\section{- Dialnet}

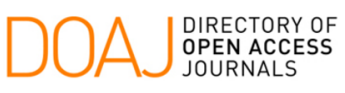

O' SHERPA/RøMEO

\section{CSIC}

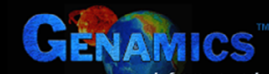

...research from your desktop

Genamics JournalSeek

\section{Crossref}

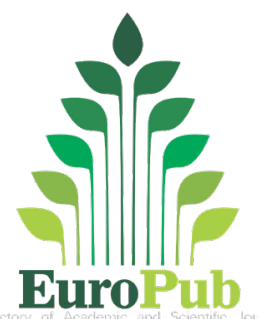

\section{ÍnDICES}

ST. WorldCat

\section{ERIHPLUS \\ EUROPEAN REFERENCE INDEX FOR THE
HUMANITIES AND SOCIAL SCIENCES}




\section{/SUMARIO/ /SUMMARY/}


Las MIPYMEs y sus estrategias mercadológicas, evaluación en ferias de comercialización MSMEs and their marketing strategies, evaluation in marketing fairs

Estimación del impacto de factores socioeconómicos sobre el empleo informal en el mercado de trabajo mexicano

Esstimation of the impact of socioeconomic factors on informal employment in the Mexican labor market

Mayra Yesenia Nava Rubio y Rogelio Varela Llamas

Edad y antigüedad laboral de los profesionales de enfermería como antecedentes del compromiso afectivo en los hospitales privados de Jalisco, México

Age and working seniority of nursing professionals as background to the affective commitment in the private hospitals in Falisco, Mexico

José Alejandro Jaime Vargas

Ambigüedad de rol en académicos: una problemática organizacional en las universidades

Role ambiguity in academics: an organisational problematic in universities

Edith Georgina Surdez Pérez y María del Carmen Sandoval Caraveo

The negative effect of incivility on job satisfaction through emotional exhaustion moderated by resonant leadership 


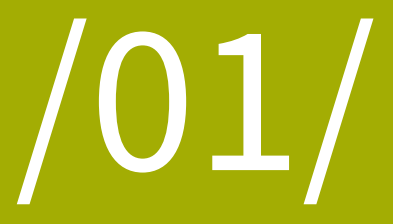




\section{LAS MIPYMES Y SUS ESTRATEGIAS MERCADOLÓGICAS, EVALUACIÓN EN FERIAS DE COMERCIALIZACIÓN MSMES AND THEIR MARKETING STRATEGIES, EVALUATION IN MARKETING FAIRS}

Marco Antonio Lara de la Calleja Docente Investigador, División de Ingeniería en Administración, Instituto Tecnológico Superior de Zacapoaxtla,

Zacapoaxtla, Puebla, (México). E-mail:1_marco_antonio@hotmail.com ORCID: https://orcid.org/0000-0001-6484-5211

Xanath Rojas Mora

Docente Investigador, División de Ingeniería en Administración, Instituto Tecnológico Superior de Zacapoaxtla,

Zacapoaxtla, Puebla, (México).

E-mail: xanath@cicu.org.mx ORCID: https://orcid.org/0000-0002-4467-3122

Zoraira Zaragoza Zamitiz

Docente Investigador, División de Ingeniería en Administración, Instituto Tecnológico Superior de Zacapoaxtla,

Zacapoaxtla, Puebla, (México).

E-mail: laezaragoza@gmail.com ORCID: https://orcid.org/0000-0002-6546-8419

Recepción: 04/10/2019 Aceptación: 29/11/2019 Publicación: 24/11/2020

\section{Citación sugerida:}

Lara de la Calleja, M. A., Rojas, X., y Zaragoza, Z. (2020). Las MIPYMEs y sus estrategias mercadológicas, evaluación en ferias de comercialización. 3C Empresa. Investigación y pensamiento crítico, 9(4), 17-29. https://doi. org/10.17993/3cemp.2020.090444.17-29 


\section{RESUMEN}

El presente artículo se desarrolla en el contexto de México, en donde las micro, pequeñas y medianas empresas (MIPYMES), son parte esencial de la economía nacional, tienen un alto impacto en la generación de empleos y en la producción del país, así como también en la posibilidad de generar acuerdos comerciales entre otras naciones. Las ferias o eventos de comercialización constituyen una ventana de oportunidad para promover sus productos o servicios de forma directa con los posibles consumidores, sin embargo diversos investigadores del Marketing coinciden en que en las MIPYMES luchan con la implementación de la Planeación Estratégica, el Plan de mercadotecnia, y otros elementos necesarios para asegurar las ventas de su empresa. El objetivo del estudio se centró en analizar las capacidades de Mercadotecnia de las MIPYMES expositoras en una feria masiva, organizada anualmente en la región de la Sierra Norte del estado de Puebla. La metodología fue de tipo descriptiva, con un enfoque cualitativo, se diseñó una rúbrica de evaluación con 5 aspectos: 1. Presentación del personal; 2. Estructura del stand; 3. Atención y entrega de información adecuada; 4. Aplicación del producto o servicio (congruencia con el evento); 5. Sustentabilidad. De acuerdo a los resultados se obtuvo información de 30 empresas de diferente giro, encontrando que la categoría con menor puntaje fue la de la estructura del stand, y la de Presentación del personal, identificando estos aspectos prioritarios para mejorar el desarrollo de su Marketing.

\section{PALABRAS CLAVE}

Pequeñas Empresas, Ferias, Comercio, Mercadotecnia, Evaluación, Exposición. 


\section{ABSTRACT}

This article is developed in the context of Mexico, where micro, small and medium enterprises (MSMEs), are an essential part of the national economy, they have a high impact on the generation of jobs and the production of the country, and the possibility of generating trade agreements between other nations. The Trade fairs constitute a window of opportunity to promote their products or services directly with potential consumers, however, several Marketing researchers agree that in MSMEs they struggle with the implementation of Strategic Planning, the Plan of marketing, and other necessary elements to ensure the sales of his company. The objective of the study focused on analyzing the Marketing capabilities of the exhibiting MSMEs in a massive fair, organized annually in the Sierra Norte region of the state of Puebla. The methodology was descriptive, with a qualitative approach, an evaluation rubric was designed with 5 aspects: 1. Presentation of the staff; 2. Booth structure; 3. Attention and delivery of adequate information; 4. Application of the product or service (congruence with the event); 5. Sustainability. According to the results, information was obtained from 30 companies of different business, finding that the category with the lowest score was that of the structure of the stand, and the Presentation of the staff, identifying these priority aspects to improve the development of their Marketing.

\section{KEYWORDS}

Small Business, Fairs, Commerce, Marketing, Evaluation, Exposition. 


\section{INTRODUCCIÓN}

En México las micro, pequeñas y medianas empresas (MIPYMES), son parte esencial de la economía nacional, tienen un alto impacto en la generación de empleos y en la producción del país, así como también por los acuerdos comerciales entre otras naciones. De acuerdo con datos del INEGI (2014), en México existen aproximadamente 4 millones 15 mil unidades empresariales, de las cuales 99.8\% son MIPYMES que generan 52\% del PIB y 72\% del empleo en el país.

La Comisión Económica para América Latina y el Caribe (Alburquerque, 2004), reconoce que los sistemas locales de empresas juegan un papel relevante en los procesos de crecimiento y cambio estructural, dado que, igual que las grandes empresas, impulsan la formación de externalidades y, por lo tanto, rendimientos crecientes y desarrollo económico. Igualmente los emprendimientos locales se han convertido cada vez más, en acciones de políticas de desarrollo, que aunado al crecimiento económico, existen factores inmateriales que traen consigo, tales como: la organización del territorio, conservación de la cultura regional, procesos que permiten una visión de ajuste y de reestructuración productiva de las localidades.

Además, las iniciativas locales se han convertido en una de las formas preferentes de la política de desarrollo, fortaleciendo los factores inmateriales del desarrollo y la organización del territorio, que los procesos de ajuste y reestructuración productiva necesitan.

De acuerdo a ProMéxico (2016), algunas de las ventajas de las MIPYMES son las siguientes:

- Son un importante motor de desarrollo del país.

- Tienen una gran movilidad, permitiéndoles ampliar o disminuir el tamaño de la planta, así como cambiar los procesos técnicos necesarios.

- Por su dinamismo tienen posibilidad de crecimiento y de llegar a convertirse en una empresa grande. 
- Absorben una porción importante de la población económicamente activa, debido a su gran capacidad de generar empleos.

- Asimilan y adaptan nuevas tecnologías con relativa facilidad.

- Se establecen en diversas regiones del país y contribuyen al desarrollo local y regional por sus efectos multiplicadores.

Es así como en México, según el Diario Oficial de la Federación (DOF, 2006), de común acuerdo con la Secretaría de Hacienda y Crédito Público (SHCP), las MIPYMES en función del número de trabajadores, se definen como:

- Micro empresas las que tienen de 1 a 10 trabajadores.

- Pequeñas empresas las que tienen de 11 a 50 empleados y que sean del sector industrial y servicios, y de 11 a 30 empleados en el sector comercio.

- Medianas empresas las que tienen de 51 a 250 empleados si pertenecen al sector industrial, de 31 a 100 empleados en el sector comercio y de 51 a 100 empleados en el sector servicios.

Señala Alburquerque (2004), que es importante insistir en que el desarrollo económico local, es un enfoque alternativo al de las políticas asistenciales de superación de la pobreza, y que busca incidir en la generación de empleo e ingresos mediante la mejora de la productividad y competitividad de los diferentes sistemas productivos locales. García y Chávez (2017) mencionan que se tiene que avanzar desde un diseño asistencial a un planteamiento de desarrollo económico, y desde una perspectiva sectorial a una de carácter horizontal e integrada, según las características, actores y capital social de cada territorio. Es en el ámbito local donde se define la demanda de modernización del tejido de empresas existente, y a partir de esa demanda debe construirse la oferta apropiada de servicios de innovación y capacitación técnica y empresarial para el fomento productivo local.

Sin embargo ante estas necesidades que presentan las MIPYMES, existe un problema general que es el desarrollo de Mercadotecnia, en donde los dueños de los negocios conocen sus productos o servicios, 
pero no son expertos en el campo del marketing y por lo tanto, luchan con la implementación de la planeación estratégica, el plan de mercadotecnia, y otros elementos necesarios para asegurar el éxito de su empresa (Day, 2000; Kotler, 2004).

Kotler (2004), menciona algunos de los errores de marketing, críticos para las pequeñas empresas, tales como: no están suficientemente enfocados en el mercado y orientados al cliente; no entienden el objetivo de verificar que hace la competencia; gestionan mal las relaciones con los diferentes públicos y partes interesadas; tienen dificultades descubriendo nuevas oportunidades; débil desarrollo de marca y esfuerzos de comunicación, y no están bien organizados para llevar a cabo marketing.

Además de estos errores, los consumidores hoy en día tienen altas expectativas sobre la calidad de sus interacciones con las empresas (Harrison, Waite y Hunter, 2006). Estudios recientes de marketing y gestión se han centrado en describir al consumidor contemporáneo, y resaltan que hoy en día es un cliente exigente y conocedor (Verona, Sawhney y Prandelli, 2008) y basan sus decisiones para la compra en factores experienciales e intangibles (Vargo y Lusch, 2004). Estas expectativas presentan tanto oportunidades y desafios para las pequeñas empresas, que deben construir relaciones con sus clientes a través de sus esfuerzos de marketing y desarrollar así una ventaja competitiva.

Sin embargo también es cierto que las pequeñas empresas enfrentan muchos desafíos con respecto al marketing, debido a su limitado tamaño y limitaciones de recursos (Huang y Brown, 1999). Este mercado cambiante y el panorama del consumidor, también sugiere la necesidad de enfoques novedosos para mejorar la comercialización de las pequeñas empresas (Bjerke y Hultman, 2002).

Por lo tanto, con el objetivo de identificar las áreas prioritarias en términos de Mercadotecnia, que las pequeñas empresas necesitan fortalecer, se desarrolló el presente estudio, a través del caso de análisis de una feria de comercialización denominada: Festival de Medicina tradicional, que se llevó a cabo en Apulco, Zacapoaxtla, Puebla, durante el año 2019. En los últimos años este festival ha ido ganando terreno y predilección entre los consumidores que pertenecen a un perfil informado y consciente de la economía 
social, local y sustentable, llegando a tener un flujo de hasta 1000 visitantes, de diversas regiones a nivel Nacional e Internacional, además se ha convertido en una propuesta cultural, con prioridad medicinal para contribuir a detener la pérdida del uso de las tradiciones y costumbres medicinales y curativas de la Sierra Nororiental de Puebla. Durante un día se dan cita pequeñas empresas, que comercializan diversos productos regionales, algunas con mejores esfuerzos de Mercadotecnia que otras, haciendo falta el análisis mencionado para poder comparar las estrategias que han desarrollado.

\section{METODOLOGÍA}

Para realizar el estudio es necesario determinar una rúbrica de evaluación, Vera (2011), define que es un conjunto de criterios o de parámetros desde los cuales se juzga, valora, califica y conceptúa sobre un determinado aspecto, que también pueden ser entendidas como pautas que permiten aunar criterios, niveles de logro y descriptores para juzgar o evaluar un aspecto del que se trate.

En consecuencia, la valoración que se pretende realizar a los expositores en el caso de estudio es de tipo cualitativo, que permitirá entender la percepción del público consumidor, conociendo el por qué una persona prefiere ciertos atributos y no otros, esto se logra al analizar sus hábitos y de dónde vienen sus decisiones.

El proceso para la recolección de los datos fue de tipo descriptivo, con un enfoque cualitativo, en donde se diseñó una rúbrica de evaluación (ver Tabla 1), con 5 aspectos a observar: 1. Presentación del personal; 2. Estructura del stand; 3. Atención y entrega de información adecuada; 4. Aplicación del producto o servicio (congruencia con el evento); 5. Sustentabilidad. Con una escala de valoración del 1 al 5, considerando el desglose de cada uno de los criterios definidos. 
Tabla 1. Rúbrica de evaluación.

\begin{tabular}{|c|c|c|c|}
\hline \multicolumn{4}{|c|}{ Rúbrica de evaluación Stand Expositor } \\
\hline & \multicolumn{3}{|r|}{ (Nombre de la empresa) } \\
\hline & \multicolumn{2}{|l|}{ Evaluador/observador: } & (Nombre del alumno) \\
\hline Items & Criterios & Valor 1 a 5 & Observaciones \\
\hline $\begin{array}{l}\text { Presentación } \\
\text { personal }\end{array}$ & $\begin{array}{l}\text { Expositor con uniforme representativo, higiene } \\
\text { personal, en caso de alimentos, con guantes, } \\
\text { mascarilla y pelo recogido (damas). }\end{array}$ & & \\
\hline Estructura de stand & $\begin{array}{l}\text { Cumple con materiales visuales, trípticos, dípticos, } \\
\text { infografía. Además tiene ordenado y limpio su } \\
\text { espacio. }\end{array}$ & & \\
\hline $\begin{array}{l}\text { Atención y entrega } \\
\text { de información } \\
\text { adecuada }\end{array}$ & $\begin{array}{l}\text { El expositor resuelve las dudas y atiende } \\
\text { oportunamente a las personas interesadas. }\end{array}$ & & \\
\hline $\begin{array}{l}\text { Aplicación del } \\
\text { producto o servicio }\end{array}$ & $\begin{array}{l}\text { Existe o es perceptible la congruencia del producto o } \\
\text { servicio con el festival de medicina tradicional. }\end{array}$ & & \\
\hline Sostenibilidad & $\begin{array}{l}\text { Se cuida que en sus productos exista el cuidado } \\
\text { del medio ambiente a través del manejo de la } \\
\text { procedencia y reciclado de materiales (envolturas, } \\
\text { empaques, etiquetas). }\end{array}$ & & \\
\hline & Total & & \\
\hline
\end{tabular}

Fuente: elaboración propia.

Para unificar los criterios y las perspectivas del consumidor, un grupo de 7 estudiantes de la carrera de Ingeniería en Administración, de la asignatura de Mercadotecnia, fue capacitado en la temática de imagen y servicio al cliente, que se requiere en las ferias de comercialización de productos. Fue así como este grupo, aplicó las rúbricas de evaluación por cada una de las empresas presentes en el Festival.

El número de empresas que se analizaron fueron 30, el desglose por giro comercial se muestra en la Tabla 2. 
Tabla 2. Giro comercial de los expositores.

Fuente: elaboración propia.

\begin{tabular}{|c|c|}
\hline Número de empresas & Giro comercial \\
\hline 2 & Vinos regionales \\
\hline 5 & Alimentos en conserva \\
6 & Artesanías \\
\hline 9 & Artículos de higiene personal \\
\hline 4 & Ropa con textiles regionales \\
\hline 4 & Accesorios de bisutería \\
\hline 30 & Total \\
\hline
\end{tabular}

\section{RESULTADOS}

De acuerdo a lo encontrado se determinó una sumatoria de cada una de las categorías de análisis ver Gráfico 1, en donde se puede determinar que con 133 puntos la atención y entrega de información adecuada, fue la estrategia con mayor posicionamiento en los expositores del Festival de medicina tradicional.

\section{Sumatoria Total}

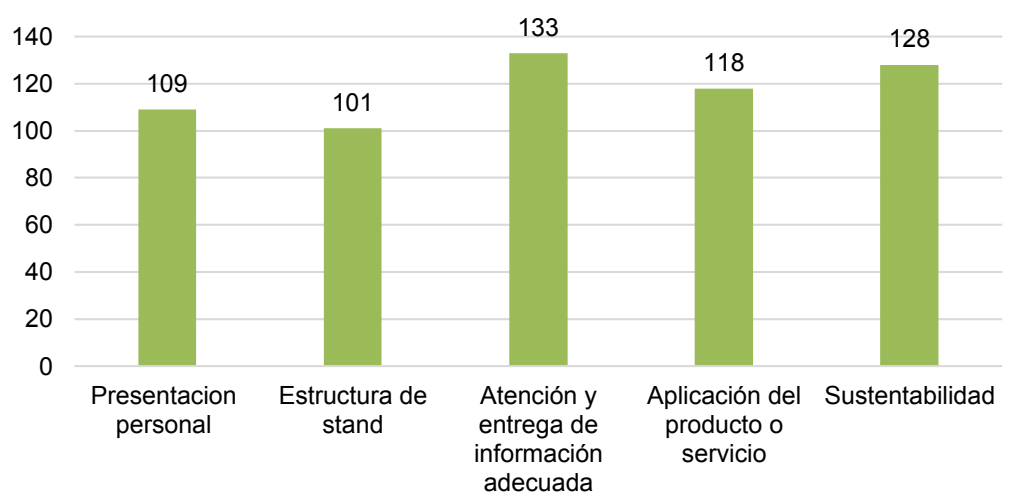

Gráfico 1. Sumatoria total de las categorías .

Fuente: elaboración propia. 
Por lo que si se obtienen los promedios, de acuerdo a los 30 expositores observados, podemos encontrar las áreas prioritarias de atención, para mejorar en cuanto a las estrategias de Mercadotecnia que están desarrollando, ver Gráfico 2.

\section{Promedio por categoría}

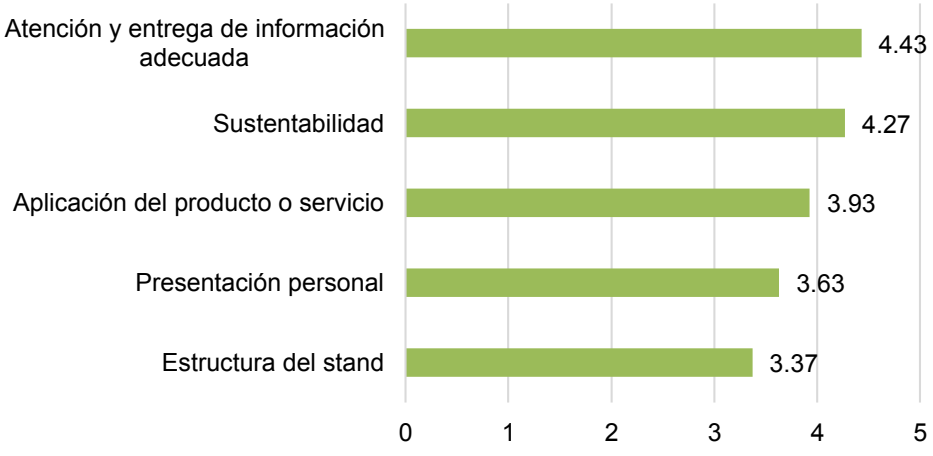

Gráfico 2. Promedio por categoría.

Fuente: elaboración propia.

Ordenando los promedios, se puede distinguir que la categoría con menor puntaje es la de la estructura del stand, con 3.37 de 5 disponible, por lo que es necesario pensar en la imagen de las pequeñas empresas, sus logotipos, sus marcas, los colores que los distinguen para lograr un posicionamiento en sus clientes; otra categoría con menor puntaje fue la de la Presentación personal con 3.63 de 5 disponible, de forma congruente con lo anterior, la imagen personal puede ayudar a reforzar el producto o servicio que se está vendiendo, por lo que es necesario que las pequeñas empresas, desarrollen acciones para establecer una mejoría en la imagen y presentación del personal.

\section{CONCLUSIONES}

Se pudo conocer las áreas prioritarias en términos de Mercadotecnia, que las pequeñas empresas presentes en el Festival de Medicina tradicional, Apulco 2019, necesitan fortalecer. Como se ha mencionado, las MIPYMES, enfrentan muchos retos respecto al desarrollo de Mercadotecnia, es verídico que tienen 
limitaciones de recursos, sin embargo es una oportunidad para pensar en estrategias alternativas y novedosas que permitan posicionar la imagen de las pequeñas empresas y con ello fomentar la comercialización en un entorno que cada vez tiene consumidores más especializados y desafiantes.

\section{REFERENCIAS BIBLIOGRÁFICAS}

Alburquerque, F. (2004). Desarrollo Económico Local y Descentralización en América Latina. Revista CEPAL, 82. https://repositorio.cepal.org/bitstream/handle/11362/10946/1/082157171_es.pdf

Bjerke, B., y Hultman, C. (2002). Entrepreneurial marketing: The growth of small firms in the new economic era. Edward Elgar.

Day, J. (2000). Commentary - The value and importance of the small firm to the world economy. European Fournal of Marketing, 34(9/10), 1033. https://doi.org/10.1108/03090560010342764

Diario Oficial de la Federación (DOF). (2006). http://www.diputados.gob.mx/LeyesBiblio/ pdf/247_210115.pdf

García M., y Chávez R. (2017). Indicadores para medir el capital humano en micro, pequeñas y medianas empresas en México. Cimexus, XII(2). https: / / dialnet.unirioja.es/servlet/articulo?codigo=6317395

Harrison, T., Waite, K., y Hunter, G. L. (2006). The internet, information and empowerment. European Fournal of Marketing, 40, (9/10), 972-993. https://doi.org/10.1108/03090560610680961

Huang, Z., y Brown, A. (1999). An analysis and classification of problems in small business. International Small Business fournal, 18(1), 73-85. https://doi.org/10.1177/0266242699181004

INEGI. (2014). http:/ / www.inegi.org:mx/

Kotler, P. (2004). Ten deadly marketing sins; signs and solutions. John Wiley \& Sons. 
ProMéxico. (2016). PYMES, eslabón fundamental para el crecimiento en México. https:/ / www.camescom.com. mx/pymes-eslabon-fundamental-para-el-crecimiento-en-mexico/

Vargo, S., y Lusch, R. (2004). Evolving to a new dominant logic for marketing. Fournal of Marketing, 68(1), 1-17. https://doi.org/10.1509/jmkg.68.1.1.24036

Vera, L. (2011). Rúbricas y listas de cotejo. Departamento de Educación y Ciencias Sociales. Universidad Interamericana de Puerto Rico. Recinto de Ponce. https://viancep2012.files.wordpress. com/2011/12/rubricas.pdf

Verona, G., Sawhney, M., y Prandelli, E. (2008). Collaborating with customers to innovate: Conceiving and marketing products in the networking age. Elgar. 


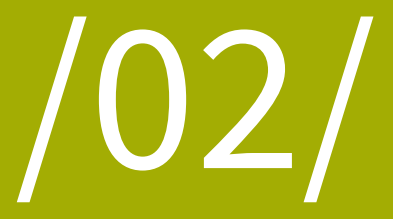




\section{ESTIMACIÓN DEL IMPACTO DE FACTORES SOCIOECONÓMICOS SOBRE EL EMPLEO INFORMAL EN EL MERCADO DE TRABAJO MEXICANO}

\section{ESTIMATION OF THE IMPACT OF SOCIOECONOMIC FACTORS ON INFORMAL EMPLOYMENT IN THE MEXICAN LABOR MARKET}

Mayra Yesenia Nava Rubio
Profesor-Investigador en la Facultad de Ciencias Administrativas de la Universidad Autónoma de Baja California (UABC).
Miembro del Sistema Nacional de Investigadores (SNI).
Doctora en Ciencias Económicas.
Mexicali, Baja California, (México).
E-mail: mnava35@uabc.edu.mx ORCID: https://orcid.org/0000-0003-3206-1353

Rogelio Varela Llamas

Profesor-Investigador en la Facultad de Economía y Relaciones Internacionales de la Universidad Autónoma de Baja California (UABC). Miembro del Sistema Nacional de Investigadores (SNI).

Doctor en Economía Industrial y Relaciones Laborales.

Tijuana, Baja California, (México).

E-mail: rvarela@uabc.edu.mx ORCID: https://orcid.org/0000-0002-8608-4537

Recepción: 04/10/2019 Aceptación: 04/12/2019 Publicación: 24/11/2020

Citación sugerida:

Nava, M. Y., y Varela, R. (2020). Estimación del impacto de factores socioeconómicos sobre el empleo informal en el mercado de trabajo mexicano. 3C Empresa. Investigación y pensamiento crítico, 9(4), 31-51. https://doi. org/10.17993/3cemp.2020.090444.31-51 


\section{RESUMEN}

Las variaciones que muestra el empleo informal en el mercado de trabajo mexicano pueden ser explicadas considerando diversos factores de orden social y económico. El interés por estudiar el empleo informal surge a través de la observación de su gran magnitud como proporción de la población empleada, que es aproximadamente del 60\% a nivel nacional para el periodo que abarca del año 2005 al año 2014. Debido a que la informalidad presenta diversas características, o en otras palabras, es heterogénea, la estimación del impacto de los factores socioeconómicos se realiza considerando su clasificación en empleo informal tipo independiente y empleo informal tipo dependiente. A su vez, los factores pertenecen a una visión teórica dualista o institucionalista. La metodología seleccionada para la estimación es un modelo de efectos fijos con datos de panel que permite concluir que los factores socioeconómicos de mayor impacto sobre los niveles de empleo informal en el mercado de trabajo mexicano son la educación de la población y la suficiencia del sector moderno o formal para captar empleo.

\section{PALABRAS CLAVE}

Factores Socioeconómicos, Empleo Informal, Empleo Informal Independiente, Empleo Informal Dependiente, Efectos Fijos, Panel de Datos. 


\section{ABSTRACT}

The variations shown by informal employment in the Mexican labor market can be explained considering various social and economic factors. The interest in studying informal employment arises through the observation of its great magnitude as a proportion of the employed population, which is approximately 60\% nationally for the period from 2005 to 2014. Because informality It has several characteristics, or in other words, it is heterogeneous, the estimation of the impact of socio-economic factors is made considering its classification in informal type independent employment and dependent type informal employment. In turn, the factors belong to a dualistic or institutionalist theoretical vision. The methodology selected for the estimation is a fixed effects model with panel data that allowes us to conclude that the socioeconomic factors with the greatest impact on the levels of informal employment in the Mexican labor market are the education of the population and the sufficiency of the modern sector or formal to capture employment.

\section{KEYWORDS}

Socioeconomic Factors, Informal Employment, Independent Informal Employment, Dependent Informal Employment, Fixed Effects, Data Panel. 


\section{INTRODUCCIÓN}

La informalidad es un tipo de empleo que posee algunas características positivas, como la disminución del desempleo, pero al que también se le han asociado algunas características negativas que contradicen los esfuerzos por lograr mejores condiciones de ocupación, crecimiento y desarrollo. Son estas peculiaridades las que le conceden importancia de análisis en el ámbito académico y justifican el objetivo gubernamental de reducirla.

En la economía mexicana, la informalidad es un fenómeno que ha alcanzado elevadas cifras, muestra de ello es que durante el periodo 2005-2014, en promedio el 58.8\% de la población ocupada estaba inmersa en ella, de acuerdo a cifras del Instituto Nacional de Estadística y Geografía (INEGI). Por su magnitud, es relevante identificar aquellos factores que contribuyen a explicarla desde un escenario macroeconómico y que sean útiles en el diseño de una estrategia que permita disminuirla.

Es importante señalar que no todo el empleo informal exhibe las mismas características. Una clasificación general en términos de la relación laboral que se sostiene comprende dos grandes categorías; informalidad independiente e informalidad dependiente. La diferencia entre ambas radica en que, en el primer caso, no existe una subordinación de carácter laboral, mientras que en el segundo caso sí.

A nivel teórico, dos enfoques proveen la explicación a dicho fenómeno; la visión dual y la institucional. La primera sostiene que la informalidad se relaciona con la estructura del mercado de trabajo y la decisión de ser informal tiene carácter involuntario. Por su parte, el enfoque institucional destaca que la causa de la informalidad se relaciona con el desempeño de las instituciones del Estado, mismas que pueden influir en favor de la elección de un empleo informal, concediéndole un carácter voluntario.

El objetivo del presente trabajo es determinar la influencia que tiene sobre la informalidad laboral dependiente e independiente un conjunto de factores de carácter dual e institucional, en el marco de un modelo econométrico de datos de panel que considera un horizonte temporal del año 2005 al año 2014 
y 24 entidades federativas de las 32 que conforman la geografía nacional. La exclusión de 8 entidades se debe a la falta de información.

\section{DESARROLLO}

Los orígenes sobre el estudio de la informalidad se remontan a los trabajos de Keith Hart, quien estudió el caso de Ghana a principios de los años setenta, destacando el término de sector informal como "un conjunto de actividades económicas que se encuentran fuera de la fuerza laboral organizada" donde plantea que el empleo informal actúa como un amortiguador para quienes se encuentran sin empleo (Hart, 1973).

La OIT define a la economía informal como el conjunto de actividades económicas que se encuentran insuficientemente contempladas por los sistemas formales o en el extremo no lo están. Aun cuando los individuos y empresas operan dentro de la ley, ésta no se aplica o no se cumple ya que la misma fomenta su incumplimiento al ser inadecuada, compleja o al imponer costos excesivos (OIT, 2012).

Algunos estudios sostienen que la informalidad es un trabajo que se realiza sin contar con el amparo del marco legal o institucional (Negrete y Eternod, 2011). Otros subrayan que puede tener significado diferente para distintas personas, pero comúnmente significa cosas "malas" como: trabajadores sin protección, regulación excesiva, baja productividad, competencia desleal, evasión de la autoridad de la ley, pago incompleto o falta de pago de impuestos y un trabajo desde las sombras (Maloney y Saavedra, 2008).

Por otra parte, la informalidad genera efectos positivos y negativos. Entre los efectos positivos, permite abatir el desempleo al convertirse en una salida a la incapacidad del sector formal para generar empleos. En cambio, los efectos negativos afectan directamente a la economía y al bienestar a través de la falta de acceso a los sistemas de seguridad social o los bajos salarios. Para Aguilera y Velázquez (2005) la 
informalidad puede traer consigo implicaciones negativas para el crecimiento económico de un país, ya que impacta sobre la productividad laboral, que es un determinante fundamental de este.

Leal (2014) menciona tres distorsiones inducidas por la informalidad. La primera, en la demanda óptima de trabajo de las empresas informales, esto es, permanecen pequeñas con el objetivo de evadir la detección de su actividad informal. Por lo que la informalidad se asocia a empresas pequeñas con baja productividad y bajo crecimiento. La segunda se refleja en las elecciones de ocupación, para algunos individuos es más atractivo convertirse en empresarios que permanecer como empleados. Por último, la mala asignación de recursos, es decir, a las empresas con baja productividad se les asignan más recursos de los que deberían.

\subsection{INFORMALIDAD LABORAL: ALGUNAS ESTADÍSTICAS}

La evolución de la informalidad laboral en México para el periodo 2005-2014 se muestra en el Gráfico 1, donde se reportan las cifras de la Tasa de Informalidad Laboral (TIL). Durante el periodo referido, en promedio la TIL fue de 58.8\%, lo que representa un elevado porcentaje de población ocupada informal.

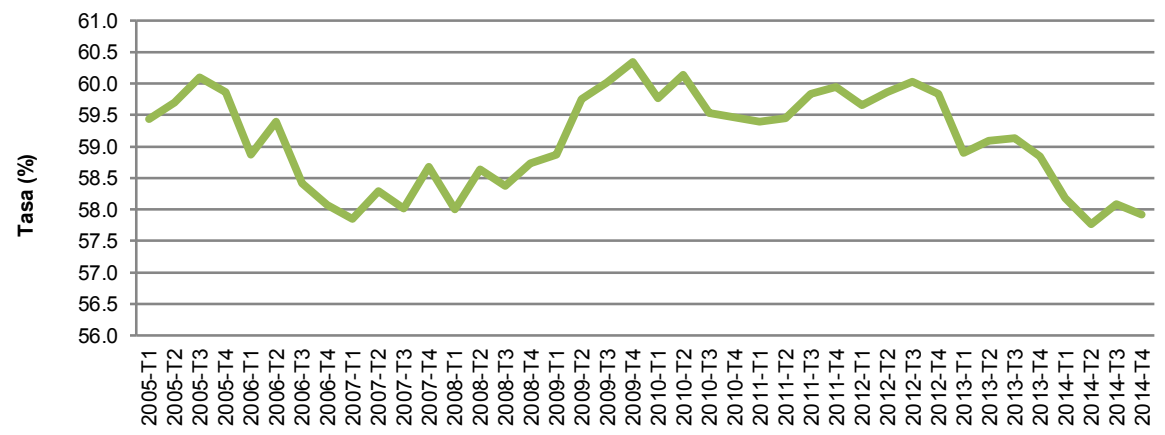

Gráfico 1. Tasa de Informalidad Laboral (TIL) en México.

Fuente: elaboración propia con datos de la Encuesta Nacional de Ocupación y Empleo (ENOE).

A partir del año 2007, la TIL muestra un comportamiento ascendente que alcanza su nivel máximo en el cuarto trimestre de 2009 equivalente a 60.4\%. Esto se relaciona con la contracción que experimentó 
la economía mexicana derivada de los efectos de la crisis internacional suscitada en 2008. Sin embargo, después del evento la tendencia se revierte y al final dicha tasa alcanza niveles muy similares a los registrados en 2007, que son de los más bajos dentro del periodo considerado.

Es conveniente conocer el comportamiento de los componentes de la TIL. En el Gráfico 2, se ilustra la Tasa de Informalidad Laboral Independiente (TILI) con frecuencia anual, esta representa en promedio 21.6\% para el periodo. Del año 2005 a 2008, muestra un comportamiento descendente significativo pasando de $22.4 \%$ a $21.0 \%$, respectivamente. Sin embargo, en 2009 se incrementa a $22.0 \%$ mostrando en lo sucesivo variaciones que distan de su valor más bajo alcanzado en 2008.

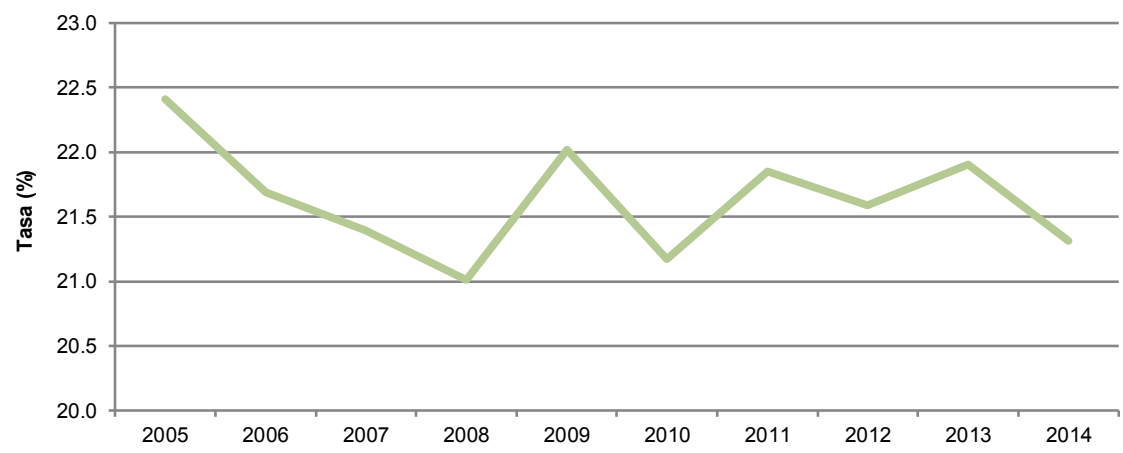

Gráfico 2. Tasa de Informalidad Laboral Independiente (TILI) en México.

Fuente: elaboración propia con datos de la Encuesta Nacional de Ocupación y Empleo (ENOE).

La Tasa de Informalidad Laboral Dependiente (TILD) en el Gráfico 3, en promedio representó $37.2 \%$ para el mismo periodo, siendo superior a la TILI en alrededor de 15.6 puntos porcentuales. En consecuencia, la TIL se compone mayormente por la informalidad del tipo dependiente y es de suponerse que parte de esta se encuentra en el sector formal de la economía. En términos generales, los niveles de informalidad observados en el país resultan elevados, lo que es preocupante desde una visión de calidad del empleo, bienestar social, crecimiento y desarrollo económico. 


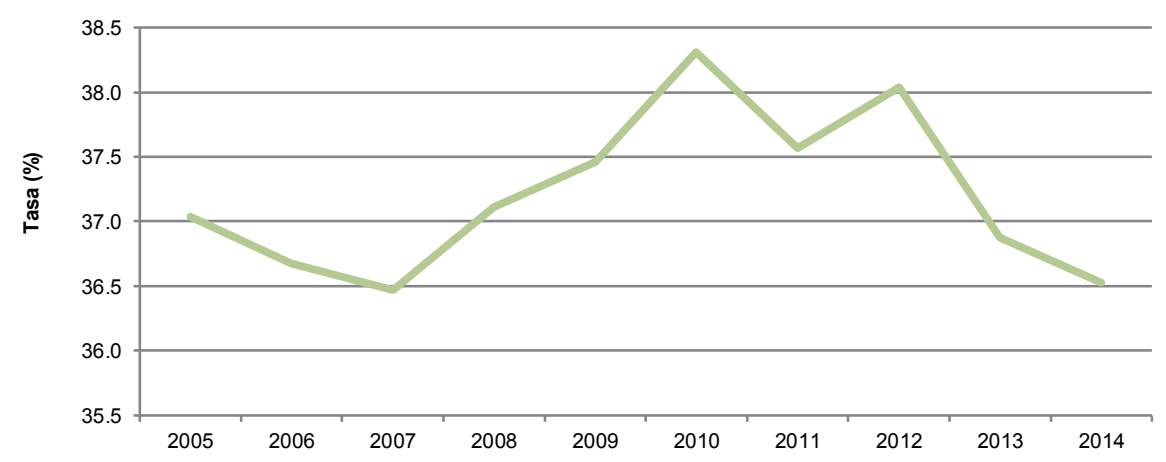

Gráfico 3. Tasa de Informalidad Laboral Dependiente (TILD) en México.

Fuente: elaboración propia con datos de la Encuesta Nacional de Ocupación y Empleo (ENOE).

\subsection{TEORÍA DUAL E INSTITUCIONAL}

Los enfoques teóricos dual e institucional proveen los argumentos fundamentales en la explicación del fenómeno de la informalidad laboral. Comenzando por la teoría dual, para Leontaridi (1998), la dualidad implica que los empleos pertenecen a un sector primario o a uno secundario. A estos sectores se hace referencia con distintas denominaciones, por un lado, un sector llamado "capitalista, formal, moderno, industrial o urbano" y otro considerado "de subsistencia, informal, tradicional, agrícola o rural" (Fields, 2004).

Leontaridi (1998) argumenta que el sector primario comprende a los "buenos" empleos caracterizados por salarios elevados, seguridad económica y rápida rotación que conducen a la promoción profesional. En contraste, el sector secundario comprende a los "malos" empleos que regularmente son no calificados, no ofrecen escalas profesionales y con niveles salariales bajos. Por su parte, Jiménez (2013) sostiene que, para la teoría dualista, los trabajadores informales constituyen la porción excluida del mercado de trabajo formal y la inserción en el mercado informal es involuntaria. 
En Fields (2005) el sector informal es un espacio de libre entrada, es decir, para un individuo es posible obtener un empleo si así lo desea, o las barreras a la entrada son pocas o inexistentes, lo que origina que los procesos de determinación de salarios sean distintos entre el sector formal e informal de la economía.

Una segunda explicación la provee la teoría institucional bajo la cual, las decisiones tomadas desde las instituciones del Estado generan incentivos que influyen en la elección racional de los agentes al escoger entre la ocupación formal o informal (Jiménez, 2012). Es decir, quienes están en el sector informal lo hacen por decisión propia.

Para Uribe y Ortiz (2004), el enfoque institucional ignora las restricciones de la estructura económica, concentrándose en las decisiones que a nivel individual se realizan con respecto a la decisión de participar en la actividad económica. Bajo este enfoque los individuos y empresas escapan al cumplimiento con las instituciones, por ejemplo, evadiendo impuestos. Entonces, el sector informal puede surgir cuando gobierno impone regulaciones e impuestos excesivos, pero carece de la capacidad para hacer cumplir la ley (Loayza, 1997).

Por otro lado, los beneficios que dictan las instituciones que deben recibir los individuos empleados en el sector formal pueden contribuir al incremento de la informalidad, tal es el caso del seguro médico. El empleo del jefe de hogar, en algunos casos ofrece seguro médico para los familiares dependientes principalmente cónyuges e hijos, como resultado, estos últimos pueden obtener relativamente poca rentabilidad de las contribuciones de seguridad social que deberán pagar si se emplean en el sector formal (OCDE, 2004).

\subsection{ANÁLISIS EMPÍRICO EN MÉXICO Y OTROS PAÍSES}

A continuación, se describen los resultados empíricos de algunas investigaciones en torno a la temática de interés. Packard (2007) examina la elección de sector en Chile y modela tres tipos de empleo: un sector formal de empleo asalariado bajo contrato, un sector informal de empleo asalariado sin contrato y el autoempleo. Los resultados indican que el autoempleo no es un sector residual de un mercado laboral 
dualista, es decir, los individuos lo eligen; por el contrario, el empleo informal si exhibe características de un sector residual.

Trabajos como el de Tannuri-Pianto y Pianto (2002) consideran datos de la encuesta de hogares "Pesquisa Nacional por Amostra de Domicílios (PNAD)" para el año de 1999 para Brasil. Estudian a los individuos formales e informales en varios puntos de la distribución de ingresos (por cuantiles) y concluyen que las diferencias más relevantes de las funciones de ingresos son sus recompensas y penalizaciones por cuestiones como el analfabetismo, el género y la afiliación sindical. La penalización es elevada para los individuos analfabetas en el sector formal. Las mujeres son más penalizadas en los cuantiles más altos del sector formal que en el sector informal. Asimismo, ser miembro de un sindicato tiene efecto positivo y significativo sobre los ingresos de los formales, en cambio sólo los trabajadores informales en los cuantiles más altos reciben un beneficio.

Otros trabajos estudian la diferencia salarial entre el sector formal e informal donde se miden las ganancias y pérdidas en los salarios derivados de la formalización. Para el caso de México en el periodo 2000-2003 en Moreno (2007) se reconoce que dos pueden ser las fuentes de la heterogeneidad del salario; la primera es una tasa impositiva aplicada a un sector relativo al otro y la segunda es la autoselección de los agentes entre sectores. Las estimaciones le permiten concluir que la fuente de esa diferencia salarial es la autoselección.

En Friedman et al. (2000), se realiza un estudio de la informalidad desde una perspectiva institucional para 69 países, encontrando que elevadas tasas de impuestos se asocian con menor actividad informal, en cambio la mayor burocracia, mayor corrupción y un entorno legal débil se asocian con una gran economía informal.

Singh et al. (2012) estudian los determinantes de la economía informal con énfasis en las instituciones y el estado de derecho. La unidad de análisis es una muestra de 100 países (avanzados, emergentes y en desarrollo). Los resultados indican que mejores instituciones se asocian a una participación menor de la 
economía informal, y que los países con mayor corrupción tienden a poseer economías informales más grandes.

Para Busso et al. (2012) la excesiva informalidad en México provoca costos en términos de productividad. Considerando los años de 1998 y 2008 los autores argumentan que la informalidad se debe a la regulación asimétrica entre trabajadores asalariados y no asalariados. La regulación laboral establece derechos para los asalariados, así como obligaciones (inscripción al Instituto Mexicano del Seguro Social, pago por despido, salario mínimo, etc.) para las empresas, pero estos no aplican para los no asalariados (informales). Así, la vía por la que afecta la informalidad a la productividad es por las distorsiones creadas en el precio de los factores dada esta asimetría.

\subsection{METODOLOGÍA Y DATOS}

La metodología instrumentada consiste en estimar un modelo de regresión con datos en panel, que considera 24 de las 32 entidades de la federación para el periodo 2005 a 2014. Existen distintas técnicas metodológicas para datos en panel, sin embargo, en el presente caso las pruebas formales como la F-restringida, Multiplicador de Lagrange de Breusch-Pagan y la de Hausman, indican que el modelo adecuado es de efectos fijos. Asimismo, la estimación con variables instrumentales no fue considerada debido a que la prueba de exogeneidad de Sargan, indicó que no existe endogeneidad.

El desarrollo metodológico se realiza siguiendo a Davidson y MacKinnon (1993) quienes parten de un modelo con datos en panel $y_{t i}=x_{t i}(\beta)+u_{t i}$, donde $t$ hace referencia a la dimensión temporal que va desde 1 hasta $T$ periodos, e $i$ es la dimensión espacial o corte transversal que involucra de 1 hasta $n$ unidades de análisis. Por lo tanto, el número total de observaciones es igual a $n T$.

Los datos fueron obtenidos de fuentes como el Banco de Información Económica (BIE) del Instituto Nacional de Estadística y Geografía (INEGI), la Encuesta Mensual de la Industria Manufacturera (EMIM), Encuesta Industrial Mensual (EIM), Encuesta Nacional de Ocupación y Empleo (ENOE), los registros administrativos de las Finanzas Públicas Estatales y Municipales y de otras como el Tercer 
Informe de Gobierno 2014-2015, Consejo Nacional de la Población (CONAPO), Secretaría de Educación Pública (SEP) y el Instituto Nacional para la Evaluación de la Educación (INEE).

El modelo para la informalidad laboral independiente compuesta por los individuos que son trabajadores por cuenta propia y empleadores es $T I L I_{t i}=\alpha_{i}+\beta D_{t i}+\delta I_{t i}+u_{t i}$. El modelo para la informalidad laboral dependiente que registra a individuos que dependen de un jefe y cuyo empleo informal puede ser subordinado y remunerado o no remunerado es $T I L D_{t i}=\alpha_{i}+\beta D_{t i}+\delta I_{t i}+u_{t i}$.

Tres factores integran al vector $D_{t i}$, el Producto Interno Bruto (PIB) pretende mostrar la relación negativa de la situación económica; si es favorable, entonces la informalidad disminuirá, debido a que el sector moderno se encontrará en condiciones para emplear formalmente una cantidad mayor de trabajadores, y viceversa.

El segundo factor es la Educación de la Población Económicamente Activa (PEA) que se expresa como EDU. Si se parte de la consideración de que en el sector informal se aglutinan los empleos menos calificados, entonces entre menor sea el nivel de educación de los trabajadores, el sector informal crecerá. Por consiguiente, la relación entre informalidad y educación se espera negativa.

El tercer factor es el tamaño del Sector Moderno (TSM) medido a través del porcentaje de población ocupada en la industria manufacturera. Se espera una relación negativa, pues la informalidad cambiará de acuerdo con la capacidad del sector moderno para generar empleo. La industria manufacturera es considerada como el sector moderno porque se compone de actividades reconocidas por hacer uso de diversos niveles de tecnología.

Entre los factores que conforman el vector $I_{t i}$ está el Costo Laboral Unitario (COSTO) en el sector moderno. El enfoque institucional resalta que los individuos y empresas buscan escapar a las obligaciones formales, entonces es de esperarse que las empresas analicen el comportamiento del costo laboral al momento de demandar trabajo formal. La relación esperada entre COSTO y la informalidad es 
positiva, a mayores costos laborales mayor informalidad (menor demanda de trabajo formal) y viceversa. El cálculo de COSTO se basó en McConnell et al. (2003).

Para el enfoque institucional las acciones e instituciones del gobierno pueden influir en las variaciones de los niveles de informalidad. Por ello, se involucra en el análisis la eficiencia en recaudación(EFICIENCIA), que mide la proporción de ingresos por impuestos que se gastan en remuneraciones al personal de la Secretaría de Administración y Finanzas y se calcula con base en IMCO (2012).

La relación entre EFICIENCIA e informalidad puede ser positiva o negativa. Es positiva cuando los individuos permanecen en la formalidad dado que perciben que sus contribuciones tributarias mejoran la calidad de las instituciones y obtienen beneficio directo. Es negativa si el individuo considera que esa eficiencia lo perjudica, incrementado el costo de permanecer formal, lo que puede conducirlo a la informalidad.

Un factor adicional es el Seguro Popular (SP), que intenta capturar la decisión voluntaria del individuo por pertenecer a la informalidad. Santana (2011) determina que el bajo costo del SP ocasiona que algunos individuos prefieran permanecer en la informalidad en lugar de afiliarse a un esquema como el del Instituto Mexicano del Seguro Social (IMSS).

En Levy (2008) se refuerza la idea de que los programas de protección social (como el SP) inducen a los trabajadores a tomar un empleo informal. La relación esperada entre SP y la informalidad es positiva, y se calcula como la proporción de la población total que se encuentra afiliada al seguro popular. Si cada vez es mayor el número de individuos que pueden acceder al SP, entonces estos decidirán optar por la informalidad, incrementándose los niveles de esta en el país.

Finalmente, los modelos estimados para la informalidad independiente y dependiente respectivamente son: 


$$
\begin{aligned}
& \text { TILI }_{t i}=\alpha_{i}+\beta_{1} \text { PIB }_{t i}+\beta_{2} \text { EDU }_{t i}+\beta_{3} \text { TSM }_{t i}+ \\
& +\delta_{1} \text { COSTO }_{t i}+\delta_{2} \text { EFICIENCIA }_{t i}+\delta_{3} S_{t i}+u_{t i} \\
& \text { TILI }_{t i}=\alpha_{i}+\beta_{1} \text { PIB }_{t i}+\beta_{2} \text { EDU }_{t i}+\beta_{3} \text { TSM }_{t i}+ \\
& +\delta_{1} \operatorname{COSTO}_{t i}+\delta_{2} \text { EFICIENCIA }_{t i}+\delta_{3} \text { SP }_{t i}+u_{t i}
\end{aligned}
$$

\subsection{RESULTADOS}

La Tabla 1 contiene las elasticidades significativas para el modelo [1]. Cuando se considera la informalidad independiente, sólo dos variables son significativas en su explicación, una corresponde a la teoría dual y otra a la institucional. Esto permite confirmar que los factores de ambos enfoques teóricos influyen en la explicación de esta parte de la informalidad total.

Tabla 1. Modelo [1]: Tasa de Informalidad Laboral Independiente (TILI).

\begin{tabular}{|c|c|c|c|}
\hline \multicolumn{2}{|c|}{ Teoría Dual } & \multicolumn{2}{c|}{ Teoría Institucional } \\
\hline Factor & Elasticidad & Factor & Elasticidad \\
\hline TSM & -0.1345 & EFICIENCIA & -0.0057 \\
\hline
\end{tabular}

Fuente: elaboración propia con base en resultado de estimación.

Se encuentra evidencia que la TILI exhibe una disminución de $0.13 \%$ cuando el factor TSM se incrementa en $1 \%$ en promedio. La informalidad dependiente e independiente se ven afectadas por la dinámica del sector moderno en una magnitud similar. Conforme mayor es la capacidad de absorción de mano de obra formal en el sector moderno, menor es la tasa de informalidad.

Otro resultado es que un incremento de $1 \%$ en promedio en EFICIENCIA, produce un decremento de $0.005 \%$ en la TILI y viceversa. Al incrementarse EFICIENCIA, la informalidad se incrementa como resultado de la búsqueda de los individuos por pagar menos impuestos o evadir los costos de la formalidad. 
En la Tabla 2 se encuentran las elasticidades significativas para TILD. En general, los signos son los esperados y destaca que un mayor número de factores macroeconómicos explican este tipo de informalidad. Desde la perspectiva dual, si el PIB se incrementa en 1\% en promedio la TILD disminuye en $0.04 \%$. Asimismo, un aumento de EDU en 1\% en promedio genera una disminución de la TILD de $0.40 \%$. Este valor es superior al resto de elasticidades e indica que el mayor nivel de educación de los individuos contribuye en gran medida a la disminución de la informalidad dependiente. Por último, el incremento en 1\% en promedio del TSM ocasiona una disminución de $0.13 \%$ de la TILD.

Tabla 2. Modelo [2]: Tasa de Informalidad Laboral Dependiente (TILD).

\begin{tabular}{|c|c|c|c|}
\hline \multicolumn{2}{|c|}{ Teoría Dual } & \multicolumn{2}{c|}{ Teoría Institucional } \\
\hline Factor & Elasticidad & Factor & Elasticidad \\
\hline PIB & -0.0448 & COSTO & 0.0186 \\
\hline EDU & -0.4064 & SP & 0.0476 \\
\hline TSM & -0.1310 & & \\
\hline
\end{tabular}

Fuente: elaboración propia con base en resultado de estimación.

Con relación al enfoque institucional, el primer factor es COSTO cuyo aumento en 1\% en promedio tiene un impacto de $0.01 \%$ en la TILD. Se puede decir que el costo que representan los trabajadores para los empleadores si es un factor que ejerce influencia sobre el número de individuos a contratar como formales; si este costo se incrementa entonces la informalidad responde en el mismo sentido y viceversa.

Por último, SP es un factor cuyo incremento en 1\% en promedio, provoca un aumento de $0.04 \%$ en la TILD, y de forma contraria. Las variaciones en este factor ejercen influencia sobre la informalidad dependiente y puede deberse a que los individuos aceptan un empleo informal en el que saben que la atención médica no será otorgada por el empleador pero que tienen la alternativa de acceder a ella a través del Seguro Popular. 


\section{CONCLUSIONES}

El presente artículo analizó desde una óptica macroeconómica la informalidad laboral en México durante el periodo 2005-2014 de acuerdo a su clasificación en independiente (TILI) y dependiente (TILD), considerando la teoría dual y la institucional planteando un modelo que permite incluirlas, conformando una estructura de datos de panel para 24 de las 32 entidades federativas de México. El modelo fue estimado mediante efectos fijos, robusto a problemas de autocorrelación y heterocedasticidad y descartando problemas de endogeneidad.

Los resultados son acordes a lo esperado, tanto la informalidad independiente como la dependiente responden a las variaciones de factores de carácter dual e institucional, sin embargo, el mayor efecto se observa en los factores de la teoría dual. Específicamente destaca la influencia de TSM sobre la TILI y de EDU sobre la TILD. En términos del valor de las elasticidades, es mayor el de la EDU 0.40 comparado con 0.13 asociada al sector moderno. A partir de estos resultados es posible argumentar que para disminuir la informalidad en el país se deben tomar acciones gubernamentales que mejoren los indicadores macroeconómicos vinculados con la estructura dual del mercado de trabajo, fomentando principalmente la educación de la población. Otra acción es promover el dinamismo del sector moderno de la economía ya que ello permitirá que la absorción de mano de obra se incremente y mejoren las condiciones de bienestar social de la población. Es importante tener en cuenta que el factor TSM es el único que, de acuerdo a las estimaciones, incide significativamente en ambos tipos de informalidad estudiado. Por lo tanto, lograr influir positivamente en este provocará que tienda a reducirse todo tipo de informalidad en el país.

El PIB es un factor estadísticamente significativo, pero únicamente para la informalidad dependiente, lo que sugiere que una situación económica difícil incidirá en un incremento de la informalidad, debido a un efecto contractivo en el mercado laboral expresado en una mayor tasa de desempleo. En este sentido, se debe dimensionar que una estrategia de reducción de la informalidad necesariamente conlleva un conjunto de acciones orientadas a fomentar las actividades productivas. 
Otro aspecto relevante es que las variaciones de la informalidad dependiente también se explican por factores institucionales como COSTO y SP. En cambio, la informalidad independiente solo por EFICIENCIA. En términos generales se puede argumentar que cualquier esfuerzo por reducir la informalidad implica desde un enfoque institucional, atender los tres factores.

Con relación a la variable COSTO, aumentos en los costos laborales provocan que la informalidad exhiba un crecimiento. Por su parte, SP sugiere que, a mayor cantidad de individuos con acceso a Seguro Popular, mayores serán los niveles de informalidad dependiente observados en el país. Sin embargo, es importante puntualizar que un resultado en esta dirección no debe ser interpretado como un argumento para sostener que el Seguro Popular es un programa social del que debe prescindir la política social. Sus beneficios han sido importantes y además es un programa congruente con las necesidades sociales de quienes están más desprotegidos. Sin embargo, se considera que debería estar diseñado en eliminar posibles inhibidores de los procesos de formalización laboral.

Finalmente, en lo que concierne a la variable de eficiencia en recaudación EFICIENCIA, la mayor eficiencia del gobierno en términos de recaudación se interpone con el objetivo de los individuos por evadir obligaciones formales o en la disminución de sus costos, por lo cual optarán por la informalidad que supone un menor costo. Es decir, para los individuos no existe un incentivo a permanecer formal cuando el gobierno se vuelve más eficiente al recaudar impuestos. Por lo cual la estrategia debería ser resaltar el beneficio de dicha recaudación y que los individuos lo vean reflejado directamente en mejoras de bienestar.

\section{REFERENCIAS BIBLIOGRÁFICAS}

Aguilera, N., y Velázquez, G. (2005). Los efectos de la informalidad. Seguridad Social, (254), 1-7. https://doctrina.vlex.com.mx/vid/efectos-informalidad-329473003 
Busso, M., Fazio, M., y Levy, S. (2012). (In) Formal and (Un) Productive: The Productivity Costs of Excessive Informality in Mexico. IDB Working Paper, 341. https://publications.iadb.org/en/ publication/11062/informal-and-unproductive-productivity-costs-excessive-informality-mexico

Davidson, R., y MacKinnon, J. G. (1993). Estimation and inference in econometrics. Oxford University Press.

Fields, G. S. (2004). Dualism in the labor market: A perspective on the Lewis Model After Half a Century. http://digitalcommons.ilr.cornell.edu/articles/268/

Fields, G. S. (2005). A Guide to Multisector Labor Market Models. Social Protection Discussion Paper Series, (0505), 1-50. http://siteresources.worldbank.org/SOCIALPROTEGTION/Resources/ SP-Discussion-papers/Labor-Market-DP/0505.pdf

Friedman, E., Johnson, S., Kaufmann, D., y Zoido-Lobaton, P. (2000). Dodging the grabbing hand: the determinants of unofficial activity in 69 countries. Fournal of Public Economics, 76(3), 459493. https://doi.org/10.1016/S0047-2727(99)00093-6

Hart, K. (1973). Informal Income Opportunities and Urban Employment in Ghana. The Fournal of Modern African Studies, 11(1), 61-89. https://doi.org/10.1017/S0022278X00008089

Jiménez, D. M. (2012). La informalidad laboral en América Latina: ¿Explicación estructuralista o institucionalista? Cuadernos de Economía, 31(58), 113-143. http://www.scielo.org.co/scielo. php? script=sci_abstract\&pid $=$ S0121-47722012000300006

Jiménez, M. (2013). La informalidad laboral en el sector formal de la Argentina. Un análisis preliminar. Documentos de trabajo, (10), 1-65. https://ri.conicet.gov.ar/handle/11336/3135 
Leal, J. (2014). The informal sector in contemporary models of the aggregate economy. Banco de México Working Papers, (2014-24), 1-20. https://www.banxico.org.mx/publications-and-press/banco-demexico-working-papers/\%7BFA2915B9-8494-C969-A311-F58ACB175938\%7D.pdf

Leontaridi, M. (1998). Segmented Labour Markets: Theory and Evidence. Fournal of Economic Surveys, 12(1). https://doi.org/103-109. 10.1111/1467-6419.00048

Levy, S. (2008). Good Intentions, Bad Outcomes: Social Policy, Informality and Economic Growth in Mexico. Brookings Institution Press.

Loayza, N. (1997). The Economics of the Informal Sector. A Simple Model and Some Empirical Evidence from Latin America. Policy Research Working Paper, 1(1727), 1-60. https://ideas.repec. org/p/wbk/wbrwps/1727.html

Maloney, W., y Saavedra J. (2008). El sector informal: ¿Qué es, por qué nos importa y cómo lo medimos? En G. Perry, W. Maloney, O. Arias, P. Fajnzylber, A. Mason y J. Saavedra. (Ed). Informalidad: Escape y Exclusión (21-41). Banco mundial en coedición con Mayol Ediciones S.A.

McConnell, G., Brue, S., y Macpherson, D. (2003). Economía Laboral. McGraw-Hill.

Moreno, J. (2007). Los salarios del sector formal e informal en México: análisis de ganancias y pérdidas por formalización. Ensayos, 26(1),1-44. https://www.researchgate.net/publication/227430742 Los_salarios_del_sector_formal_e_informal_en_Mexico_analisis_de_ganancias_y_perdidas_ por_formalizacion

Negrete, R., y Eternod, M. (2011). Informalidad y Género. En XII Encuentro Internacional de Estadísticas de Género: empoderamiento, autonomía económica y políticas públicas. Instituto Nacional de Estadística y Geografia (INEGI). 
Organización Internacional del Trabajo (OIT). (2012). Guía de recursos sobre economía informal. http://ilo.org/public/spanish/support/lib/resource/subject/informal.htm

Organización para la Cooperación y el Desarrollo Económicos (OGDE). (2004). Perspectivas del Empleo de la OCDE. Publicaciones de la OCDE.

Packard, T. (2007). Do Workers in Chile Choose Informal Employment? A Dynamic Analysis of Sector Choice. Policy Research Working Paper, (4232), 1-56. https://www.academia.edu/28941129/ Do_workers_in_Chile_choose_informal_employment_A_dynamic_analysis_of_sector_choice

Santana, A. (Goord.). (2011). El Seguro Popular de Salud en México: Posibles efectos sobre la economía informal. Avance-Análisis, Investigación y Estudios para el Desarrollo A.C. https://ethos.org.mx/wpcontent/uploads/2016/04/El-Seguro-Popular-de-Salud-en-Mexico.pdf

Singh, A., Jain-Ghandra, S., y Mohommad, A. (2012). Inclusive Growth, Institutions, and the Underground Economy. IMF Working Paper, (WP/12/47), 1-13.

Tannuri-Pianto, M., y Pianto, D. M. (2002). Informal Employment in Brazil- A Choice at the Top and Segmentation at the Bottom: A Quantile Regression Approach. En XXIV Brazilian Econometrics Meeting, Rio de Janeiro, Brasil. http://citeseerx.ist.psu.edu/viewdoc/ download?doi=10.1.1.454.4705\&rep=repl\&type=pdf

Uribe, J. I., y Ortiz, C. H. (2004). Una propuesta de conceptualización y medición del sector informal. Documentos de trabajo, Universidad del Valle, Departamento de Economía, Centro de Investigaciones y Documentación Socioeconómica. http://bibliotecavirtual.clacso.org.ar/ar/libros/colombia/ cidse/doc76.pdf 


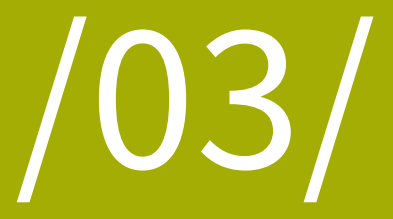




\section{EDAD Y ANTIGÜEDAD LABORAL DE LOS PROFESIONALES DE ENFERMERÍA COMO ANTECEDENTES DEL COMPROMISO AFECTIVO EN LOS HOSPITALES PRIVADOS DE JALISCO, MÉXICO}

AGE AND WORKING SENIORITY OF NURSING PROFESSIONALS AS BACKGROUND TO THE AFFECTIVE COMMITMENT IN THE PRIVATE HOSPITALS IN JALISCO, MEXICO

José Alejandro Jaime Vargas Posgrado en Negocios.

Universidad Autónoma de Guadalajara. Zapopan, Jalisco, (México). E-mail: jose.jaime@edu.uag.mx ORCID: https://orcid.org/0000-0002-4821-1136

Recepción: 26/09/2019 Aceptación: 06/11/2019 Publicación: 24/11/2020

Citación sugerida:

Jaime, J. A. (2020). Edad y antigüedad laboral de los profesionales de enfermería como antecedentes del compromiso afectivo en los hospitales privados de Jalisco, México. 3C Empresa. Investigación y pensamiento crítico, 9(4), 53-71. https:// doi.org/10.17993/3cemp.2020.090444.53-71 


\section{RESUMEN}

El Compromiso organizacional es uno de los constructos de estudio tanto de las ciencias sociales como económico administrativas, iniciando por los autores Meyer y Allen (1991), quienes consideraron que es importante conocer el sentir de las personas hacia su empresa propusieros tres dimensiones a investigar el compromiso afectivo, el normativo y de continuidad.

Para la realización de este trabajo se utilizó una muestra de 149 profesionales de la salud de Guadalajara y Zapopan, (Jalisco) para determinar los factores sociodemográficos de los participantes. Se utilizó el modelo del Compromiso Organizacional propuesto por Meyer y Allen (1991) y para los propósitos de este estudio se utilizó solamente la dimensión del compromiso afectivo, que tiene 6 ítems, con el objetivo de determinar si la edad y antigüedad laboral son determinantes o antecedentes de la permanencia en el trabajo.

Los resultados obtenidos muestran que la edad y la antigüedad laboral influyen en el compromiso afectivo de los profesionales de la salud, los resultados coinciden con los autores Dorien y Cols (2010) y Ng y Fieldman (2011) citados por Böhrt, Solares y Romero (2014), concuerdan que el compromiso afectivo es más bajo en empleados de mayor edad y de antigüedad laboral y es más débil o va disminuyendo a medida que aumentaban los años de antigüedad laboral, los resultados obtenidos en este estudio coinciden con los autores mencionados y se concluye que de los 149 profesionales de enfermería de Guadalajara y Zapopan, (Jalisco) a mayor edad y antigüedad laboral del profesional de enfermería en los hospitales privados de estudio de Guadalajara y Zapopan disminuye el compromiso afectivo. Otra de las conclusiones es que los profesionales de enfermería no serían felices en pasar el resto de su vida en la misma empresa.

\section{PALABRAS CLAVE}

Compromiso afectivo, Edad, Antigüedad laboral, Profesionales de la salud, Permanencia. 


\section{ABSTRACT}

Organizational commitment is one of the study constructs of both the social and administrative economic sciences, beginning with the authors Meyer and Allen (1991), who considered that it is important to know the feelings of people towards their company, proposing three dimensions to investigate the affective, normative and continuity commitment.

To carry out this work, a sample of 149 health professionals from Guadalajara and Zapopan, (Jalisco) was used to determine the sociodemographic factors of the participants. The Organizational Commitment model proposed by Meyer and Allen (1991) was used and for the purposes of this study only the affective commitment dimension, which has 6 items, was used in order to determine if age and work seniority are determining or not. history of permanence at work.

The results showed that age and work seniority influence the affective commitment of health professionals, the results coincide with the authors Dorien and Cols (2010) and Ng and Fieldman (2011) cited by Böhrt, Solares and Romero (2014), agree that affective commitment is lower in older and older employees and is weaker or decreases as the years of work seniority increased, the results obtained in this study coincide with the authors mentioned and it is concluded that of the 149 nursing professionals from Guadalajara and Zapopan, (falisco), the older and the older the nursing professional in the private study hospitals of Guadalajara and Zapopan decrease affective commitment. Another conclusion is that nursing professionals have not been happy to spend the rest of their lives in the same company.

\section{KEYWORDS}

Affective commitment, Age, Job tenure, Health professionals, Work permanence. 


\section{INTRODUCCIÓN}

La salud es uno de los derechos fundamentales para todo ser humano y es considerado un factor insustituible que influye en el bienestar social, el desarrollo, la economía y la educación de los pueblos, esto coincide con la Organización Mundial de la Salud (OMS) 2013 al considerar que son aspectos que obligan a las instituciones hospitalarias a ofrecer atención médica oportuna, aceptable, asequible y de calidad satisfactoria, así mismo, emitió la obligación que tienen las unidades médicas de asegurar una atención médica satisfactoria. La OMS plantea la necesidad por conocer aquellos factores organizacionales que originan las deficiencias existentes en las instituciones (públicas y privadas) de salud, por esa razón, es necesario tener información que permita a los hospitales atender las necesidades de su capital humano para disponer de programas de bienestar que busque elevar la satisfacción laboral y a su vez, el compromiso organizacional, y en consecuencia una mejor atención hospitalaria.

Un hospital es la célula fundamental de la prestación de los servicios de salud en cualquier sociedad y se comporta como una empresa productora de servicios hospitalarios, con una función de producción y una serie de entradas que son transformadas en el proceso, lo que da como resultado un producto hospitalario (Cortés-Martínez, 2010) y que tiene como objetivo responder a las necesidades y cuidados de la salud de los pacientes, atendiendo a las necesidades laborales de sus empleados y contribuir como empresa a la generación de resultados financieros. Dentro de los hospitales existen tienen diversos tipos de personal profesional como son doctores, especialistas, profesionales de la salud, administrativos, entre otros, Zurriaga et al. (2000) indican que los profesionales de organizaciones sanitarias han sido considerados como un grupo ocupacional que experimenta altos niveles de experiencias del trabajo de carácter negativo como ausentismo, abandono, estrés laboral, un estado de agotamiento físico, emocional o mental que puede tener consecuencias en la autoestima del empleado, esto puede ser causado por el entorno y ambiente laboral que incluye las actividades, puesto, responsabilidades, instalaciones, compañeros, supervisores, lo anterior puede incidir en las actitudes del empleado en su medio laboral. 
La generación de investigaciones relativas a variables como el clima organizacional, la satisfacción laboral, el compromiso organizacional, ha tenido gran importancia dentro de las organizaciones desde hace décadas, y del sector salud no ha sido la excepción, cada vez más, los hospitales públicos y privados a través de recursos humanos se han interesado en conocer la percepción de sus empleados sobre sus actividades, jefes, entorno y empresa para evaluar los resultados y tomar acciones orientadas a mejorar las áreas

Los primeros investigadores del compromiso organizativo (Becker, 1960; Kanter, 1968) citados por Iqbal (2008); identificaron que el compromiso es principalmente una función del comportamiento individual y la disposición de las personas para dar su energía a la organización a través de acciones y elecciones a lo largo del tiempo. Becker 1960; Kanter, 1968) citados por Iqbal (2008) 960; Kanter, 1968) citados por Iqbal (2008) 960; Kanter, 1968 citados por Iqbal (2008; 1960) describió el compromiso como la tendencia a participar en líneas de actividad consistentes como la intención de permanecer en la organización (Iqbal, 2008).

Al estudio del compromiso de los empleados se le unió el estudio de las organizaciones, de ahí se desprende las investigaciones sobre el compromiso organizacional, dos autores Meyer y Allen, entre otros autores, fueron los pioneros y realizaron estudios sobre el tema, para 1991 presentaron tres tipos de compromisos los cuales son el compromiso afectivo, compromiso el continuo y el compromiso normativo. Para este estudio se analiza solamente el compromiso afectivo porque este tipo de compromiso se ha asociado con resultados positivos como son una tasa de rotación más baja, absentismo, motivación, dedicación, etc. (Meyer y Allen, 1997), también se relaciona con la mejora de los aspectos operativos de la organización, como el aumento de los niveles de rendimiento, una mayor satisfacción laboral y una mayor participación (Khan y Zafar, 2013).

El compromiso afectivo tiene sus antecedentes en cuatro categorías: las características personales (edad, sexo, antigüedad laboral y educación) (Angle y Perry 1981; Glisson y Durick 1988, Morris y Sterers, 1977; Meyer y Allen, 1991) características estructurales (descentralización en la toma de decisiones, 
relación empleado/supervisor, claridad en los roles) Brooke, Russell y Price, 1988; Morris y Steers, 1980) citados por Meyer y Allen (1991) mencionan que las características relacionadas con el puesto y las experiencias (por experiencias se divide en dos categorías: aquellas que satisfacen las necesidades de los empleadores para sentirse cómodos en la organización, tanto físicas como psicológicas y aquellas que contribuyen a los sentimientos del empleado en su competencia en su rol en el trabajo) (Meyer y Allen, 1991).

\section{DESARROLLO}

\subsection{PLANTEAMIENTO DEL PROBLEMA}

El planteamiento del problema en este estudio consiste en examinar si la edad y la antigüedad laboral tienen una relación positiva con el compromiso afectivo, siendo ésta una variable del compromiso organizacional.

\subsection{OBJETIVO}

Determinar la relación entre la edad y la antigüedad laboral antecedentes o predecesores del compromiso afectivo así como su intención de permanencia en los hospitales privados de tercer nivel de atención en la ciudad de Guadalajara y Zapopan, Jalisco (México).

\subsection{HIPÓTESIS}

$\mathrm{H}_{1}$ : A mayor antigüedad laboral menor es el compromiso afectivo de los profesionales de enfermería. $\mathrm{H}_{2}$ : A mayor edad de los profesionales de enfermería menor es el compromiso afectivo

\subsection{PROBLEMA GENERAL}

¿ A mayor antigüedad laboral menor es el compromiso afectivo de los profesionales de enfermería? ¿A mayor edad de los profesionales de enfermería menor es el compromiso afectivo? 


\subsection{REVISIÓN DE LA LITERATURA}

En la revisión de la literatura existen estudios por Satarr y Jan (2015) citado por Böhrt, Solares y Romero (2014), quienes demuestran que hay una asociación considerable entre la satisfacción del trabajo, el compromiso organizacional y los atributos demográficos tales como género, edad, estado civil, experiencia, designación y calificación profesional de los empleados. Se han hecho estudios sobre la importancia de los factores sociodemográficos sobre el compromiso organizacional con resultados que señalan que la edad es una de las variables que más influyen en el compromiso afectivo tal como lo señala Baba y Jamal, estos autores en 1979 realizaron un estudio en Canadá con 377 empleados de diversas áreas de producción donde utilizaron seis variables entre ellas la edad, género, educación, estado civil, niños en casa e ingreso y en su conclusión determinaron que la edad era el único predictor demográfico del compromiso organizacional.

Por su parte Yucel y Erzincan en el año 2012 llevaron a cabo un estudio con maestros en varias escuelas de educación secundaria en Turquía analizando la satisfacción laboral y el compromiso organizacional, las variables de control estudiadas en este artículo son el género, la edad, el estado civil, el nivel educativo y la permanencia laboral, todas estas variables como antecedentes del compromiso organizativo y concluyeron que es especialmente la edad del empleado lo que afecta el compromiso organizativo y la satisfacción laboral. En su discusión postulan que los maestros más jóvenes, son más propensos a sentirse emocionalmente más apegados e identificados con los problemas de la organización como si fueran propios y expresaron el deseo de pasar el resto de su carrera en la organización mientras su satisfacción laboral sea alta o baja pero no moderada. Consideraron la edad en cinco categorías categorizando a los participantes por incrementos de 10 años (es decir, 21- 30, 31- 40, 41-50, 51- 60 y 61 y más).

Por su parte, Brimeyer, Perrucci y MacDermid, (2010), citados por Böhrt et al., (2014), analizaron la relación de las variables edad y antigüedad con el nivel de compromiso en una muestra de 400 empleados de una empresa manufacturera; los resultados mostraron que los trabajadores con mayor edad, sin importar su antigüedad en la organización, indicaban estar más comprometidos que los más 
jóvenes. Sin embargo, Dorien y cols. (2010) estudiaron la influencia de la edad en el desarrollo del compromiso de tipo Afectivo a partir de un meta-análisis de 83 estudios, revelando que el Compromiso Afectivo era más bajo en trabajadores con mayor edad, adicionalmente, establecieron que a mayor antigüedad en la organización, menor Compromiso Afectivo. Ng y Fieldman (2011) citados por Böhrt $e t$ al. (2014) analizaron esta misma relación y los resultados mostraron que a mayor antigüedad, más alto el compromiso; sin embargo el compromiso afectivo era más débil a medida que aumentaban los años de antigüedad (Böhrt et al., 2014).

También existen resultados opuestos entre las investigaciones para la edad y el vínculo de compromiso organizativo al mostrar que la edad tenía un vínculo significativamente positivo con el compromiso afectivo y normativo y una relación insignificante con el compromiso de continuación (Meyer y Allen, 1998) citado por Khan y Zafar. Se considera que los trabajadores de edad avanzada tengan un compromiso afectivo mayor debido a varias razones, incluyendo una mayor satisfacción con sus puestos de trabajo, mejores puestos, etc. La percepción del trabajo y la realización personal puede ser diferente para los empleados que se encuentran en diferentes grupos de edad. Los empleados en el rango de edad más joven pueden no desarrollar apego emocional a la organización en un corto período de tiempo y podrían mostrar menor disponibilidad para comprometerse con una organización por un mayor plazo (Khan y Zafar, 2013).

Investigaciones anteriores postulan que a medida que los trabajadores se quedan con una organización también es probable que aumente su nivel de compromiso (Mathieu y Zajac, 1990, citados Khan y Zafar, 2013). Por otro lado, Ng y Fieldman (2011) citados por Böhrt et al. (2014) mostraron también que a mayor antigüedad, más alto el compromiso; sin embargo el compromiso afectivo era más débil a medida que aumentaban los años de antigüedad en la organización (Böhrt et al., 2014). Un estudio hecho en Malasia realizado en empleados de "cuello blanco" encontró que el compromiso afectivo no estaba significativamente relacionado con la antigüedad laboral (Ahmad y Bakar, 2003) atribuyéndolo al incierto ambiente de negocios en el país. Otra investigación llevada a cabo por Nogueras (2006) citado 
por Khan y Zafar (2013) mostró un vínculo positivo entre los niveles de compromiso de las enfermeras a medida que aumentaba el número de años laborados en su organización (Khan y Zafar, 2013).

Por lo tanto, la edad y la antigüedad laboral fueron sugeridas por autores como Ritzer y Trice (1969), Alutto, Hrebiniak, y Alonso (1973), Meyer y Allen (1984) y Sheldon (1971) citados por Cohen (1993) como los mejores indicadores que generan la estabilidad laboral. Sin embargo, las conclusiones de la investigación han demostrado relaciones débiles entre el compromiso organizacional, la edad y la antigüedad laboral. Una explicación de estas débiles relaciones fue propuesta por Meyer y Allen (1984) argumentando que los empleados más jóvenes pueden estar más comprometidos debido a su conciencia de que, con menos experiencia trabajo, a menudo tienen menos oportunidades de trabajo (Cohen, 1993).

Los resultados demuestran que la edad y la antigüedad laboral influyen en el compromiso afectivo de los profesionales de la salud, los resultados coinciden con Dorien y Cols, (2010) al mencionar que el compromiso afectivo era más bajo en empleados de mayor edad, sin embargo, Ng y Fieldman (2011) citados por Böhrt et al. (2014) analizaron esta misma relación y los resultados mostraron que a mayor antigüedad, más alto el compromiso; sin embargo el compromiso afectivo era más débil a medida que aumentaban los años de antigüedad. De una población de 149 profesionales de la salud, 12 de ellos fueron quienes tenían más de 15 años trabajando en la misma organización, cuya edad estaba en el rango de 30 a 50 años.

\subsection{MARCO TEÓRICO}

Para los investigadores y personal de recursos humanos la importancia del compromiso organizacional se debe principalmente a que tiene un impacto directo en actitudes y conductas del empleado; como aceptación de metas, valores y cultura de la organización, menor ausentismo y baja rotación de personal. Por ello el compromiso organizacional es un concepto que ha crecido en importancia en la psicología organizacional, y se centra en estudiar los vínculos que se generan entre los empleados y la organización (Betanzos y Paz, 2007). 
Los primeros estudios sobre el compromiso organizacional data de los años sesentas y setentas del siglo pasado, autores como Porter, Steers, Mowda y Boulian dedicaron años en el estudio del compromiso, generando modelos teóricos e instrumentos que sentaron las bases de investigaciones posteriores. En los años ochenta surgen trabajos de autores como Allen y Meyer, en 1984 propusieron un modelo bidimensional para medir el compromiso organizacional en el que distinguían entre compromiso afectivo y de continuidad y en 1990 añadieron una tercera dimensión a su modelo a la que bautizaron como compromiso normativo (Gallardo, 2008).

El interés en un principio se orientó hacia resultados de la organización tales como el desempeño de los empleados, la eficacia, la satisfacción laboral, el absentismo entre otros. De las tres dimensiones, se considera para esta investigación analizar solamente el compromiso afectivo, este tipo de compromiso ocupa una posición vital, ya que capta el significado fundamental del compromiso, que es el apego emocional entre el empleado y la organización. El compromiso afectivo se define como "apego emocional del empleado a, identificación con y participación en la organización” (Meyer y Allen, 1991). en otras palabras, los empleados comprometidos afectivamente permanecen en el lugar de trabajo porque quieren (Kloutsiniotis y Mihail, 2017).

Estudios previos indicaron que en comparación con el compromiso de continuidad y el compromiso normativo, el compromiso afectivo se correlacionaba de una manera más significativa con los resultados del trabajo como el rendimiento, el absentismo (Meyer y Herscovitch, 2001). Mientras que otro estudio empírico demostró que el compromiso afectivo desempeñó un papel crucial, pero no completamente comprendido, tanto en la retención de empleados como en la promoción del bienestar del personal (Kloutsiniotis y Mihail, 2017).

\subsection{DISEÑO DEL ESTUDIO}

La presente investigación es exploratoria, el tipo de estudio es descriptivo. 


\subsubsection{METODOLOGÍA}

Se utilizó el instrumento del Copromiso Organizacional propuesto por Meyer y Allen (1991). El instrumento consta de 17 reactivos en total y solamente se utilizó para los propósitos de este estudio la dimensión compromiso afectivo que tiene 6 items.

1. Tengo una fuerte sensación de pertenecer a esta empresa;

2. Esta empresa tiene un gran significado para mí;

3. Me siento como parte de una familia en esta empresa;

4. Realmente siento como si los problemas de esta empresa fueran mis propios problemas;

5. Disfruto hablando de mi empresa con gente que no pertenece a ella;

6. Sería muy feliz pasando el resto de mi vida laboral en esta empresa.

Se utilizó una escala de Likert de 5 opciones (Muy en desacuerdo(1), Algo en desacuerdo (2), Ni de acuerdo ni en desacuerdo(3), Algo de acuerdo (5), Muy de acuerdo(6)).

La realización del análisis factorial y obtención de los resultados demográficos fue utiliando SPSS versión 23 para la obtención del KMO, prueba de Barlett y los resultados sociodemográficos de los participantes.

\subsection{UNIVERSO DE TRABAJO Y MUESTRA}

El universo de trabajo de la investigación fueron profesionales de enfermería de tres hospitales de Tercer Nivel de atención (espacialidades) ubicados en Guadalajara (Jalisco), y Zapopan (Jalisco).

Muestra: haciendo la limpieza de datos a través de SPSS con la técnica de Mahalanobis y de Alfa de Cronbach, de 170 instrumentos que se recibieron contestados en su totalidad, sólo 149 permanecieron para proceder a realizar el análisis, de los factores demográficos para este estudio se consideró la edad y años de antigüedad laboral del personal en las empresas. 
Se procedió a realizar la validación de criterio de las variables del estudio de la dimensión compromiso afectivo con la prueba de KMO y Barlett y los datos que se obtuvieron fueron:

Tabla 1. Prueba de KMO y Bartlett Compromiso Organizacional.

\begin{tabular}{|c|c|c|}
\hline \multicolumn{3}{|c|}{ Prueba de KMO y Bartlett emprendedurismo } \\
\hline Medida Kaiser-Meyer-Olkin de adecuación de muestreo & 866 \\
\hline \multirow{2}{*}{$\begin{array}{c}\text { Prueba de esfericidad de } \\
\text { Bartlett }\end{array}$} & Aprox. Chi-cuadrado & 322.54 \\
\hline & gl & 15 \\
\hline
\end{tabular}

Fuente: elaboración propia con resultados de SPSS.

\section{Distribución de puntuaciones del KMO y criterios de evaluación propuestos por Kaiser (1974). $1.00 \mathrm{KMO}>0.90$ Excelentes $\quad 0.90 \mathrm{KMO}>0.80$ Buenos $0.80 \mathrm{KMO}>0.70$ Aceptables $0.70 \mathrm{KMO}>0.60$ Mediocres $0.60 \mathrm{KMO}>0.50$ Malos $0.00 \mathrm{KMO} \leq 0.50$ Muy malos}

Fuente: (Frías-Navarro y Pascual, 2012).

En Tabla 1 se observa que se obtuvieron resultados del KMO 0.866, y de acuerdo a Frías-Navarro y Pascual (2012) es un valor bueno, así como la prueba de Barlett de 0.000 este valor es aceptable.

Tabla 2. Varianza Total Explicada.

\begin{tabular}{|c|c|c|c|}
\hline Componente & \multicolumn{3}{|c|}{ Autovalores iniciales } \\
\hline $\mathbf{1}$ & Total & \% de varianza & \% acumulado \\
\hline $\mathbf{2}$ & 3.427 & 57.120 & 57.120 \\
\hline $\mathbf{3}$ & 0.679 & 11.319 & 68.439 \\
\hline $\mathbf{4}$ & 0.612 & 10.193 & 78.631 \\
\hline $\mathbf{5}$ & 0.506 & 8.429 & 87.061 \\
\hline $\mathbf{6}$ & 0.399 & 6.653 & 93.714 \\
\hline
\end{tabular}

Fuente: elaboración propia con resultados de SPSS .

De acuerdo a la Tabla 2, la varianza total explicada indica que una sola pregunta responde el 57.12\% de toda la dimensión. 
Tabla 3. Tiempo en la empresa por Edad.

\begin{tabular}{|c|c|c|c|c|c|c|}
\hline \multicolumn{7}{|c|}{ Edad } \\
\hline \multicolumn{3}{|c|}{ Tiempo en la empresa } & Frecuencia & Porcentaje & $\begin{array}{c}\text { Porcentaje } \\
\text { válido }\end{array}$ & Porcentaje \\
\hline \multirow{4}{*}{$\begin{array}{c}\text { Menos de } 5 \\
\text { años }\end{array}$} & \multirow{4}{*}{ Válido } & $\begin{array}{c}\text { Menos de } 30 \\
\text { años }\end{array}$ & 74 & 76.3 & 76.3 & 76.3 \\
\hline & & $\begin{array}{c}\text { De } 30 \text { a } 50 \\
\text { años }\end{array}$ & 22 & 22.7 & 22.7 & 99.0 \\
\hline & & $\begin{array}{l}\text { Más de } 50 \\
\text { años }\end{array}$ & 1 & 1.0 & 1.0 & 100.0 \\
\hline & & Total & 97 & 100.0 & 100.0 & \\
\hline \multirow{4}{*}{ De 5 a 15 años } & \multirow{4}{*}{ Válido } & $\begin{array}{c}\text { Menos de } 30 \\
\text { años }\end{array}$ & 4 & 10.0 & 10.0 & 10.0 \\
\hline & & $\begin{array}{c}\text { De } 30 \text { a } 50 \\
\text { años }\end{array}$ & 34 & 85.0 & 85.0 & 95.0 \\
\hline & & $\begin{array}{c}\text { Más de } 50 \\
\text { años }\end{array}$ & 2 & 5.0 & 5.0 & 100.0 \\
\hline & & Total & 40 & 100.0 & 100.0 & \\
\hline $\begin{array}{l}\text { Más de } 15 \\
\text { años }\end{array}$ & Válido & $\begin{array}{c}\text { De } 30 \text { a } 50 \\
\text { años }\end{array}$ & 12 & 100.0 & 100.0 & 100.0 \\
\hline
\end{tabular}

Fuente: elaboración propia con resultados de SPSS.

\section{RESULTADOS}

La Tabla 3 muestra que las personas que tienen menos de 5 años trabajando en la empresa tienen menos de 30 años de edad (lo que representa el 76.3\% de las 97 que están en este rango), pero en el rango de antigüedad laboral de 5 a 15 años, este mismo grupo disminuye drásticamente a 4 trabajadores (lo que representa el 10\%). Por otro lado, este mismo grupo tiene el mayor porcentaje de trabajadores por antigüedad laboral en el rango de 30 a 50 años con 34 trabajadores (lo que representa el el 85\% de las 40 trabajadores), lo que signnifica que en este rango la estabilidad laboral es más relevante porque hay más permanencia. 
El contraste significativo lo prepresenta los profesionales de la salud que tienen más de 15 años de antigüedad laboral porque sólo 12 trabajadores en total. Por lo tanto, se confirma la Hipótesis $\left(\mathbf{H}_{1}\right)$ "a mayor es la antigüedad laboral menor es el compromiso afectivo" y "a mayor es la edad de los profesionales de enfermería menor es el compromiso afectivo" lo que confirma la Hipótesis $\left(\mathrm{H}_{2}\right)$.

Tabla 4. Resultados por edad.

\begin{tabular}{|c|c|}
\hline \multicolumn{2}{|c|}{ Edad=Menos de 30} \\
Matriz de componente a,b \\
\hline $\begin{array}{c}\text { 2. Esta empresa tiene un gran significado } \\
\text { personal para mí }\end{array}$ & $\mathbf{1}$ \\
\hline $\begin{array}{c}\text { 4. Realmente siento como si los problemas } \\
\text { de esta empresa fueran mis propios } \\
\text { problemas }\end{array}$ & 0.777 \\
\hline $\begin{array}{c}\text { 3. Me siento como parte de una familia en } \\
\text { esta empresa }\end{array}$ & 0.769 \\
\hline $\begin{array}{c}\text { 5. Disfruto hablando de mi empresa con } \\
\text { gente que no pertenece a ella }\end{array}$ & 0.736 \\
\hline $\begin{array}{c}\text { 1. Tengo una fuerte sensación de } \\
\text { pertenecer a mi empresa }\end{array}$ & 0.679 \\
\hline $\begin{array}{c}\text { 6. Sería muy feliz pasando el resto de mi } \\
\text { vida laboral en esta empresa }\end{array}$ & 0.678 \\
\hline $\begin{array}{c}\text { Método de extracción: análisis de componentes principales } \\
\text { a. Edad=Menos de } 30 \text { años } \\
\text { b. 1 componente extraído }\end{array}$ \\
\hline Fuente: elaboracion ropia con resultados de SPSS.
\end{tabular}

\begin{tabular}{|c|c|}
\hline \multicolumn{2}{|l|}{ Edad= De 30 a 50 años } \\
\hline \multicolumn{2}{|l|}{ Matriz de componente $a, b$} \\
\hline & Componente \\
\hline & 1 \\
\hline $\begin{array}{l}\text { 1. Tengo una fuerte sensación de } \\
\text { pertenecer a mi empresa }\end{array}$ & 0.867 \\
\hline $\begin{array}{l}\text { 2. Esta empresa tiene un gran significado } \\
\text { personal para mí }\end{array}$ & 0.825 \\
\hline $\begin{array}{l}\text { 3. Me siento como parte de una familia en } \\
\text { esta empresa }\end{array}$ & 0.776 \\
\hline $\begin{array}{l}\text { 5. Disfruto hablando de mi empresa con } \\
\text { gente que no pertenece a ella }\end{array}$ & 0.771 \\
\hline $\begin{array}{l}\text { 6. Sería muy feliz pasando el resto de mi } \\
\text { vida laboral en esta empresa }\end{array}$ & 0.738 \\
\hline $\begin{array}{l}\text { 4. Realmente siento como si los problemas } \\
\text { de esta empresa fueran mis propios } \\
\text { problemas }\end{array}$ & 0.650 \\
\hline \multicolumn{2}{|c|}{ Método de extracción: análisis de componentes principales } \\
\hline \multicolumn{2}{|l|}{ a. $E d a d=D e ~ 30$ a 50 años } \\
\hline b. 1 componente extraído & \\
\hline
\end{tabular}

Fuente: elaboración propia con resultados de SPSS.

El presente estudio pretende analizar también la intención de permanencia del empleado en su empresa, los resutados que muestra la Tabla 4 del ítem: "Sería muy feliz pasando el resto de mi vida laboral en esta empresa" en este estudio se refiere a la intención de permanencia del empleado en su empresa/ organización. De acuerdo a los resultados se observa que a más años que el empleado tenga trabajando en su empresa sería feliz pasar el resto de su vida laboral en la misma organización. Sumando los valores 
"De acuerdo" y "Totalmente de acuerdo" los datos son: Menos de 5 años de antigüedad el 29.8\% de los empleados dicen estar felices de permanecer en la empresa el resto de su vida laboral. Entre 5 y 15 años representan el 60\% y con más de 15 años de antigüedad con el 75\%. Este resultado coincide con el presentado por Contreras y Contreras (2018) quienes presentan que un 90.1\% de los colaboradores tienen la intención de permanecer en la institución.

En la edad aquellos que tienen menos de 30 años y con una edad que oscila entre los de 30 a 50 años el resultado que muestra la Tabla 4 presenta en los últimos lugares de las seis preguntas que el empleado sería feliz en pasar el resto de su vida en la empresa. Este resultado coincide con la hipótesis $\left(\mathrm{H}_{1)}\right.$ y la hipótesis $\left(\mathrm{H}_{2}\right)$.

$\mathrm{H}_{1}$ : A mayor antigüedad laboral menor es el compromiso afectivo de los profesionales de enfermería. $\mathrm{H}_{2}$ : A mayor edad de los profesionales de enfermería menor es el compromiso afectivo.

\section{CONCLUSIONES}

Los resultados obtenidos muestran que la edad y la antigüedad laboral influyen en el compromiso afectivo de los profesionales de la salud, los resultados coinciden con los autores Dorien y Cols (2010) y Ng y Fieldman (2011) citados por Böhrt et al. (2014) concuerdan que el compromiso afectivo es más bajo en empleados de mayor edad y de antigüedad laboral y es más débil o va disminuyendo a medida que aumentaban los años de antigüedad laboral, los resultados obtenidos en este estudio coinciden con los autores mencionados y se concluye que de los 149 profesionales de enfermería de Guadalajara y Zapopan, (Jalisco) a mayor edad y antigüedad laboral del profesional de enfermería en los hospitales privados de estudio de Guadalajara y Zapopan disminuye el compromiso afectivo. Otra de las conclusiones es que los profesionales de enfermería no serían felices en pasar el resto de su vida en la misma empresa.

Las limitaciones de este estudio es que se basó solamente en los profesionales de enfermería en los municipios de Guadalajara y Zapopan, (Jalisco), con dos variables edad y antigüedad laboral con el 
compromiso afectivo, en una población de 149 empleados de hospitales privados. La recomendación es el estudio del compromiso normativo y de continuidad con factores de permanencia en los hospitales privados de Zapopan y Guadalajara, Jalisco (México) y se utilicen otras variables sociodemográficas.

\section{REFERENCIAS BIBLIOGRÁFICAS}

Baba, V. V., y Jamal, M. (1979). On Becker's Theory of Commitment: An Empirical Verification Among Blue-Collar Workers. Relations industrielles / Industrial Relations, 34(1), 123-139. https:// www.riir.ulaval.ca/sites/riir.ulaval.ca/files/1979_34-1_7.pdf

Betanzos, N., y Paz, F. (2007). Análisis psicométrico del compromiso organizacional como variable actitudinal. Anales de psicología, 23(2), 207-215. https://www.redalyc.org/pdf/167/16723205.pdf

Böhrt, R., Solares, L., y Romero, G. (2014). Evolución del contrato psicológico y el compromiso organizacional con la edady la antigüedad. Ajayu. Órgano de Difusión Científica del Departamento de Psicología de la Universidad Católica Boliviana “San Pablo". https: / / www.redalyc.org/pdf/4615/461545457001. pdf

Cohen, A. (1993). Age and Fob tenure in Relation to Organizational Commitment: A Meta-Analysis. Department of Political Science, University of Haifa.

Contreras, I. A., y Contreras, F. A. (2018). Compromiso organizacional y la intención de permanencia de los profesionales de enfermería en una institución de salud privada, Lima. Revista Científica De Ciencias De La Salud, 11(2). https://doi.org/10.17162/rccs.v1 1i2.1104

Frías-Navarro, D., y Pascual, M. (2012). Prácticas del análisis factorial exploratorio (AFE) en la investigación sobre conducta del consumidor. Suma Psicológica, 19(1), 47-58. https://www. uv.es/ friasnav/FriasNavarroMarcopsSoler.pdf 
Gallardo, E. (2008). Evolución en el estudio y medida del compromiso organizativo. Problemáticas y soluciones (Tesis Doctoral). Universidad de Barcelona (España). https://dialnet.unirioja.es/servlet/ articulo? codigo $=2734826$

González, V., López, J. R., Espejo, B., Zornoza, A., y Zurriaga, R. (2000). Efecto de las características del puesto de trabajo sobre la satisfacción, el compromiso y el absentismo en organizaciones sanitarias. Revista de Psicología Aplicada, 10(3). https://dialnet.unirioja.es/servlet/ articulo? codigo $=159342$

Iqbal, A. (2008). Organizational climate and employees' commitment: a study of the pakistani knitwear industry. Prince Sultan University.

Kaiser, H. F. (1974). An index of factorial simplicity. Psychometrika, 39, 31-36. https://doi.org/10.1007/ BF02291575

Khan, F., y Zafar, S. (2013). An Empirical Study of Affective Commitment across. Demographic groups in the Banking Sector of Pakistan. Pakistan Fournal of Commerce and Social Sciences, 7(3), 555563. http://www.jespk.net/publications/145.pdf

Kloutsiniotis, P. V., y Mihail, D. M. (2017). Linking innovative human resource practices, employee attitudes and intention to leave in healthcare services. Employee Relations, 39(1), 34-53. https://doi. org/10.1108/ER-11-2015-0205

Meyer, J. P., y Allen, N. J. (1984). Testing the 'side-bet theory' of organizational commitment: some methodological considerations. Fournal of Applied Psychology, 69(3), 372-378. https://doi. org/10.1037/0021-9010.69.3.372

Meyer,J. P., y Allen, N. J. (1991). A three component conceptualization of organizational commitment. Human Resource Management Review, 1, 61-98. https://doi.org/10.1016/1053-4822(91)90011-Z 


\section{Organización Mundial de la Salud (OMS). http://www.who.int/es}

Organización Panamericana de la Salud (OPS). https: / www.paho.org/es

Yucel, I., y Erzincan, G. (2012). Job satisfaction, organizational commitment and demographic characteristics among teachers in Turkey: Kounger is better? Procedia - Social and Behavioral Sciences, 46, 1598-1608. https://www.researchgate.net/publication/275541964_Job_Satisfaction_Organizational_ Commitment_and_Demographic_Characteristics_Among_Teachers_in_Turkey_Younger_is_ Better/fulltext/5551595008ae956a5d25f455/Job-Satisfaction-Organizational-Commitmentand-Demographic-Characteristics-Among-Teachers-in-Turkey-Younger-is-Better.pdf 


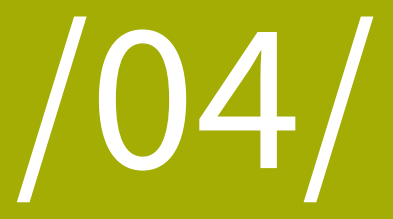




\section{AMBIGÜEDAD DE ROL EN ACADÉMICOS: UNA PROBLEMÁTICA ORGANIZACIONAL EN LAS UNIVERSIDADES ROLE AMBIGUITY IN ACADEMICS: AN ORGANIZATIONAL PROBLEMATIC IN UNIVERSITIES}

Edith Georgina Surdez Pérez

Doctora en Gestión Estratégica y Políticas de Desarrollo. Profesor, División Académica de Ciencias Económico Administrativas. Universidad Juárez Autónoma de Tabasco, (México). E-mail: edith.2109@hotmail.com ORCID: http://orcid.org/0000-0001-8731-9273

María del Carmen Sandoval Caraveo

Doctorado en Gestión Estratégica y Políticas de Desarrollo. Profesor, División Académica de Ciencias Económico Administrativas

Universidad Juárez Autónoma de Tabasco, (México). E-mail: sandovalcaraveo29@hotmail.com ORCID: http://orcid.org/0000-0002-5482-3032

Citación sugerida:

Surdez, E. G., y Sandoval, M. del C. (2020). Ambigüedad de rol en académicos: una problemática organizacional en las universidades. 3C Empresa. Investigación y pensamiento crítico, 9(4), 73-91. https://doi. org/10.17993/3cemp.2020.090444.73-91

Nota: Este artículo se puede leer traducido en inglés en:

https://doi.org/10.17993/3cemp.2020.090444.73-91.eng 


\section{RESUMEN}

El objetivo de este trabajo fue identificar la presencia de ambigüedad de rol en académicos, que dividen su tiempo laboral entre actividades docentes y de investigación, de cinco áreas del conocimiento de una universidad de México. El estudio fue cuantitativo de diseño no experimental transversal, descriptivo y correlacional. La confiabilidad del instrumento fue de 0.93 en el coeficiente Alpha de Cronbach. Los resultados señalan que el $80.3 \%$ de la muestra percibe ambigüedad de rol, con mayor intensidad en las demandas laborales y en las normas; el análisis de varianza ANOVA mostró diferencia significativa en la percepción de ambigüedad con las normas y las áreas del conocimiento. Se concluye que es necesario en las universidades poner atención cuidadosa en la precisión y claridad de la normatividad relacionada con el trabajo docente y de investigación, así como proporcionar suficiente información sobre lo que la institución espera del desempeño de una función.

\section{PALABRAS CLAVE}

Demandas Laborales, Normatividad, Universidad, Papel del Profesor, Expectativas de Desempeño, Docencia-Investigación. 


\section{ABSTRACT}

The objective of this study was to identify the presence of role ambiguity in academics, who divide their working hours between teaching and researching, of five areas of knowledge in a university in Mexico This is a study with a quantitative approach, a non-exploratory, transactional, descriptive, and correlational design. The reliability of the instrument used was of 0.93 in Cronbach's Alpha Coefficient. The results identified that $80.3 \%$ of the sample perceives role ambiguity more strongly on the dimensions of 'Gob demands' and 'Norms'. Subsequently, the analysis of variance (ANOVA) showed a significant difference in the perception of role ambiguity on the dimension of 'norms' and the areas of knowledge. Therefore, it is concluded that it is necessary for universities to draw attention to establishing precision and clarity on the normativity related to teaching and researching activities, as well as providing the adequate information regarding the institution's expectations on job performance.

\section{KEYWORDS}

Job Demands, Normativity, University, Teacher's Role, Performance expectations, Teaching-Researching. 


\section{INTRODUCCIÓN}

La ambigüedad de rol se produce por indefinición respecto al rol que debe desempeñar un individuo en una institución. Surge cuando los esfuerzos para adquirir claridad en el rol son frustrados, se presenta por lo general en las personas cuando se enfrentan a diversas demandas en el trabajo y no tienen los recursos y la información para atenderlas (Malone, 2002; Orgambídez-Ramos, Pérez-Moreno y BorregoAlés, 2015) afectando la satisfacción del individuo en su trabajo y obstaculizando el alcance de metas organizacionales. En este sentido, este estudio tiene como finalidad medir la existencia de ambigüedad de rol en profesores de una universidad, debido a que actualmente el papel del profesor se caracteriza por el desempeño de una multiplicidad de actividades y el cumplimiento de diversos lineamientos que rigen su trabajo. Por una parte, su rol como académico está siendo definido por los indicadores de diversos sistemas de evaluación con normatividad y requisitos heterogéneos derivados de la política pública en materia de educación superior enfocada a la calidad y la productividad. Por otra parte, el profesor debe cumplir con diversas comisiones que se le solicitan de forma interna en su universidad, entre las que se pueden mencionar, tutorías, asesorías disciplinares, reestructuración y elaboración de programas educativos, entre otras.

Específicamente en México se pueden mencionar el Programa para el Desarrollo Profesional Docente (PRODEP) que tiene por objeto "Profesionalizar a los/as profesores/as de tiempo completo para que alcancen las capacidades de investigación-docencia, desarrollo tecnológico e innovación y, con responsabilidad social, se articulen y consoliden en grupos académicos" (Secretaria de Educación Pública, 2016, párr. 1). Este programa demanda la realización en equilibrio de las actividades de docencia, investigación y gestión académica. Así también, el Sistema Nacional de Investigadores (SNI) regulado por el Consejo Nacional de Ciencia y Tecnología (CONACYT) que otorga reconocimiento público a "los científicos y tecnólogos que hayan sobresalido por la calidad de su producción y en la formación de nuevos investigadores, así como por su aportación al fortalecimiento de la investigación científica o tecnológica del país" (CONACYT, 2017, p. 113). Ser acreditado por estos organismos significa para los 
profesores reconocimiento académico y económico por lo que los profesores se esfuerzan por cumplir con estos requerimientos externos.

Derivado de lo anterior, se ameritan investigaciones empíricas para identificar si el profesorado de universidades está padeciendo de ambigüedad de rol, en qué aspectos se presenta y, además, acorde a su perfil sociodemográfico y académico en quienes se muestra con mayor evidencia, con el fin de inhibir factores y circunstancias que pudieran originarles este problema. La ambigüedad de rol se ha medido en diversas poblaciones: soldados profesionales, estudiantes de pregrado, empleados públicos, consejeros empresariales y personal administrativo empresarial (Bernhard, 1996; Díaz-Fúnez, Pecino y Mañas, 2016; Kirk-Brown y Wallace, 2004; Mansilla, 2011; Meliá, Zornoza, Sanz, Morte y González, 1987; Núñez y Fresatti, 2016; Osca, González-Camino, Bardera y Peiró, 2003; Rizzo, House, y Lirtzman, 1970). No obstante, son insuficientes los estudios sobre ambigüedad de rol en profesores universitarios, y éstos se han focalizado a una sola área del conocimiento: Salud (Gomley, 2005) Ciencias Sociales y Administrativas (Surdez, Magaña y Sandoval, 2017). Para contribuir con una perspectiva holística e identificar variabilidad en la percepción sobre el fenómeno estudiado, este trabajo aporta conclusiones derivadas de una investigación empírica que mide la ambigüedad de rol considerando cinco áreas del conocimiento.

\section{REVISIÓN DE LA LITERATURA}

La ambigüedad de rol se refiere a la falta de claridad sobre el papel que se está desempeñando, los objetivos del trabajo individual o el alcance de las responsabilidades (Slipak, 1996). Es la circunstancia de un individuo consistente en no tener adecuados referentes para hacer su trabajo, afectando la satisfacción y el desempeño laboral (De Arquer, Daza y Nogareda, 1995). También ha sido definido como la falta de información emitida con claridad sobre las expectativas de desempeño, las metas, los deberes, la autoridad, las responsabilidades, las obligaciones y otras condiciones laborales relacionadas 
con el desempeño de rol (González-Romá et al., 1995; Yun et al., 2007; citados por Díaz-Fúnez et al., 2016, p. 392).

En los años 50 es cuando se inician las investigaciones sobre la ambigüedad de rol pero es en los 60 cuando adquieren mayor relevancia. Posteriormente los estudios tienden hacia el análisis de los resultados negativos de la ambigüedad de rol tales como carencia de satisfacción en el trabajo, ausentismo, poca productividad e incluso el retiro definitivo del trabajo y altas tasas de rotación (Mansilla, 2011).

La ambigüedad se puede originar cuando al individuo no se le da suficiente y adecuada información sobre 1) las expectativas relevantes con respecto al desempeño de una función y su alcance en términos de derechos, deberes y responsabilidades; 2) las actividades cruciales para el cumplimiento de los deberes de una posición, así como los pasos o la mejor manera de lograr un trabajo; 3) las consecuencias de no cumplir con los deberes 4) compensaciones o castigos y la naturaleza de éstos, así como retroalimentación de comportamiento satisfactorio o insatisfactorio 5) oportunidades de ascenso (Fisher, citado en Nuñez y Frezatti, 2016).

La ambigüedad de rol ha sido considerada como una fuente de estrés laboral cuando se presenta un desajuste entre las demandas y los recursos y cuando se dan diversas transiciones en el desempeño de los roles (Peiró, 2001) y como "un factor psicosocial de riesgo en el lugar de trabajo con alta probabilidad de afectar la salud" (Soler, Fernández-Valera y Meseguer, 2016, p. 61). En este sentido, las demandas en el trabajo vienen a ser los aspectos físicos, psicológicos, sociales y organizacionales que son causales de estrés cuando los trabajadores realizan un esfuerzo importante para cumplir con el desempeño exigido (Soler et al., 2017).

Existen diversos estudios sobre la ambigüedad de rol. El instrumento para medir esta problemática más citado en la literatura fue utilizado para identificar conflicto y ambigüedad de rol en gerentes de empresas complejas y sus consecuencias (Rizzo et al., 1970). En el estudio los autores argumentan que la ambigüedad de rol es una variable que interviene de forma importante en las prácticas organizacionales. 
Los resultados reportaron que existe una clara correlación negativa entre ésta y la satisfacción laboral y que las prácticas organizacionales específicas que tienden a estar asociados con ambigüedad de rol son retraso en decisiones, distorsión y supresión de la información, y violación de la cadena de mando. Así mismo, que esta problemática disminuye cuando los superiores proveen estructura y estándares para el trabajo; se da énfasis en el desarrollo personal, adecuada comunicación horizontal, planeación, alta receptividad a las ideas y coordinación de flujo de trabajo.

En un estudio con profesores de enfermería se reportó que el personal que experimentaba ambigüedad de rol consideraba que sus relaciones de trabajo con el decano estaban obstaculizadas y que era más evidente en profesores jóvenes y sin experiencia (Gomley, 2005). A su vez, otros autores reportan que consecuencias disfuncionales asociadas a la ambigüedad de rol son: incremento de la tensión laboral y la disminución de la satisfacción laboral (Lloret, González y Peiró, 1995); otros resultados han señalado que la ambigüedad de rol es un predictor significante de desgaste emocional y se asocia negativamente con la satisfacción laboral intrínseca (Kirk-Brown y Wallace, 2004). Así mismo, en un estudio en el que participaron soldados profesionales encontraron que cuando disminuye la claridad de rol se dan síntomas de deterioro físico y aparecen conductas de búsqueda de ayuda (Osca et al., 2003).

Por otra parte, estudiosos del tema reportan que la ambigüedad sobre los objetivos y la política general de la organización generan los mayores efectos negativos sobre la satisfacción laboral (Meliá et al., 1987) y que la ambigüedad de rol produce estrés, depresión y disminuye la autoestima lo que deriva en deseos de abandonar el puesto de trabajo, en contraparte, la información y comunicación adecuadas disminuyen este tipo de conflictos (Slipak, 1996). Otros autores sugieren que el ambiente de comunicación es una consideración importante para controlar la ambigüedad de rol (Schulz y Auld, 2006). A su vez, en un estudio sobre estrés de rol en estudiantes universitarios, se encontró que la ambigüedad de rol fue el predictor más poderoso y consistente de los resultados psicológicos y académicos (Bernhard, 1996). Está relacionada con faltar a clases y conseguir notas bajas. 
En contraste con las anteriores investigaciones que reportan consecuencias negativas en el trabajo y en el individuo, se puede mencionar una investigación en la que participaron vendedores y el resultado reportó que, en un nivel moderado, los estresores de rol como la ambigüedad y el conflicto de rol pueden ser estimuladores para un mayor compromiso en la búsqueda de mejorar el desempeño (Onyemah, 2008).

\section{METODOLOGÍA}

Se utilizó un enfoque cuantitativo con un diseño no experimental transversal. Se seleccionaron de forma no probabilística 116 profesores-investigadores de una población de 220 integrantes de grupos de investigación de las áreas del conocimiento de Ciencias Agropecuarias, Ingeniería y Arquitectura, Informática y Sistemas, y Ciencias Básicas de una universidad del Sureste Mexicano. Los datos sociodemográficos de la muestra se presentan en la Tabla 1.

Tabla 1. Datos sociodemográficos de la muestra.

\begin{tabular}{|c|c|c|c|c|c|}
\hline Edad & Género & Estado civil & $\begin{array}{c}\text { Antigüedad en el } \\
\text { trabajo }\end{array}$ & SNI & PRODEP \\
\hline 33 a $43(39.7 \%)$ & Hombres (56\%) & Solteros $(20.7 \%)$ & $\begin{array}{c}1 \text { a } 10(21.6 \%) \\
11 \text { a } 20(43.1 \%)\end{array}$ & Si $(18.1 \%)$ & Si $(70.7 \%)$ \\
\hline 44 a $54(40.5 \%)$ & Mujeres $(44 \%)$ & Casados $(79.3 \%)$ & 21 a $30(35.3 \%)$ & No $(81.9 \%)$ & \\
\hline 55 a $65(19.8 \%)$ & & & & \\
\hline
\end{tabular}

Fuente: elaboración propia.

\subsection{INSTRUMENTO}

El instrumento de investigación es una traducción y adaptación del cuestionario de Rizzo et al. (1970) con adaptaciones en diversos proyectos de investigación (Magaña, Sánchez y Rosas, 2009; Magaña et al., 2009; Surdez, 2013) y el trabajo de Surdez, Magaña y Sandoval (2017). En la primera sección se incluyen variables sociodemográficas (edad, género, estado civil, antigüedad en el trabajo, acreditación al perfil PRODEP y vigencia en el SNI). La segunda sección del instrumento analiza la ambigüedad de rol en los profesores a través de 4 dimensiones (véase Tabla 2). 
Tabla 2. Especificaciones de las dimensiones de ambigüedad de rol.

\begin{tabular}{|c|l|}
\hline Dimensiones & Definición operacional \\
\hline $\begin{array}{c}\text { Ambigüedad con la autonomía } \\
\text { Ambigüedad con las demandas } \\
\text { laborales }\end{array}$ & $\begin{array}{l}\text { Ambigüedad en los niveles de independencia en las } \\
\text { decisiones relacionadas con el trabajo del puesto. }\end{array}$ \\
\hline Ambigüedad con la contribución & $\begin{array}{l}\text { Ambigüedad en las instrucciones, métodos y resultados de } \\
\text { trabajo asociados al rol. }\end{array}$ \\
\hline Ambigüedad con las normas & $\begin{array}{l}\text { Ambigüedad en la aportación del trabajo desempeñado } \\
\text { por el rol a los objetivos de la institución. }\end{array}$ \\
\hline & $\begin{array}{l}\text { Ambigüedad en los lineamientos institucionales asociados al } \\
\text { desempeño y evaluación del rol. }\end{array}$ \\
\hline
\end{tabular}

Fuente: elaboración propia.

El cuestionario tiene una escala tipo Likert de 5 puntos: totalmente en desacuerdo (1), en desacuerdo (2), ni de acuerdo ni en desacuerdo (3), de acuerdo (4) y totalmente de acuerdo (5). Consta de 16 frases para determinar si el profesor percibe que se están dando problemas de ambigüedad de rol. Por el sentido positivo de las frases la puntuación más baja denota mayor ambigüedad de rol. El instrumento fue validado en una investigación anterior con profesores universitarios, que obtuvo una confiabilidad de 0.92 de coeficiente Alfa de Cronbach y cargas factoriales arriba de 0.60 (Surdez, Magaña y Sandoval, 2017). Para confirmar la confiabilidad del instrumento con los profesores participantes en la investigación que aquí se presenta, se comprobó la coherencia interna de los ítems en cada dimensión del cuestionario empleando un análisis de Alfa de Cronbach. Los resultados de este análisis indican un grado de consistencia interna aceptable para cada una de las dimensiones del estudio: ambigüedad con la autonomía (0.78), ambigüedad con las demandas laborales (0.86), ambigüedad con la contribución (0.88) y ambigüedad con las normas (0.81). De manera general, la confiabilidad del instrumento reportó 0.93 que indica una alta consistencia interna (García, 2011).

\subsection{ANÁLISIS DE LOS DATOS}

Los datos se analizaron a través de estadística descriptiva para identificar niveles de ambigüedad de rol y determinar en qué dimensiones se percibía con mayor y menor intensidad esta variable. Con el 
propósito de determinar la existencia de diferencias estadísticamente significativas entre las dimensiones de las variables de ambigüedad de rol con relación al estado civil, el género, pertenencia al SNI y perfil PRODEP se utilizó la prueba t de Student. Posteriormente, para determinar diferencias entre la ambigüedad de rol con las áreas del conocimiento, la edad y la antigüedad en el trabajo de los docentes, se utilizó el análisis de varianza ANOVA con pruebas post hoc de Bonferroni, y para identificar la existencia de relaciones entre las dimensiones de la variable ambigüedad de rol con la edad y antigüedad en el trabajo se utilizó el análisis de correlación de Pearson.

\section{RESULTADOS}

La distribución de frecuencias mostró una distribución normal con un valor mínimo registrado de 1.38 y un valor máximo de 4.94, una curtosis de 0.605 , una asimetría de -0.864 , una media de 3.80 y una desviación estándar de 0.71. Para determinar la percepción de ambigüedad de rol en los profesores, las respuestas se clasificaron en cuatro grupos, en el primer grupo se encontraban los docentes que presentaron puntuaciones menores o iguales al percentil 25, en el segundo grupo se registraron los que estaban arriba del percentil 25 y abajo del 50, en el tercer grupo se registraron quienes estaban arriba del percentil 50 y menor al $75 \mathrm{y}$ al final los sujetos que estaban arriba del percentil 75 . El 27\% de la muestra presenta un nivel alto de ambigüedad de rol, el 26\% un nivel moderado, el 27.3\% un nivel bajo y un 19.7\% no registra ambigüedad; por tanto, el 80.3\% de la muestra percibe cierta ambigüedad de rol en las dimensiones analizadas (véase Tabla 3).

Tabla 3. Niveles de ambigüedad de rol, rango de valores (escala 1-5).

\begin{tabular}{|c|c|c|c|}
\hline Nivel de ambigüedad de rol & Percentil & Rango & $\%$ \\
\hline Alto & 25 & Valores $\leq 3.38$ & 27 \\
\hline Moderado & 50 & $3.39-3.94$ & 26 \\
\hline Bajo & 75 & $3.95-4.35$ & 27.3 \\
\hline Sin ambigüedad & 100 & Valores $\geq 4.36$ & 19.7 \\
\hline
\end{tabular}

Fuente: elaboración propia. 
Para determinar las dimensiones en que había mayor ambigüedad de rol se realizó un análisis estadístico descriptivo, encontrándose más ambigüedad en las demandas laborales y las normas, la menor ambigüedad fue en la autonomía (véase Tabla 4).

Tabla 4. Análisis descriptivo de las dimensiones de la variable ambigüedad de rol.

\begin{tabular}{|c|c|c|c|c|c|}
\hline Dimensiones & N & Mínimo & Máximo & Media & D.E. \\
\hline Ambigüedad con la autonomía & 116 & 1.75 & 5 & 4.14 & 0.73 \\
\hline Ambigüedad con las demandas laborales & 116 & 1 & 5 & 3.46 & 0.90 \\
\hline Ambigüedad con la contribución & 116 & 1 & 5 & 4.09 & 0.88 \\
\hline Ambigüedad con las normas & 116 & 1 & 5 & 3.55 & 0.85 \\
\hline N válido (por lista) & 116 & & & & \\
\hline
\end{tabular}

Fuente: elaboración propia.

Con el propósito de determinar la existencia de diferencias significativas entre las dimensiones de ambigüedad de rol con relación al estado civil, el género, pertenencia del profesor al SNI y al PRODEP se utilizó la prueba t de Student (véase Tablas 5 y 6).

Tabla 5. Diferencia de medias de las dimensiones de ambigüedad de rol con el estado civil.

\begin{tabular}{|c|c|c|c|c|c|c|}
\hline \multicolumn{1}{|c|}{ Dimensiones } & Estado civil & $\mathbf{N}$ & Media & D.E. & t & Sig. \\
\hline Ambigüedad con la autonomía & Soltero & 24 & 4.16 & 0.85 & 0.18 & 0.75 \\
\hline & Casado & 92 & 4.13 & 0.71 & \\
\hline Ambigüedad con las demandas & Soltero & 24 & 3.57 & 0.78 & 0.86 & 0.28 \\
\hline laborales & Casado & 92 & 3.42 & 0.93 & 0.86 \\
\hline Ambigüedad con la contribución & Soltero & 24 & 4.00 & 0.80 & -0.46 & 0.56 \\
\hline & Casado & 92 & 4.11 & 0.90 & \\
\hline Ambigüedad con las normas & Soltero & 24 & 3.52 & 0.59 & -0.10 & $0.02^{*}$ \\
\hline
\end{tabular}

Nota: ${ }^{*} p \leq 0.05$

Fuente: elaboración propia.

Como se puede observar en la Tabla 5, la prueba t señaló diferencias significativas en la percepción de ambigüedad de rol con relación al estado civil de los profesores en la dimensión de ambigüedad con las 
normas, siendo los solteros quienes perciben mayor ambigüedad de rol.

Tabla 6. Diferencia de medias de las dimensiones de ambigüedad de rol con el género.

\begin{tabular}{|c|c|c|c|c|c|c|}
\hline Dimensiones & Género & $\mathbf{N}$ & Media & D.E. & $\mathbf{t}$ & Sig \\
\hline \multirow{2}{*}{ Ambigüedad con la autonomía } & Hombre & 65 & 4.18 & 0.67 & \multirow{2}{*}{0.72} & \multirow{2}{*}{0.29} \\
\hline & Mujer & 51 & 4.08 & 0.81 & & \\
\hline \multirow{2}{*}{ Ambigüedad con las demandas laborales } & Hombre & 65 & 3.46 & 0.90 & \multirow{2}{*}{0.01} & \multirow{2}{*}{0.79} \\
\hline & Mujer & 51 & 3.46 & 0.90 & & \\
\hline \multirow{2}{*}{ Ambigüedad con la contribución } & Hombre & 65 & 4.07 & 0.84 & \multirow{2}{*}{-0.21} & \multirow{2}{*}{0.32} \\
\hline & Mujer & 51 & 4.11 & 0.93 & & \\
\hline \multirow{2}{*}{ Ambigüedad con las normas } & Hombre & 65 & 3.53 & 0.95 & \multirow{2}{*}{-0.40} & \multirow{2}{*}{$0.03^{*}$} \\
\hline & Mujer & 51 & 3.59 & 0.70 & & \\
\hline
\end{tabular}

Nota: ${ }^{*} \mathrm{p} \leq 0.05$

Fuente: elaboración propia.

En la Tabla 6 se observa que existe una diferencia estadísticamente significativa en la percepción de los profesores con relación al género en la dimensión de ambigüedad con las normas, el resultado indica que los hombres perciben mayor ambigüedad. La prueba t no indicó diferencias significativas entre la ambigüedad de rol con la pertenencia de los profesores al Sistema Nacional de Investigadores y la acreditación del Reconocimiento a Perfil Deseable PRODEP.

El análisis de varianza ANOVA señaló una diferencia significativa entre la percepción de ambigüedad con las normas y las áreas del conocimiento (véase Tabla 7), en este caso la prueba post hoc de Bonferroni indicó específicamente que la diferencia de medias se encuentra entre Ciencias Agropecuarias y Ciencias Básicas en la que los profesores de esta última perciben la mayor ambigüedad de rol. Por otra parte, no se encontraron diferencias en la percepción de la ambigüedad de rol de los profesores con la edad y la antigüedad en el trabajo. 
Tabla 7. Diferencia de medias de las dimensiones de ambigüedad de rol con las áreas del conocimiento.

\begin{tabular}{|c|c|c|c|c|c|c|c|c|}
\hline Dimensiones & Áreas del conocimiento & $\mathbf{N}$ & Media & D.E. & Mín. & Máx. & $\mathbf{F}$ & Sig. \\
\hline \multirow{6}{*}{$\begin{array}{c}\text { Ambigüedad con } \\
\text { la } \\
\text { autonomía }\end{array}$} & Ciencias Agropecuarias & 23 & 4.03 & 0.87 & 2 & 5 & \multirow{6}{*}{0.25} & \multirow{6}{*}{0.91} \\
\hline & Ingeniería y Arquitectura & 16 & 4.08 & 0.73 & 1.75 & 5 & & \\
\hline & Informática y Sistemas & 26 & 4.17 & 0.72 & 1.75 & 5 & & \\
\hline & Ciencias Biológicas & 28 & 4.22 & 0.69 & 2 & 5 & & \\
\hline & Ciencias Básicas & 23 & 4.15 & 0.68 & 2.25 & 5 & & \\
\hline & Total & 116 & 4.14 & 0.73 & 1.75 & 5 & & \\
\hline \multirow{6}{*}{$\begin{array}{l}\text { Ambigüedad con } \\
\text { las demandas } \\
\text { laborales }\end{array}$} & Ciencias Agropecuarias & 23 & 3.49 & 1.03 & 1.25 & 5 & \multirow{6}{*}{1.58} & \multirow{6}{*}{0.18} \\
\hline & Ingeniería y Arquitectura & 16 & 3.61 & 0.80 & 2 & 4.75 & & \\
\hline & Informática y Sistemas & 26 & 3.70 & 0.72 & 1.75 & 4.75 & & \\
\hline & Ciencias Biológicas & 28 & 3.41 & 0.90 & 1 & 5 & & \\
\hline & Ciencias Básicas & 23 & 3.10 & 0.95 & 1 & 4.25 & & \\
\hline & Total & 116 & 3.46 & 0.90 & 1 & 5 & & \\
\hline \multirow{6}{*}{$\begin{array}{l}\text { Ambigüedad con } \\
\text { la contribución }\end{array}$} & Ciencias Agropecuarias & 23 & 4.30 & 0.76 & 2 & 5 & \multirow{6}{*}{2.20} & \multirow{6}{*}{0.07} \\
\hline & Ingeniería y Arquitectura & 16 & 4.28 & 0.69 & 2.5 & 5 & & \\
\hline & Informática y Sistemas & 26 & 4.04 & 0.78 & 2.75 & 5 & & \\
\hline & Ciencias Biológicas & 28 & 4.21 & 0.95 & 1 & 5 & & \\
\hline & Ciencias Básicas & 23 & 3.65 & 1.01 & 1.5 & 5 & & \\
\hline & Total & 116 & 4.09 & 0.88 & 1 & 5 & & \\
\hline \multirow{6}{*}{$\begin{array}{l}\text { Ambigüedad con } \\
\text { las normas }\end{array}$} & Ciencias Agropecuarias & 23 & 3.90 & 0.78 & 2.5 & 5 & \multirow{6}{*}{2.74} & \multirow{6}{*}{$0.03^{*}$} \\
\hline & Ingeniería y Arquitectura & 16 & 3.73 & 0.82 & 2 & 4.75 & & \\
\hline & Informática y Sistemas & 26 & 3.58 & 0.89 & 1.75 & 5 & & \\
\hline & Ciencias Biológicas & 28 & 3.48 & 0.82 & 1 & 4.5 & & \\
\hline & Ciencias Básicas & 23 & 3.14 & 0.78 & 1 & 4.5 & & \\
\hline & Total & 116 & 3.55 & 0.85 & 1 & 5 & & \\
\hline
\end{tabular}

Nota: ${ }^{*} \mathrm{p} \leq 0.05$

Fuente: elaboración propia. 
El análisis de correlación de Pearson determinó una correlación positiva débil (.188) entre la dimensión ambigüedad con la autonomía y la antigüedad en el trabajo, lo que indica que los profesores con mayor antigüedad perciben más ambigüedad en esta dimensión (véase Tabla 8).

Tabla 8. Correlación de las dimensiones de ambigüedad de rol con la edad de los profesores y la antigüedad en el trabajo.

\begin{tabular}{|c|c|c|c|c|c|c|}
\hline Dimensiones & $\begin{array}{l}\text { Ambigüedad } \\
\text { con la } \\
\text { autonomía }\end{array}$ & $\begin{array}{l}\text { Ambigüedad } \\
\text { con las } \\
\text { demandas } \\
\text { laborales }\end{array}$ & $\begin{array}{c}\text { Ambigüedad } \\
\text { con la } \\
\text { contribución }\end{array}$ & $\begin{array}{l}\text { Ambigüedad } \\
\text { con las } \\
\text { normas }\end{array}$ & Edad & Antigüedad \\
\hline $\begin{array}{l}\text { Ambigüedad con la } \\
\text { autonomía }\end{array}$ & 1 & $.620^{\star *}$ & $.560^{* *}$ & $.438^{* *}$ & 0.151 & $.188^{*}$ \\
\hline $\begin{array}{l}\text { Ambigüedad con las } \\
\text { demandas laborales }\end{array}$ & & 1 & $.658^{* *}$ & $.761^{\star *}$ & 0.068 & 0.107 \\
\hline $\begin{array}{l}\text { Ambigüedad con la } \\
\text { contribución }\end{array}$ & & & 1 & $.716^{\star *}$ & 0.126 & 0.144 \\
\hline $\begin{array}{c}\text { Ambigüedad con las } \\
\text { normas }\end{array}$ & & & & 1 & 0.120 & 0.13 \\
\hline Edad & & & & & 1 & $.658^{* *}$ \\
\hline Antigüedad & & & & & & 1 \\
\hline \multicolumn{7}{|c|}{ ** La correlación es significativa en el nivel 0,01 ( 2 colas). } \\
\hline
\end{tabular}

Fuente: elaboración propia.

\section{CONCLUSIONES}

Se logró alcanzar el objetivo de medir la existencia de ambigüedad de rol en profesores que realizan actividades de docencia e investigación en cinco áreas del conocimiento de una universidad en el Sureste de México. El análisis de frecuencias indicó que más de la mitad de la muestra percibe ambigüedad de rol con nivel alto a moderado, situación que amerita atenderse si se considera que este problema de rol puede conducir a incremento de la tensión laboral, disminución de la satisfacción laboral y factores de riesgo psicosocial (Kirk-Brown y Wallace, 2004; Osca et al., 2003; Soler et al., 2016). 
En el análisis descriptivo para identificar en qué dimensiones se percibe más ambigüedad de rol, se observó mayor ambigüedad en las demandas laborales y en las normas, lo que denota que no hay suficiente y adecuada información sobre lo que se espera con respecto al desempeño de una función, que es una de las causas de ambigüedad de rol que señala Fisher (citado en Nuñez y Frezatti, 2016). Por lo anterior, se recomienda tomar en cuenta los resultados de investigaciones que señalan que un ambiente de comunicación y suficiente información contribuye a controlar la ambigüedad de rol (Schulz y Auld, 2006; Bernhard, 1996).

La prueba t no señaló diferencias entre las dimensiones de ambigüedad con la autonomía, las demandas laborales y la contribución con relación al estado civil. Sin embargo, el análisis reportó diferencias estadísticamente significativas entre esta variable sociodemográfica con la dimensión de ambigüedad con las normas en la que los solteros perciben mayor ambigüedad de rol que los casados. También esta prueba indicó diferencias entre el género de los docentes en la ambigüedad con las normas, mostrando que los hombres perciben mayor ambigüedad de rol que las mujeres en esta dimensión; se sugiere una línea de investigación para valorar la dimensión de ambigüedad con las normas bajo una perspectiva de género.

Por otra parte, no se encontraron diferencias estadísticas entre las dimensiones de ambigüedad de rol con el hecho de que el profesor posea el perfil PRODEP y sea miembro del SNI. Tampoco entre las áreas del conocimiento con la autonomía, demandas laborales y contribución, por lo tanto, los profesores de las cinco áreas del conocimiento perciben de manera semejante la ambigüedad de rol en estas dimensiones. Las diferencias solo fueron señaladas en la dimensión de ambigüedad con las normas entre Agropecuarias y Básicas, lo que revela que la percepción de la ambigüedad no es igual entre los profesores de estas áreas del conocimiento en lo referente a los objetivos y lineamientos institucionales asociadas al rol, lo que presenta una oportunidad de indagar sobre las causas que la generan.

Se probó una débil correlación entre la ambigüedad en la autonomía y la antigüedad en el trabajo, es decir los profesores con más años en el trabajo son quienes perciben más ambigüedad en esta dimensión. 
Sin embargo, por presentar una correlación muy baja este resultado no es determinante.

Por tanto, de estos resultados, se sugiere que en las universidades se implementen acciones que permitan clarificar al profesor hacia dónde dirigir sus esfuerzos académicos para el logro de los objetivos institucionales. También asegurarse que el profesor perciba de forma precisa y adecuada la normatividad que guía su actuación en el ejercicio docente y de investigación.

Se concluye que en las instituciones de educación superior se deben realizar investigaciones sobre ambigüedad de rol y correlacionarlos con otras variables como bienestar laboral, estrés, rotación de personal y desgaste emocional. Ahora bien, a pesar de los hallazgos en esta investigación, los resultados tienen limitaciones por su diseño transversal de tipo descriptivo correlacional, que no posibilita el análisis de relaciones causales entre las variables del estudio. Así mismo, los resultados reflejan las condiciones de ambigüedad de rol de la muestra estudiada y deben considerarse con cautela para otras poblaciones.

\section{REFERENCIAS BIBLIOGRÁFICAS}

Bernhard, E. (1996). Gender differences in role stress: Role ambiguity, conflict and overload during the college transition. Northwestern University.

Consejo Nacional de Giencia y Tecnología (GONAGYT). (2017). Reglamento del Sistema Nacional de Investigadores. Diario Oficial de la Federación, pp. 105-118. https://www.conacyt.gob.mx/ index.php/el-conacyt/sistema-nacional-de-investigadores/marco-legal/reglamento-sni/13493reglamento-sni/file

De Arquer, M. I., Daza, F. M., y Nogareda, G. (1995). Ambigüedad y conflicto de rol. Notas Técnicas de Prevención edición electrónica (NTP-e 388). https://www.insst.es/documents/94886/326827/ ntp_388.pdf/33bd683f-a191-43b6-bab4-766ba19a9ba8 
Díaz-Fúnez, P.A., Pecino, V., y Mañas, M.A. (2016). Ambigüedad de rol, satisfacción laboral y ciudadanía organizacional en el sector público: un estudio de mediación multinivel. Revista de Psicología, 34(2), 387-412. https://doi.org/10.18800/psico.201602.007

García, C. H. (2011). La medición en las ciencias sociales y en la psicología, En R. Landero y M. T. González, Estadística con SPSS y metodología de la investigación (pp.139-166). Editorial Trillas.

Gomley, D. K. (2005). Organizational climate, role ambiguity, role conflict and nurse faculty work role balance: Influence on organizational commitment and turnover intention (Doctoral Dissertation). Universidad de Cincinnati, $\mathrm{OH}$.

Kirk-Brown A., y Wallace, D. (2004). Predicting burnout and job satisfaction in workplace counselors: the influence of role stressors, job challenge, and organizational knowledge. Fournal of Employment Counseling, 41(1), 29-37.

Lloret, S., González V., y Peiró J. M. (1995). El estrés de rol en enfermeras un modelo causal. Revista de Psicología General y Aplicada, 48(3), 393-405. https://dialnet.unirioja.es/servlet/ articulo? codigo $=2161481$

Magaña, D. E., Rosas, J. A, Lamoyi, G. L., Aguilar, N., Surdez, E. G., Sandoval, M. G., y Guzmán, G. (2009). Factores organizacionales relacionados al síndrome de desgaste emocional en los cuerpos académicos de la Universidad Juárez Autónoma de Tabasco. (Primer Informe de investigación-CONACYTSEGTORIAL00000000080973). Tabasco, México

Magaña, D. E., Sánchez, P., y Rosas, J. A. (2009). Síndrome de desgaste emocional y su relación con el conflicto y ambigüedad de rol en el profesor investigador de la Universidad Juárez Autónoma de Tabasco (Informe de investigación final-PROMEP 20080783). Tabasco, México

Malone, R.J. (2002). Tenure-track faculty socialization: the presence and effects of role ambiguity role, role conflict and role overload (Tesis Doctoral). ProQuest. 
Mansilla, F. (2011). Consecuencias del estrés de rol. Medicina y seguridad del trabajo, 57 (225), 361-370. http://dx.doi.org/10.4321/S0465-546X2011000400010

Meliá, J. L., Zornoza, A., Sanz, M. J., Morte, M. P., y González, V. (1987). La incidencia de los factores del conflicto de rol y de la ambigüedad de rol sobre los factores de la satisfacción laboral [The incidence of role conflict factors and role ambiguity factors in job satisfaction factors]. En Proceedings of Segundo Congreso Nacional de Evaluación Psicológica, Madrid, 287. https://www. uv.es/ meliaj1/Papers/1987_Melia_Factores.pdf

Nuñez, M., y Frezatti, F. (2016). Role Conflict, role ambiguity and job satisfaction; Perceptions of the Brazilian controllers. Revista de Administração-RAUSP, 51(2), 165-181. https://doi.org/10.5700/ rausp 1232

Onyemah, V. (2008). Role Ambiguity, Role Conflict, and Performance: Empirical Evidence of an Inverted U Relationship. Fournal of Personal Selling E Sales Management, XXVIII (3), 299-313. https:// doi.org/10.2753/PSS0885-3134280306

Orgambídez-Ramos, A., Pérez-Moreno, P. J., y Borrego-Alés, Y. (2015). Estrés de rol y satisfacción laboral: examinando el papel mediador del engagement en el trabajo. Fournal of Work and Organizational Psychology, 31, 69-77. https://doi.org/10.1016/j.rpto.2015.04.001

Osca, A., González-Camino, G., Bardera, P., y Peiró, J.M. (2003). Estrés de rol y su influencia sobre el bienestar psíquico y físico en soldados profesionales. Psicothema 15(1), 54-57. http://www. psicothema.com/pdf/1022.pdf

Peiró, J.M. (2001). El estrés laboral: Una perspectiva individual y colectiva. Seguridady Salud en el trabajo, 13, 18-38. https://www.researchgate.net/publication/39174637_El_estres_laboral_Una_ perspectiva_individual_y_colectiva 
Rizzo, J., House, R., y Lirtzman, S. (1970). Role conflict and ambiguity in complex organizations. Administrative Science Quarterly, 15(2), 150-164.

Schulz, J., y Auld, G. (2006). Perceptions of role ambiguity by chairpersons and executive directors Queensland sporting organizations. Sport Management Reviere, 9, 183-201.

Secretaría de Educación Pública. (2016). Reglas de operación del Programa para el Desarrollo del Personal Docente (PRODEP). Diario Oficial de la Federación. http://www.dgesu.ses.sep.gob. mx/Documentos/DSA\%20gobmx/PDF/Reconocimiento\%20a\%20Profesores $\% 20$ de $\% 20$ Tiempo $\% 20$ Completo $\% 20$ con $\% 20$ Perfil $\% 20$ Deseable..pdf

Slipak, O. E. (1996). Estrés Laboral. ALCMEON, 4. https://www.alcmeon.com.ar/5/19/a19_03.htm

Soler, M. I., Fernández-Valera, M. M., y Meseguer, M. (2016). El papel moderador de la resiliencia entre situaciones de demandas de rol laboral y de malestar autopercibido. Revista Mexicana de Psicología, 33(1), 61-70. http://www.redalyc.org/pdf/2430/243056043007.pdf

Soler, M. I., Fernández-Valera, M. M., y Meseguer, M. (2017). El papel mediador de la autoeficacia profesional entre situaciones de demandas de rol y salud autopercibida. Escritos de Psicología, 10(3), 151-158. http://dx.doi.org/10.5231/psy.writ.2017.1511

Surdez, E. G. (2013). Conflicto y ambigüedad de rol en profesores investigadores de cuerpos académicos: el caso de la Universidad Juárez Autónoma de Tabasco (Tesis Doctoral). Universidad del Mayab, Mérida Yucatán, México.

Surdez, E. G., Magaña, D. E., y Sandoval, M. del G. (2017). Evidencias de ambigüedad de rol en profesores universitarios. Revista Electrónica de Investigación Educativa, 19(1), 73-83. http://dx.doi. org/10.24320/redie.2017.19.1.889 


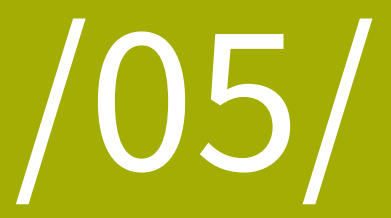




\title{
THE NEGATIVE EFFECT OF INCIVILITY ON JOB SATISFACTION THROUGH EMOTIONAL EXHAUSTION MODERATED BY RESONANT LEADERSHIP
}

\author{
Abdul Samad Dahri \\ Faculty of Business Administration and Social Sciences \\ Mohammad Ali Jinnah University, (Pakistan). \\ E-mail: dahriabdulsamad@gmail.com ORCID: https://orcid.org/0000-0003-4517-3493
}

Muhammad Asif Qureshi

Faculty of Business Administration and Social Sciences

Mohammad Ali Jinnah University, (Pakistan).

E-mail: qureshimuhammdasif@gmail.com ORCID: https://orcid.org/0000-0002-6081-5805

Abdul Ghaffar Mallah

Department of Business Administration

Government Degree college. University of Sindh, (Pakistan). E-mail: ag83.mallah@gmail.com ORCID: https://orcid.org/0000-0001-7174-3838

Recepción: 22/04/2020 Aceptación: 10/06/2020 Publicación: 24/11/2020

\section{Citación sugerida:}

Dahri, A. S., Qureshi, M. A., y Mallah, A. G. (2020). The negative effect of incivility on job satisfaction through emotional exhaustion moderated by resonant leadership. 3C Empresa. Investigación y pensamiento crítico, 9(4), 93-123. https://doi.org/10.17993/3cemp.2020.090444.93-123 


\section{ABSTRACT}

Job dissatisfaction challenge among nurses has a remarkable impact on patient safety and quality of any healthcare system. The study examines the negative effect of workplace incivility on job satisfaction among nurses through the mediation of emotional exhaustion and helps understand the moderating role of resonant leadership between emotional exhaustion and job satisfaction. The study adopts a cross-sectional self-administered survey design to collect 129 responses of registered nurses based on a stratified random sampling technique in Pakistan. Smart-PLS analyzed data revealed the statistically direct insignificant effect of workplace incivility and significant indirect effect on job satisfaction through emotional exhaustion. The results affirmed the emotional exhaustion mediation where resonant leadership had a significant positive moderating role that buffered the negative effect of emotional exhaustion on job satisfaction. Though potentially useful for HR managers, this study is exposed to sample and generalizability limitations. Therefore, opens consideration for solutions in further explorations.

\section{KEYWORDS}

Resonant Leadership, Workplace incivility, Emotional exhaustion, Job Satisfaction. 


\section{INTRODUCTION}

The healthcare stands as the backbone for the development and growth of any nation (Mills, 2014) which mainly comprises of nurses in general (Davis, Sloan, \& Wunderlich, 1996). Likewise, in a survey of 1,507 adults in the UK, care providers were ranked as more important than lawyers, bankers, and politicians. Whereas, nurses were ranked the second most important, after doctors in healthcare (Ford, 2015).

Moreover, 1 million patients die annually in hospitals across the world due to avoidable patient-related errors (Godschalk, Hartel \& Sbrzensy, 2017). Where, nurses found to play a unique role by interpreting working conditions, improving interpersonal relations among staff and supervisors and intervening for lower patient-related errors and well-being (Kohn, Corrigan, \& Donaldson, 2000). Therefore, patientcentered nursing actions can impact the whole system in hospitals (Houck \& Colbert, 2017).

Sadly, job dissatisfaction was spotted as one of the chronic issues amongst nurses by scholars for example Irvine and Evans (1995); Takase, Maude, and Manias (2005); Lu, While, and Barriball (2007). Also reported in 2013 by Business Insider that registered nurses had the 14th unhappiest job in America (Griswold, 2013). Moreover, reduced job satisfaction among nurses was reported to have financial consequences for the healthcare sector, such that, healthcare sector is $\$ 300$ billion question as a global investment pointed in World Economic Forum by Bernaert and Dimitrova (2017) and with an all-time high investment of $\$ 142.6$ billion was marked for 2016 for developing country which most countries failed to achieve. As per KPMG report (Kerfoot, 2015) in the United States alone, dissatisfied employees were counted for worth $\$ 4.4$ million financial loss.

Similarly, the nursing sector has gone through several changes over time (Kraft, Kästel, Eriksson, \& Hedman, 2017) thus job satisfaction needs continuous monitoring (Coomber, \& Barriball, 2007), particularly among nursing employees in developing countries like Pakistan. Therefore, job satisfaction is 
vital to retaining and attracting well-qualified personnel in the healthcare sector (Mosadegh \& Hossein, 2006).

No doubt there could be several reasons as complexity and conditions at healthcare workplaces such as increased stress, work pressure, conflict costs, patient safety risk resulting in job dissatisfaction among nurses and lack of delivering quality care in healthcare service (Bird, 2015). Past literature reveals organizations suffer financial losses due to counter-productive behaviors at the workplace (Lawrence \& Robinson, 2007) which violate important organizational norms and present threat to the well-being of an organization (Robinson \& Bennett, 1995) and termed as workplace incivility by Andersson and Pearson (1999).

As evident in Pakistani context studies that healthcare remains an emotionally exhaustive workplace as an outcome of many factors typically, uncivil behavior from within and outside hospital premises (Laeeque, Bilal, Hafeez, \& Khan, 2018) which plunges job satisfaction among nurses in public healthcare in context of Pakistan (Shah, Ali, Dahri, Ahmed \& Brohi, 2018; Dahri \& Hamid, 2018). Even though, incivility is very less known in literature and lacks exploration (Walker, 2014) specifically from Asian perspective (Ghosh, 2017).

As emotional exhaustion bridges the negative effect between incivility and job satisfaction, here, leaders can play as major influencer. As employees look upon their leaders for acceptable conduct at workplace (Koseoglu, Liu, \& Shalley, 2017). Clark and Springer (2010) found that 85\% nurse endorsed nurse leaders can create civil and respectful environment through mentoring and role-modeling. Accordingly, Wilkes, Cross, Jackson, and Daly (2015) found positive effect of nurse leadership style on incivility in the nursing environment.

On contrarily, Cassum (2014) revealed that in Pakistani context abuse from leaders is social norm. Whereas, according to Iqbal, Fatima, and Naveed (2020) empirically found that leaders with sympathy towards subordinates and concern with their values results in positive behavioral outcomes. In this 
regard, Casale (2017) claims resonant leaders have built in emotional intelligence ability to address subordinates' negative emotional experiences of incivility which also helps settling ones' dissatisfaction among academia nurses Therefore, literature derives potential investigation for role played resonate leadership to buffer negative effect of emotional exhaustion on job dissatisfaction among nurses.

\section{LITERATURE REVIEW}

Incivility is one of the factors that has not only sabotaged varying international workplaces such as in Canada (Laschinger, Leiter, Day, Gilin-Oore, \& Mackinnon, 2012), Korea (Kim \& Shapiro, 2008), Singapore (Lim \& Teo 2009); but also affected the local context healthcare sector nurses in Pakistan (Ziaud-Din, Arif \& Shabbir, 2017). The worsening situation due to lack of government attention (Basharat, 2017) is consequently dampening job satisfaction among public hospital nurses in Pakistan (Laeeque, et al., 2018).

Despite the impact, incivility was found insignificant with job satisfaction in Turkish Airline employees by Cingöz and Kaplan (2015) and among African nurses by Alola, Olugbade, Avci, and Öztüren (2019).

Literature reveals mediating role of emotional exhaustion on job satisfaction arising out of negative factors at workplace. For instance, nurses in healthcare sector are prone to emotional exhaustion due to emotional demands of work exceeding one's endurance during interpersonal interactions (Maslach, Schaufeli, \& Leiter, 2001). Hur, Kim, and Park (2015) in this direction reported incivility as major negative factor that prompts emotional exhaustion which reduced the job satisfaction among nurses. Similarly, in Pakistan, Khan, Imran, and Nisar (2016) reported nurses experience emotional exhaustion among registered nurses which eventually reduced their job satisfaction.

On contrary, inconsistencies were observed in literature regarding the mediating role of emotional exhaustion. Such as, Khokhar, Chaudhry, Bakht, Alvi and Mohyuddin (2016) while examining mediating role of emotional exhaustion and found not related to stressing factors in hospitals. Similarly, Aryee, 
Sun, Chen, and Debrah, (2008); Knudsen, Ducharme, and Roman (2009); followed by Tayfur, Bayhan Karapinar, and Metin Camgoz, (2013) also found emotional exhaustion inconsistent mediating results against hypothesized relations. While, emphasized for further investigation regarding mediating role of emotional exhaustion which this study has attempted to explore.

Moreover, leaders affect the employees and get things done (Piccolo \& Colquitt, 2006). Even though, management articulate policies that are implemented and practices by leaders in field forefronts for wellbeing in general. Yet, Shahid (2015) revealed in global trends that 86\% respondents agree to leadership crises. Reflected for healthcare sector in a recent survey by AMN (2017) highlighting 82\% nurses who agree for the severe need of leadership.

Though leadership style has been discussed much, yet, needs further exploration as a leadership style may vary person to person perception, creating a gap of less agreed definition (Janda, I960). Similarly, Voon, Lo, Ngui, and Ayob (2011) contends the effect of leadership may also vary according to the style of leaders with respect to subordinates.

Resonant leadership style develops emotional intelligence that remedies different work-related strains (Cummings, 2004). The resonant leadership domains include emotional self-awareness, self-management, socio-political awareness, and effective management of others (Goleman, Boyatzis \& McKee, 2002). In a systematic review, leadership styles were consistent with the notion of resonant leadership and were associated strongly with buffering conflict management, job security, anxiety, as well as emotional exhaustion, and job satisfaction (Cowden, Cummings, \& ProfettoMcGrath, 2011).

This notion becomes handy when dealing with individuals working in the social service sector where emotionally intense working environment leads to emotional exhaustion among employees (Dormann \& Zapf, 2004) and reduces their job satisfaction (Coomber \& Barriball, 2007) such as healthcare sector. Similarly, Estabrooks and colleagues (2011) examined that resonant leadership had significant effect to reduce the variation of emotional exhaustion, and job satisfaction. 


\section{THEORETICAL PERSPECTIVE}

Job Demands-Resources (JD-R) model (Schaufeli \& Bakker 2004), where, occupation may have its own specific risk factors associated with burnout or occupational stress, classified as job demands (Bakker, Demerouti, \& Euwema, 2005). Whereas, COR theory (Hobfoll, 1989) suggests any stressor at workplace will deplete the emotional resource. In the context of AET theory by Weiss and Cropanzano's (1996) any negative event will affect negatively and vice versa.

Similarly, empirical evidence indicates a chronic pattern of nurses experiencing incivility in healthcare sector sourced from the doctor, physician, co-worker, patient and their family that drains emotional resources serves as a chronic stressor (Lee and Ashforth 1996). These micro stressors such as workplace incivility, which deplete emotional resources (Cortina et al., 2001) resulting in emotional exhaustion among nurses (Guidroz et al., 2010) leading to reduced job satisfaction (Cortina et al., 2001).

Whereas, in the light of literature and supporting theories, the resonant leadership with emotional intelligence capability may supplement the positive emotional resource and tune-in to buffer the inconsistent negative relation between emotional exhaustion and job satisfaction. Thus, resonant leadership will serve as a positive event and job resource to mitigate the negative effect of emotional exhaustion on job satisfaction caused by job demand (stressor) such as workplace incivility.

\section{HYPOTHESIS DEVELOPMENT}

\subsection{WORKPLACE INCIVILITY AND JOB SATISFACTION}

Workplace incivility is an experience of uncivil interaction from different sources which can source from coworker or customer (Schilpzand, Pater, \& Erez, 2016). Accordingly, Flanagan and Flanagan (2002) reported that the way employee interact had a profound impact on their level of job satisfaction. Similarly, previous studies have found workplace incivility to be associated with increased psychological distress and organizational withdrawal, as well as decreased job satisfaction (e.g., Cortina, Magley, Williams, \& Langhout, 2001; Lim \& Cortina, 2008). 
H1: Workplace incivility experience has a negative influence on job satisfaction.

\subsection{WORKPLACE INCIVILITY AND EMOTIONAL EXHAUSTION}

Exposure to uncivil behaviors can have a negative influence on employees in terms of mood, cognitive distraction, fear, perceived injustice, damaged social identity, and anger (Barling, Rogers, \& Kelloway, 2001). Such as being ignored by a coworker, patients at the hospital, excluded or not invited in an important meeting, rude or harsh words by others in a disrespectful manner (Pearson, Andersson, \& Wegner, 2001). These uncivil behaviors are wired strongly with employee emotional exhaustion. This argument followed by Laschinger, Leiter, Day, and Gilin (2009) as interaction with the coworker is among events of depletion of emotional resources and appraise feeling of exhaustion.

H2: Workplace incivility is positively associated with emotional exhaustion.

\subsection{EMOTIONAL EXHAUSTION AND JOB SATISFACTION}

Job satisfaction is an attitude reflecting how well people like or dislike their job (Spector, 1985). Relevantly, healthcare frontline employees face more interaction within and outside of the hospital, this takes out their emotional resources and eventually brings in emotional exhaustion eventually affecting one's job satisfaction negatively. In past literature, emotional exhaustion consequences encompass associations with conflicts at work and reduced job satisfaction (Wolpin, Burke, \& Greenglass, 1991). Thus seemingly, emotionally exhausted employees often develop negative attitudes about customers, the organization, their job, and themselves (Cordes and Dougherty, 1993).

Similarly, in different field such as public healthcare sector, $42.2 \%$ from a sample of 179 physicians in the hospital of Sindh, reported experiencing emotional exhaustion having a negative impact on job satisfaction (Zafar, Khan, Siddiqui, Jamali, \& Razzak, 2016).

H3: Emotional exhaustion has a negative effect on job satisfaction. 


\subsection{EMOTIONAL EXHAUSTION AS A MEDIATOR}

Extended studies show that it is undeniable that emotional exhaustion has accumulated mediating effects between negative workplace factors and employee job outcome such as job satisfaction. Such that, emotional exhaustion successfully mediates the relationship between abusive supervisor and job satisfaction (Aryee, Sun, Chen, \& Debrah, 2008). Similarly, literature has also reported emotional exhaustion as a useful mediator between the relationship of coworker incivility and job satisfaction based on AET among 286 retail bankers (Hur, Kim, \& Park, 2015). Moreover, recently, Khan, Imran, and Nisar (2016) highlighted that emotional exhaustion has a direct significant relationship with job satisfaction. It is; therefore, the mediating role of emotional exhaustion was essential to examine, specifically with job satisfaction as a dependent variable among nurses affected by workplace incivility as a predictor variable.

H4: Emotional exhaustion will mediate between the relationship between workplace incivility and job satisfaction.

\subsection{MODERATING ROLE OF RESONANT LEADERSHIP}

According to Baron and Kenny (1986) moderator is effective when there exists inconsistent relation among variables. Likewise, the inconsistent results between emotional exhaustion and job satisfaction were observed by different scholars (e.g., Khokhar et al., 2016; Aryee et al., 2008; Knudsen et al., 2009; Tayfur et al., 2013) which calls for the potential moderator between emotional exhaustion and job satisfaction to buffer the negative effect of emotional exhaustion on job satisfaction.

According to Tian, Zhang, and Zou (2014) argued that supervisor support moderates the negative event and its mediated outcome, thus respective scholarly knowledge needs further expansion. Further, in this regard Marturano (2016) emphasized considering logic and ethics as key elements regarding leadership studies to promote organizational and cultural way of thinking. With empathy, emotional and selfawareness, resonant leadership serves this purpose at best. Resonant leaders intend to boost performance by relationship management, empathy, authenticity and emotional harmonization. Moreover, the 
resonant leadership has the capacity and capability to adapt with respect to situations in the workplace, therefore, has positive link with job satisfaction and deemed to buffer between the emotional exhaustion on job satisfaction among nurses.

H5: Resonant leadership is positively related to job satisfaction

H6: Resonant leadership will moderate the relationship between emotional exhaustion and job satisfaction

\section{RESEARCH MATERIALS AND METHODS}

Wherever Times New Roman is specified, Times Roman, or Times may be used. If neither is available on your word processor, please use the font closest in appearance to Times New Roman that you have access to. Please avoid using bit-mapped fonts if possible. True-Type 1 fonts are preferred.

\subsection{MEASUREMENT SCALES}

\subsubsection{RESONANT LEADERSHIP}

Measured using the 6-item Resonant Leadership Scale (Cummings, 2006), on 5- point liker type scale (0.95). Recently used by Laschinger, Wong, Cummings, and Grau (2014) and reported (a=0.94).

\subsubsection{WORKPLACE INCIVILITY}

Demonstrating verbal or actions of mild disrespectful misbehavior, damaging social norms of conduct. Measured through 7-items (7-point Likert, 1- not at all to 7- very much) developed by Cortina et al. (2001) recently used by Zurbrügg and Miner (2016) with alpha $=0.85$.

\subsubsection{EMOTIONAL EXHAUSTION}

Running out of emotional resources due to social stress or job demands that lead employees to emotional exhaustion. Measured with 9-items (7-point Likert, 1- never to 7-very often) scale was developed by 
Maslach and Jackson (1981), originally scale reported good reliability of scale (alpha $=0.89$ ). While recently used by Medler-Liraz and Seger-Guttmann (2018) with alpha (0.90).

\subsubsection{JOB SATISFACTION}

It reveals like or dislike, motivation and attitude of employee towards ones' job. Measured through 15item scale (7-point Likert, 1-completely dissatisfied to 7-completely satisfied) developed by Warr, Cook, and Wall (1979) with original alpha= 0.85, recently used by Koon and Pun (2017) with alpha= .892.

\section{METHODS}

\subsection{POPULATION, SAMPLE, SAMPLING FRAME, AND SAMPLING TECHNIQUE}

The research design of the study was cross-sectional and quantitative in nature. The data collection from 736 registered nurses. This population size was divided in large and medium strata based on number of beds available with hospitals, for which 484 questionnaires were distributed to registered nurses in city district public hospitals in Sindh province of Pakistan. The sample was drawn on stratified random sampling based on sample frame with a list of registered nurses as per current attendance register at hospitals. As a result, 310 questionnaires were received from each stratum making up response rate of $64 \%$ in total which is acceptable and above the criteria provided by Sekaran and Bougie (2016) that 30\% response rate as sufficient for surveys.

\subsection{DATA ANALYSIS}

Out of collected 310 questionnaires, 129 in total were useable and screened for outliers and missing values through SPSS data screening. Where the majority of respondents were female $98(75.96 \%)$ and the male were only 31 (24.04\%). Education levels scored $65 \%$ bachelors and rest were undergraduates. Whereas, $85 \%$ were married and rest were single. While, $75 \%$ had work experience above 10 years and the rest had below 3 years. Screened data was further analyzed by PL-SEM for complete results due to 
the non-normal distribution of data and presented for the present study (Henseler, Ringle, \& Sarstedt, 2015).

\section{RESULTS}

\subsection{MEASUREMENT MODEL}

For the measurement model, multicollinearity, convergent validity, and discriminant validity values were evaluated.

\subsubsection{MULTICOLLINEARITY TEST}

Multicollinearity is tested to assure there is no unusual correlations between variables used in the model. It increases the standard error values for coefficients which is problem for regression analysis and effects with statistical significance of (Hair et al., 2014). For multiclonality, Variance Inflated Factor (VIF) is verified. Whereby, Gentile et al. (2009) recommended VIF values should be below 10. Table 1 reveals acceptable VIF values accordingly for the current model.

\subsubsection{CONVERGENT VALIDITY}

Hair, Hult, Ringle, and Sarstedt (2014) suggested for convergent validity factor loadings, average variance extracted (AVE) and composite reliability (CR) must be checked. Results reveal achievement of recommended values as for factor loadings were higher than 0.6, for AVE values were higher than 0.5 and GR values for measurement were also above 0.7 (see Table 1). However, item (Wil) with lower factor loadings was dropped.

\subsubsection{DISCRIMINANT VALIDITY}

After AVE square and cross loading method following Fronell-Larcker criterion for discriminant validity of constructs, recent literature is following more rigorous methods for discriminant validity. For assessment of discriminant validity (Henseler et al., 2015) suggested Hetero-trait-mono-trait (HTMT) 
ratio of correlation evaluation. Where, all values for HTMT should be below 0.90 (Gold \& Arvind Malhotra, 2001) and HTMT values accorded the thresholds for this study construct (see Table 1).

Table 1. Hetero-trait-mono-trait, Variance Inflated Factor, Composite Reliability, Average Variance Extracted.

\begin{tabular}{|c|c|c|c|c|c|c|c|}
\hline & & \multicolumn{3}{|c|}{ HTMT/ CR/ AVE/ VIF } \\
\hline EE & EE & JS & RL & WI & CR & AVE & VIF \\
\hline JS & & & & & 0.957 & 0.713 & 1.624 \\
\hline RL & 0.551 & & & & 0.966 & 0.653 & \\
\hline WI & 0.217 & 0.45 & & & 0.887 & 0.566 & 1.500 \\
\hline
\end{tabular}

Before moving on to structural model fit indices are observed to ensure that besides convergent and discriminant validity, construct validity is also achieved. Where model fir indices such as SRMR is one of these recommended measures before further analysis as a poor model cannot be trusted. SRMR $<0.1$ is acceptable, whereas, values below 0.055 represents an ideal fit (Hair, Black, Babin, Anderson, \& Tatham, 2010). Likewise, SRMR for the current model is 0.062 that gives full confidence to model to proceed for complex results.

\subsection{STRUCTURAL MODEL}

For assessing the structural model (Table 2, and Figure 1), standard beta, t-values via were produced by bootstrapping on resampling of 5000 , the $R^{2}$, predictive relevance $\left(\mathrm{Q}^{2}\right)$, and the effect size $\left(\mathrm{f}^{2}\right)$ were examined suggested by Hair et al. (2014). 
Table 2. Structural model.

\begin{tabular}{|c|c|c|c|c|c|c|}
\hline Path & Beta & St. Dev & T Value & P Value & R2 & f2 \\
\hline EE -> JS & -0.322 & 0.088 & 3.654 & 0.00 & 0.358 & 0.122 \\
\hline RL -> JS & 0.26 & 0.075 & 3.489 & 0.00 & 0.479 & 0.119 \\
\hline RL ${ }^{*}$ EE JS -> JS & 0.239 & 0.057 & 4.217 & 0.00 & 0.155 \\
\hline WI -> EE & 0.598 & 0.063 & 9.558 & 0.00 & & 0.558 \\
\hline WI -> JS & -0.177 & 0.101 & 1.752 & 0.08 & & 0.038 \\
\hline & \multicolumn{2}{|c|}{ Indirect (Mediation) Coefficient } & & \\
\hline
\end{tabular}

Referring to Table 2, results reveal statistical support for hypothesized relations as H2, H3, H4, H5 and $\mathrm{H} 6$ except $\mathrm{H} 1$, where statistically insignificant direct relationship between workplace incivility (WI) and job satisfaction (JS) (b= -0.177, $\mathrm{p}>0.05)$ results not supporting $\mathrm{H} 1$.

The direct relationship between resonant leadership $(\mathrm{RL})$ and job satisfaction was significant $(\mathrm{b}=0.26$, $\mathrm{p}<0.01)$, and direct relationship between emotional exhaustion $(\mathrm{EE})$ and job satisfaction $(\mathrm{b}=-0.322, \mathrm{p}<$ 0.01) was statistically significant. Similarly, the indirect relationships between workplace incivility was significantly mediated by emotional exhaustion on job satisfaction $(b=-0.192, p<0.001)$. Whereas, the moderated effect (in bold) of RL between EE and JS ( $b=0.239, \mathrm{p}<0.01)$ was also statistically significant and supported the hypothesis.

The value of $\mathrm{R}^{2}$ and $\mathrm{f}^{2}$ values must be between ' 0 ' to ' 1 ', suggested by Hair et al. (2014) to examining the change explained by independent variable (IV) on dependent variable (DV) through $\mathrm{R}^{2}$ and to see the effect size of IV on DV through $\mathrm{f}^{2}$. Table 2 shows Table 2 describes variance $\left(\mathrm{R}^{2}\right)$ in EE is $35.8 \%$ and in JS is $47.9 \%$ from the respective IV and DV in the model. While, the results of $\mathrm{f}^{2}$ suggest acceptable effect size in support of hypothesized relations following Cohen (1988) guideline.

It is important to mention that a significant negative effect of WI through EE on JS was $(b=-0.382)$ which after moderation of RL was reduced $(b=-0.322)$ and reflected in diverse standard deviation in 
responses of respondents for respective variables. Further, Table 2 elaborated as $\mathrm{f}^{2}$, depicted at 12.2\% for EE on JS, 11.9\% for RL on JS, 15.5\% shows moderating effect of RL on EE and JS, for WI on EE $55.8 \%$, and effect of WI on JS was low due to insignificant statistical relation at $3.8 \%$. These variations are at peak for relationship between EE on JS which in particular, shows the positive and significant buffering effect of RL on negative EE effect towards JS. Tabular description is depicted in following figure that shows acceptable path coefficient and t-values for inner and also reveals cross loadings with t-values of each item for outer model.

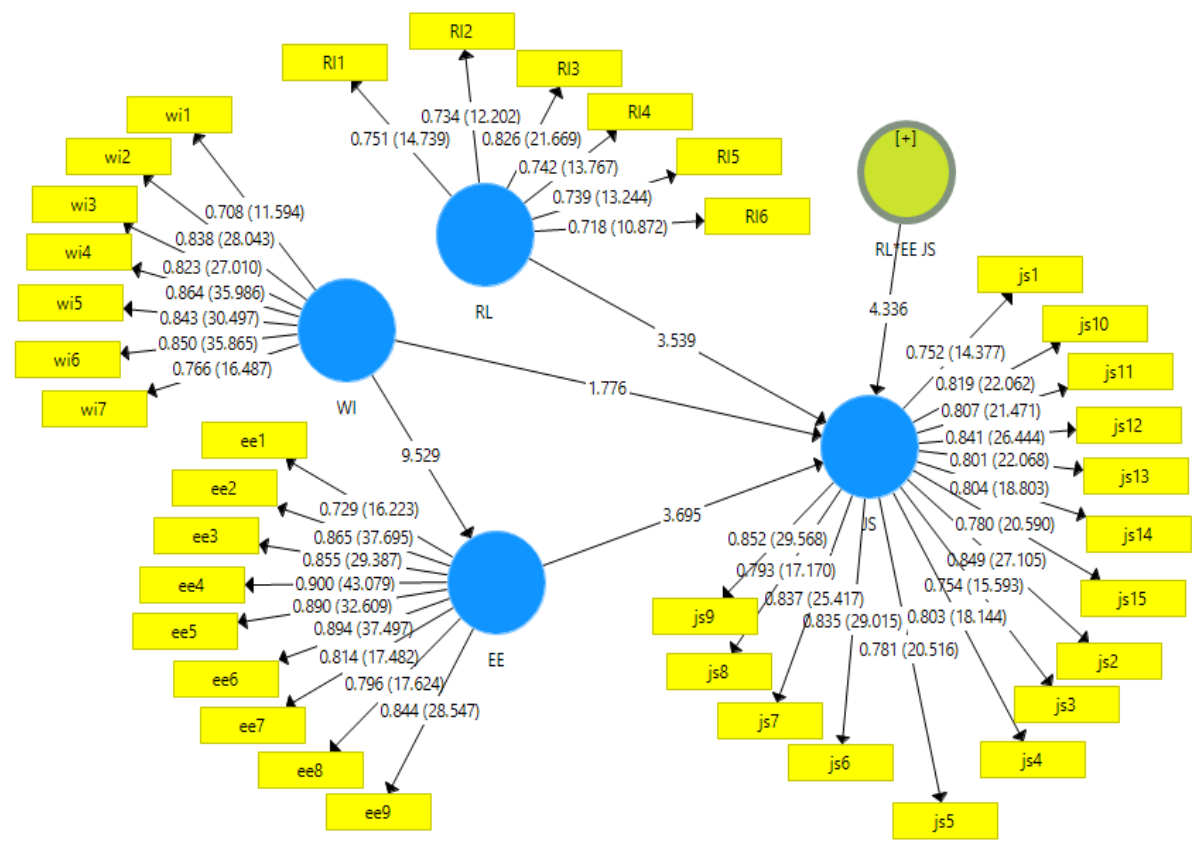

Figure 1. Structural model.

Finally, for the predictive relevance of the model through blindfolding procedure by Hair et al., (2014) was followed. Where the $\mathrm{Q}^{2}$ values were greater than ' 0 ', suggesting sufficient model productiveness. Which were 0.231 for $\mathrm{EE}$ and 0.281 for JS. This reveals that hypothesized model has subsequent predictive relevance for $\mathrm{EE}$ at $23.1 \%$ and $28.1 \%$ for JS respectively. 
Since moderating variable is continuous in nature, thus product indicator approach was applied (Henseler \& Fassott, 2010) using Smart-PLS referring to Figure 2 that visualizes the interaction of moderating variable RL which reduces the negative relationship between EE and JS. Hence, supporting H6 as resonant leadership to buffer the negative relation between EE and JS.

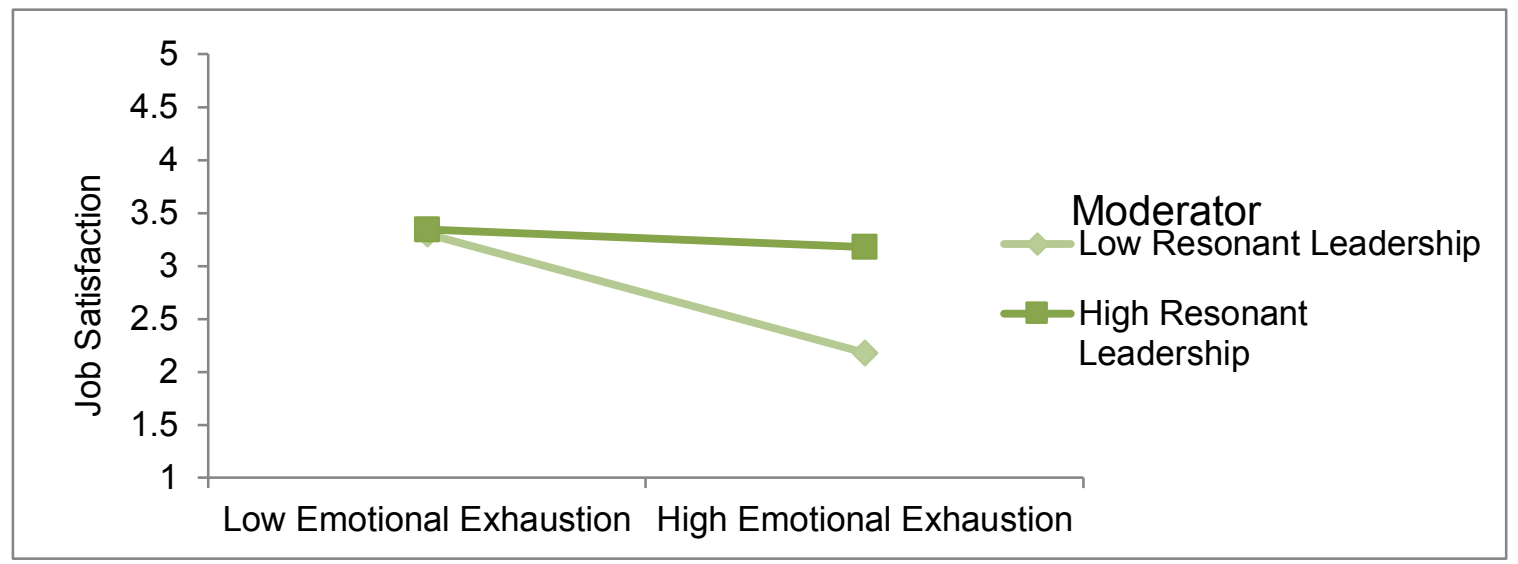

Figure 2. Moderation interaction Plot.

\section{DISCUSSION}

This study has put an effort to address the problem of job satisfaction among nurses in public healthcare hospitals in Pakistan. Where workplace incivility was emphasized to be the factor that has direct negative relation with job satisfaction $(\mathrm{H} 1)$ and emotional exhaustion $(\mathrm{H} 2)$. Results of the analysis revealed the rejection of direct effect of incivility on job satisfaction $(\mathrm{H} 1)$ which is also in line with Alola et al. (2019) who stated the same results among nurses in the Africa. These results are not only in line with past literature but also practical, as workplace incivility is covert feeling (Andersson \& Pearson, 1999) that leaves a deep mark of negative emotions rather direct indication or reporting for discomfort or dissatisfaction.

Accordingly, the indirect significant relation of workplace incivility and job satisfaction gives insight that nurses avoid the source of incivility by engaging more in absenteeism and turnover rather direct 
reporting job dissatisfaction as an output. Thus, $\mathrm{H} 2$ was also supported between workplace incivility and emotional exhaustion which further mediated the workplace incivility effect on job satisfaction indirectly among nurses supporting. Therefore, workplace incivility is threat to any organization if not directly then indirectly has the potential to sabotage workplace.

Though, leadership features ranging from good to bad are discussed in research, resonant leadership style has recently been spotted for self-awareness, socio-political skill, and emotional intelligence increases the chance of enhancing job satisfaction and may lower negative job evaluation (Goleman $e t$ al., 2002). Thus, misbehaved, emotionally exhaustive working, and low job satisfaction can be helped by potential buffering features of resonant leadership which was reflected in H3. Thus, the successful emotionally intelligent resonance of leaders does influence positively to settle the escalated negative effects of workplace incivility carried thorough emotional exhaustion on job satisfaction among nurses in the public healthcare sector.

\section{PRACTICAL AND THEORETICAL IMPLICATION}

This study is quite useful statistically and practically by highlighting the job dissatisfaction issue caused by workplace incivility and transferred with more power destroying nurses' job satisfaction through emotional exhaustion. Where, the indirect effect of incivility at the workplace through emotional exhaustion may be reduced in terms of employee feedback and understanding the emotional issues of nurses by their leaders more practically in the field. Moreover, resonant leaders have a key role to buffer these negative effects between escalated emotional exhaustion and job satisfaction among nurses. While, providing more flexibility, motivation, and sharing ownership of the work between resonant leader and employees stands out as an effectively efficient solution for HR managers and policymakers. Where positive resonating moderating effect of resonant leadership with emotional intelligence suggest saving millions of dollars and a million lives of patient, particularly in developing countries like Pakistan. 
Therefore, programs arranged by management to enhance resonant leaders' skills and improve employee interaction with leaders would be tremendously resourceful in cultures such as Pakistan.

Theoretically, all three theories in social science (JDR, COR, AET) found in-line with literature and findings of this study have theoretically expanded in the field of resonant leadership as moderating variable to help develop a civil working environment and helping to address the job satisfaction issue among nurses in Pakistan. These results imply that even though incivility induce risk of job dissatisfaction boosted by emotional exhaustion among healthcare employees. Where resonant leadership attracts more research influx as moderator by buffering effect on interactional, job and negative events related negativities on job satisfaction.

\section{CONCLUSIONS}

This study emphases the buffering role played by the resonant leaders in exhaustive working conditions which is chronical in social interaction jobs, specifically in healthcare sector. Uncivil behavioral conduct must also be focused by scholars as it burns the emotions and nurtures never ending spiral of negative events that engulfs the whole organization. This study provides empirical evidence to support the argument that resonant leadership style can play positive role between the emotional exhaustion and job satisfaction among nurses. Moreover, limited resources, lack of government interest, unethical behavioral conduct, discourteous interaction experienced by nurses devastates their emotions. This emotionally exhaustive workplace tarnishes job satisfaction among nurses, where emotional intelligent skills of resonant leaders are practical and appreciable. Likewise, the authors believe that hospital management would arrange workshops to nurture resonant leadership style in nurses' supervisors to help overcome satisfaction concern among nurses regarding their job. This study is among a few initial studies that expand the literature on resonant leadership regarding reducing the indirect effect of workplace incivility on job satisfaction in an emotionally exhaustive environment of developing country like Pakistan. Interestingly, 
this study confirms the buffering effect of resonant leadership style that would prove a milestone for a longer sustainable quality and satisfying healthcare services by satisfied nurses.

\section{REFERENCES}

Alola, U. V., Olugbade, O. A., Avci, T., \& Öztüren, A. (2019). Customer incivility and employees' outcomes in the hotel: Testing the mediating role of emotional exhaustion. Tourism Management Perspectives, 29, 9-17. https://doi.org/10.1016/j.tmp.2018.10.004

Andersson, L. M., \& Pearson, G. M. (1999). Tit for tat? The spiraling effect of incivility in the workplace. Academy of management review, 24(3), 452-471. https://www.jstor.org/ stable $/ 259136$ ? origin $=$ crossref\&seq $=1$

Aryee, S., Sun, L. Y., Chen, Z. X. G., \& Debrah, Y. A. (2008). Abusive supervision and contextual performance: The mediating role of emotional exhaustion and the moderating role of work unit structure. Management and Organization Reviere, 4(3), 393-411. https://doi.org/10.1111/j.17408784.2008.00118.x

Bakker, A. B., Demerouti, E., \& Euwema, M. C. (2005). Job resources buffer the impact of job demands on burnout. Fournal of occupational health psychology, 10(2), 170. https://doi. org/10.1037/1076-8998.10.2.170

Barling, J., Rogers, A. G., \& Kelloway, E. K. (2001). Behind closed doors: In-home workers' experience of sexual harassment and workplace violence. Fournal of occupational health psychology, 6(3), 255. https://doi.org/10.1037/1076-8998.6.3.255

Baron, R. M., \& Kenny, D. A. (1986). The moderator-mediator variable distinction in social psychological research: Conceptual, strategic, and statistical considerations. Fournal of personality and social psychology, 51(6), 1173. https://doi.org/10.1037/0022-3514.51.6.1173 
Basharat, R. (2017, May 26). Govt spends less GDP on health: Survey. https:/ / nation.com.pk/26-May-2017/ govt-spendsless-gdp-on-health-survey

Bernaert, A., \& Dimitrova, D. (2017). Global healthcare: the $\$ 300$ billion question. World Economic Forum. https://www.weforum.org/agenda/2017/11/the-300-billion-global-health-question/

Bird, J. (2015). Nurses satisfied with salaries, but not with where they work. http:/ / www.fiercehealthcare.com/ story/nurses-satisfiedsalaries-not-where-they-work/2015-11-17

Bozeman, B., \& Gaughan, M. (2011). Job satisfaction among university faculty: Individual, work, and institutional determinants. The fournal of Higher Education, 82(2), 154-186. https://muse.jhu.edu/ article/425313

Gasale, K. R. (2017). Exploring nurse faculty incivility and resonant leadership. Nursing education perspectives, 38(4), 177-181. https://nursing.ceconnection.com/ ovidfiles/00024776-201707000-00004.pdf

Gassum, L. A. (2014). Verbal violence at workplace: A reality from Pakistani context. Fournal of Nursing Education and Practice, 4(8). http://www.sciedu.ca/journal/index.php/jnep/article/view/4340

Ghin, W. W. (1998). The partial least squares approach to structural equation modeling. Modern methods for business research, 295(2), 295-336. https:/ / psycnet.apa.org/record/1998-07269-010

Gingöz, A., \& Kaplan, A. (2015). The effect of workplace incivility on job satisfaction and organizational trust: A study of industrial enterprises in Turkey. In WEI International Academic Conference Proceedings, Vienna, Austria (pp. 12-15). https://www.westeastinstitute.com/wp-content/uploads/2015/04/ Ay $\%$ C5 $\% 9$ Fe-and-Asli.pdf 
Coomber, B., \& Barriball, K. L. (2007). Impact of job satisfaction components on intent to leave and turnover for hospital-based nurses: a review of the research literature. International journal of nursing studies, 44(2), 297-314. https://doi.org/10.1016/j.ijnurstu.2006.02.004

Cordes, C. L., \& Dougherty, T. W. (1993). A review and an integration of research on job burnout. Academy of management reviere, 18(4), 621-656. https://doi.org/10.2307/258593

Cortina, L. M., Magley, V. J., Williams, J. H., \& Langhout, R. D. (2001). Incivility in the workplace: Incidence and impact. Journal of occupational health psychology, 6(1), 64. https://doi. org/10.1037/1076-8998.6.1.64

Cowden, T., Gummings, G.G., \& Profetto-McGrath, J. (2011). Leadership practices and staff nurses' intent to stay: A systematic review. Fournal of Nursing Management, 19(4), 461-477. https:// doi.org/10.1111/j.1365-2834.2011.01209.x

Gropanzano, R., Rupp, D. E., \& Byrne, Z. S. (2003). The relationship of emotional exhaustion to work attitudes, job performance, and organizational citizenship behaviors. Fournal of Applied psychology, 88(1), 160. https://doi.org/10.1037/0021-9010.88.1.160

Cummings, G. G. (2004). Investing relational energy: The hallmark of resonant leadership. Canadian Journal of Nursing Leadership, 17(4), 76-87. https://www.longwoods.com/content/17019/nursingleadership/investing-relational-energy-the-hallmark-of-resonant-leadership

Dahri, A. S., \& Hamid, K. A. (2018). Effect of Workplace Incivility on Job Satisfaction Among Nurses: Mediating Role of Emotional Exhaustion. The Journal of Social Sciences Research, (Special Issue 4), 80-90. https://doi.org/10.32861/jssr.spi4.80.90

Davis, G. K., Sloan, F., \& Wunderlich, G. S. (Eds.). (1996). Nursing staff in hospitals and nursing homes: Is it adequate? National Academies Press. 
Dormann, G., \& Zapf, D. (2004). Customer-related social stressors and burnout. Fournal of occupational health psychology, 9(1), 61. https://doi.org/10.1037/1076-8998.9.1.61

Estabrooks, G.A., Squires, J.E., Hayduk, L.A., Cummings, G.G., \& Norton, P.G. (2011). Advancing the argument for the validity of the Alberta context tool with unregulated nursing care providers in residential long-term care. BMC Medical Research Methodology, 11, 107. https://doi. org/10.1186/1471-2288-11-107

Flanagan, N. A., \& Flanagan, T. J. (2002). An analysis of the relationship between job satisfaction and job stress in correctional nurses. Research in nursing $\&$ health, 25(4), 282-294. https://doi. org/10.1002/nur. 10042

Ford, S. (2015). Nurses and doctors top list of 'important' jobs. Nursing Times. https: / / www.nursingtimes.net/ nurses-and-doctors-top-list-of-important-jobs/5089725

Gentile, D., Anderson, C., Yukawa, S., Ihori, N., Saleem, M., Ming, L.K., Shibuya, A., Liau, A. K., Khoo, A., Bushman, B. J., Huesman, R., \& Sakamoto, A. (2009). The effects of prosocial video games on prosocial behaviors: International evidence from correlational, longitudinal, and experimental studies. Personality and Social Psychology Bulletin, 35(6), 752-763. https://doi.org/10.1177/0146167209333045

Ghosh, R. (2017). Workplace Incivility in Asia-How do we take a Socio-Cultural Perspective? Taylor \& Francis. (pp. 263-267).

Godschalk, B., Hartel, I., \& Sbrzensy, R. (2017). Best practices in patient safety: 2nd Global Ministerial Summit on Patient Safety. https://www.bundesgesundheitsministerium.de/fileadmin/ Dateien/5Publikationen/Gesundheit/Broschueren/Best-PracticePatient Safety.pdf 
Gold, A. H., Malhotra, A., \& Segars, A. H. (2001). Knowledge management: An organizational capabilities perspective. Fournal of management information systems, 18(1), 185-214. https://doi.org/1 $0.1080 / 07421222.2001 .11045669$

Goleman, D., Boyatzis, R., \& McKee, A. (2002). The new leaders: Transforming the art of leadership into the science of results. Little, Brown.

Hair Jr, J. F., Black, W. G., Babin, B. J., Anderson, R. E., \& Tatham, R. L. (2010). SEM: An introduction. Multivariate data analysis: A global perspective, 629-686.

Hair, J. F., Ringle, G. M., \& Sarstedt, M. (2011). PLS-SEM: Indeed a silver bullet. The fournal of Marketing Theory and Practice, 19, 139-152. https://doi.org/10.2753/MTP1069-6679190202

Hair, J. F., Ringle, G. M., \& Sarstedt, M. (2013). Editorial-partial least squares structural equation modeling: Rigorous applications, better results and higher acceptance. Long Range Planning, 46(12), 1-12. https://papers.ssrn.com/sol3/papers.cfm?abstract_id=2233795

Hair, J. F.,Hult, G. T. M., Ringle, G., \& Sarstedt, M. (2014). A primer on partial least squares structural equation modeling (PLS-SEM). SAGE Publications, Inc.

Henseler, J., \& Fassott, G. (2010). Testing moderating effects in PLS path models: An illustration of available procedures. In Handbook of partial least squares (pp. 713-735). Springer, Berlin, Heidelberg.

Henseler, J., Ringle, G.M., \& Sarstedt, M. (2015). A new criterion for assessing discriminant validity in variance-based structural equation modeling. Fournal of the Academy of Marketing Science, 43(1), 115-135. https://doi.org/10.1007/s11747-014-0403-8

Hobfoll, S. E. (1989). Conservation of resources: A new attempt at conceptualizing stress. American Psychologist, 44(3), 513. https://doi.org/10.1037/0003-066X.44.3.513 
Houck, N. M., \& Colbert, A. M. (2017). Patient safety and workplace bullying: an integrative review. Fournal of nursing care quality, 32(2), 164-171. https://journals.lww.com/jncqjournal/ Abstract/2017/04000/Patient_Safety_and_Workplace_Bullying_An.12.aspx

Hur, W. M., Kim, B. S., \& Park, S. J. (2015). The relationship between coworker incivility, emotional exhaustion, and organizational outcomes: The mediating role of emotional exhaustion. Human Factors and Ergonomics in Manufacturing \& Service Industries, 25(6), 701-712. https://doi.org/10.1002/ hfm.20587

Iqbal, K., Fatima, T., \& Naveed, M. (2020). The Impact of Transformational Leadership on Nurses' Organizational Commitment: A Multiple Mediation Model. European Fournal of Investigation in Health, Psychology and Education, 10(1), 262-275. https://doi.org/10.3390/ejihpe10010021

Irvine, D. M., \& Evans, M. G. (1995). Job satisfaction and turnover among nurses: integrating research findings across studies. Nursing research, 44(4), 246-253. https://pubmed.ncbi.nlm.nih. gov/7624236/

Janda, K. F. (1960). Towards the explication of the concept of leadership in terms of power. Human Relations, 6(2), 34-42.

Kerfoot, K. (2015). Four Measures that Are Key to Retaining Nurses. https:/ / www.hhnmag.com/articles/3253four-measures-that-are-key-to-retaining-nurses

Khan, N. Z. A., Imran, A., \& Nisar, Q. A. (2016). Emotional Exhaustion as Stressor agent for Job Stress in Call Centers: Empirical evidence from perspective of Job Satisfaction and Turnover Intention as Work Outcomes. European Online Fournal of Natural and Social Sciences, 5(4), 908. http:// european-science.com/eojnss/article/view/3144 
Khokhar, M. M., Chaudhry, M. A., Bakht, N., Alvi, A., \& Mohyuddin, M. (2016). Burnout among female nursing students. Pakistan Armed Forces Medical Journal, 66(6). https://pafmj.org/ index.php/PAFMJ/article/view/1276

Kim, T.-Y., \& Shapiro, D. (2008). Revenge against supervisor mistreatment: negative emotion, group membership, and crosscultural difference. International Journal of Conflict Management, 19, 339-358.

Knudsen, H. K., Ducharme, L. J., \& Roman, P. M. (2009). Turnover intention and emotional exhaustion" at the top": Adapting the job demands-resources model to leaders of addiction treatment organizations. Fournal of Occupational Health Psychology, 14(1), 84. https://www.ncbi.nlm. nih.gov/pmc/articles/PMC2746447/

Kohn, L. T., Corrigan, J. M., \& Donaldson, M. S. (Eds.). (2000). To Err Is Human: Building a Safer Health System. Institute of Medicine; Committee on Quality of Health Care in America. The National Academies Press. https://doi.org/10.17226/9728.

Koon, V. Y., \& Pun, P. Y. (2017). The Mediating Role of Emotional Exhaustion and Job Satisfaction on the Relationship Between Job Demands and Instigated Workplace Incivility. The fournal of Applied Behavioral Science. https://doi.org/10.1177/0021886317749163

Koseoglu, G., Liu, Y., \& Shalley, G. E. (2017). Working with creative leaders: Exploring the relationship between supervisors' and subordinates' creativity. The Leadership Quarterly, 28(6), 798-811. https:// core.ac.uk/download/pdf/216391443.pdf

Kraft, M., Kästel, A., Eriksson, H., \& Hedman, A. M. R. (2017). Global Nursing - a literature review in the field of education and practice. Nursing open, 4(3), 122-133. https://doi.org/10.1002/ nop2.79 
Laeeque, S. H., Bilal, A., Hafeez, A., \& Khan, Z. (2018). Violence breeds violence: burnout as a mediator between patient violence and nurse violence. International journal of occupational safety and ergonomics, 25(4), 604-613. https://doi.org/10.1080/10803548.2018.1429079

Laschinger, H. K. S., Leiter, M. P., Day, A., Gilin-Oore, D., \& Mackinnon, S. P. (2012). Building empowering work environments that foster civility and organizational trust: Testing an intervention. Nursing research, 61(5), 316-325. https://journals.lww.com/nursingresearchonline/ Abstract/2012/09000/Building_Empowering_Work_Environments_That_Foster.2.aspx

Laschinger, H. K. S., Wong, G. A., Gummings, G. G., \& Grau, A. L. (2014). Resonant leadership and workplace empowerment: The value of positive organizational cultures in reducing workplace incivility. Nursing Economics, 32(1), 5-18. https://www.bc.edu/content/dam/files/centers/cwf/ individuals/pdf/LeadershipandWorkplaceempowerment.pdf

Lawrence, T. B., \& Robinson, S. L. (2007). Ain’t misbehaving: Workplace deviance as organizational resistance. Fournal of Management, 33(3), 378-394. https://doi.org/10.1177/0149206307300816

Lee, R. T., \& Ashforth, B. E. (1996). A meta-analytic examination of the correlates of the three dimensions of job burnout. Fournal of Applied Psychology, 81(2), 123. https://doi.org/10.1037/00219010.81 .2 .123

Lim, S., Cortina, L. M., \& Magley, V. J. (2008). Personal and workgroup incivility: impact on work and health outcomes. Fournal of Applied Psychology, 93(1), 95. https://doi.org/10.1037/00219010.93.1.95

Lim, V. K., \& Teo, T. S. (2009). Mind your E-manners: Impact of cyber incivility on employees' work attitude and behavior. Information \& Management, 46(8), 419-425. https://doi.org/10.1016/j. im.2009.06.006 
Locke, E. A., Smith, P. G., Kendall, L. M., Hulin, G. L., \& Miller, A. M. (1964). Convergent and discriminant validity for areas and methods of rating job satisfaction. Fournal of Applied Psychology, 48(5), 313. https://doi.org/10.1037/h0043202

Lu, H., While, A. E., \& Barriball, K. L. (2007). Job satisfaction and its related factors: a questionnaire survey of hospital nurses in Mainland China. International journal of nursing studies, 44(4), 574-588. https://doi.org/10.1016/j.ijnurstu.2006.07.007

Marturano, A. (2016). Leadership: Where organization studies meet ethics. Iranian fournal of Management Studies, 9(4), 767-782. https://ijms.ut.ac.ir/article_59533.html

Maslach, G., \& Jackson, S. E. (1981). The measurement of experienced burnout. Fournal of organizational behavior, 2(2), 99-113. https://doi.org/10.1002/job.4030020205

Maslach, C., Schaufeli, W. B., \& Leiter, M. P. (2001). Job burnout. Annual Review of Psychology, 52(1), 397-422. https://www.annualreviews.org/doi/abs/10.1146/annurev.psych.52.1.397

Medler-Liraz, H., \& Seger-Guttmann, T. (2018). Authentic emotional displays, leader-member exchange, and emotional exhaustion. Fournal of Leadership \& Organizational Studies, 25(1), 76-84. https://doi.org/10.1177/1548051817725266

Mills, A. (2014). Health care systems in low-and-middle-income countries. New England fournal of Medicine, 370(6), 552-557. https://www.nejm.org/doi/10.1056/NEJMra1 110897

Moore, J. E. (2000). One road to turnover: An examination of work exhaustion in technology professionals. MIS Quarterly, 141-168. https://www.jstor.org/stable/3250982

Mosadegh M, R, A., \& Hossein, Y, M, M. (2006). A study of relationship between managers' leadership style and employees' job satisfaction. Leadership in Health Services, 19(2), 11-28. https:// www.emerald.com/insight/content/doi/10.1108/13660750610665008/full/html 
Pearson, G. M., Andersson, L. M., \& Wegner, J. W. (2001). When workers flout convention: A study of workplace incivility. Human Relations, 54(11), 1387-1419. https://doi. org/10.1177/00187267015411001

Piccolo, R. F., \& Colquitt, J. A. (2006). Transformational Leadership and job behaviors: The mediating role of core job characteristics. Academy of Management fournal, 49(2), 327-340. https:// doi.org/10.5465/amj.2006.20786079

Robinson, S. L., \& Bennett, R. J. (1995). A typology of deviant workplace behaviors: a multidimensional scaling study.Academy of Management fournal, 38(2), 555-572. https: / /www.researchgate. net/profile/Rebecca_Bennett4/publication/228079661_A_Typology_of_Deviant_Workplace_ Behaviors_A_Multidimensional_Scaling_Study/links/00b7d533037a7c87cc000000/ATypology-of-Deviant-Workplace-Behaviors-A-Multidimensional-Scaling-Study.pdf

Schaufeli, W. B., \& Bakker, A. B. (2004). Job demands, job resources, and their relationship with burnout and engagement: A multi-sample study. Fournal of Organizational Behavior: The International Journal of Industrial, Occupational and Organizational Psychology and Behavior, 25(3), 293-315. https:// www.wilmarschaufeli.nl/publications/Schaufeli/209.pdf

Schilpzand, P., De Pater, I. E., \& Erez, A. (2016). Workplace incivility: A review of the literature and agenda for future research. Fournal of Organizational Behavior, 37(1). https://doi.org/10.1002/ job. 1976

Sekaran, U., \& Bougie, R. (2016). Research methods for business: A skill building approach. John Wiley \& Sons.

Shah, S. M. M., Ali, R., Dahri, A. S., Ahmed, N., \& Brohi, Z. A. M. (2018). Determinants of Job Satisfaction among Nurses: Evidence from South Asian Perspective. Fournal of Academic Research in Business and Social Sciences, 8(5), 19-26. https://ideas.repec.org/a/hur/ijarbs/v8y2018i5p19-26. html 
Shahid, S. (2015). Outlook on the Global Agenda 2015. In World Economic Forum. http:/ / www3.weforum. org/docs/GAC14/WEF_GAC14_OutlookGlobalAgenda_Report.pdf

Spector, P. E. (1985). Measurement of human service staff satisfaction: Development of the Job Satisfaction Survey.American journal of community psychology, 13(6), 693-713. https://doi.org/10.1007/ BF00929796

Spence Laschinger, H. K., Leiter, M., Day, A., \& Gilin, D. (2009). Workplace empowerment, incivility, and burnout: Impact on staff nurse recruitment and retention outcomes. Fournal of nursing management, 17(3), 302-311. https://doi.org/10.1111/j.1365-2834.2009.00999.x

Takase, M., Maude, P., \& Manias, E. (2005). Nurses' job dissatisfaction and turnover intention: Methodological myths and an alternative approach. Nursing E health sciences, 7(3), 209-217. https:// doi.org/10.1111/j.1442-2018.2005.00232.x

Tayfur, O., Bayhan, P., \& Metin, S. (2013). The mediating effects of emotional exhaustion cynicism and learned helplessness on organizational justice-turnover intentions linkage. International fournal of Stress Management, 20(3), 193-221. https://doi.org/10.1037/a0033938

Tian, Q., Zhang, L., \& Zou, W. (2014). Job insecurity and counterproductive behavior of casino dealersthe mediating role of affective commitment and moderating role of supervisor support. International Fournal of Hospitality Management, 40, 29-36. https://doi.org/10.1016/j.ijhm.2014.03.005

Voon, M. L., Lo, M. G., Ngui, K. S., \& Ayob, N. B. (2011). The influence of leadership styles on employees' job satisfaction in public sector organizations in Malaysia. International fournal of Business, Management, and Social Sciences, 2(1), 24-32. https://www.academia.edu/14954558/The_ influence_of_leadership_styles_on_employees_job_satisfaction_in_public_sector_organizations_ in_Malaysia 
Walker, R. Y. (2014). Incivility in nursing education: Its effect on the job satisfaction of nurse faculty in associate degree programs (Doctoral dissertation). Capella University.

Weiss, H. M., \& Cropanzano, R. (1996). Affective events theory: A theoretical discussion of the structure, causes, and consequences of affective experiences atwork. https:/ / www.researchgate.net/publication/228079335_ Affective_Events_Theory_A_Theoretical_Discussion_of_The_Structure_Cause_and_ Consequences_of_Affective_Experiences_at_Work

Wilkes, L., Gross, W., Jackson, D., \& Daly, J. (2015). A repertoire of leadership attributes: An international study of deans of nursing. Fournal of Nursing Management, 23(3), 279-286. https://doi. org/10.1111/jonm.12144

Wolpin, J., Burke, R. J., \& Greenglass, E. R. (1991). Is job satisfaction an antecedent or a consequence of psychological burnout? Human relations, 44(2), 193-209. https://doi. org/10.1177/001872679104400205

Zafar, W., Khan, U. R., Siddiqui, S. A., Jamali, S., \& Razzak, J. A. (2016). Workplace violence and self-reported psychological health: coping with post-traumatic stress, mental distress, and burnout among physicians working in the emergency departments compared to other specialties in Pakistan. The Fournal of emergency medicine, 50(1), 167-177. https://doi.org/10.1016/j.jemermed.2015.02.049

Zia-ud-Din, M., Arif, A., \& Shabbir, M. A. (2017). The impact of workplace incivility on employee absenteeism and organization commitment. International fournal of Academic Research in Business and Social Sciences, 7(5), 205-221. https://hrmars.com/papers_submitted/2893/The_Impact_of_ Workplace_Incivility_on_Employee_Absenteeism_and_Organization_Commitment.pdf

Zurbrügg, L., \& Miner, K. N. (2016). Gender, Sexual Orientation, and Workplace Incivility: Who Is Most Targeted and Who Is Most Harmed? Frontiers in psychology, 7, 565. https://doi.org/10.3389/ fpsyg.2016.00565 


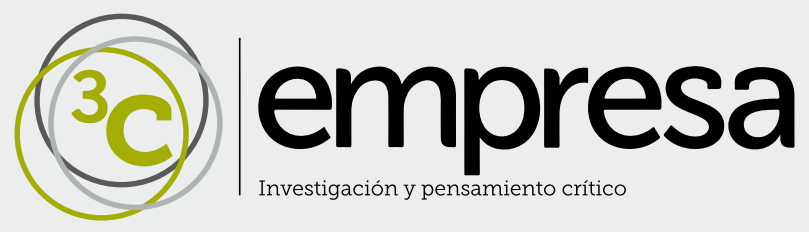

